Aus dem Institut für Neuro- und Sinnesphysiologie

(Prof. Dr. rer. nat. S. O. Rizzoli)

im Zentrum Physiologie und Pathophysiologie

der Medizinischen Fakultät der Universität Göttingen

\title{
Therapeutischer Nutzen einer \\ mitochondrialen Katalase-Expression in \\ einem Mausmodell des Rett-Syndroms
}

\author{
INAUGURAL-DISSERTATION \\ zur Erlangung des Doktorgrades \\ für Zahnmedizin \\ der Medizinischen Fakultät der \\ Georg-August-Universität zu Göttingen
}

vorgelegt von

Ina Dewenter

aus

Göttingen

Göttingen 2021 
Dekan:

\section{Betreuungsausschuss}

Betreuer/in:

Ko-Betreuer/in:

\section{Prüfungskommission}

Referent/in:

Ko-Referent/in:

Drittreferent/in:

Datum der mündlichen Prüfung:
Prof. Dr. med. W. Brück

Prof. Dr. rer. nat. M. Müller

Prof. Dr. rer. nat. B. Schwappach-Pignantaro

Prof. Dr. rer. nat. M. Müller.

PD Dr. Anke Zieseniß.

Prof. Dr. Nicolai Miosge. 
Hiermit erkläre ich, die Dissertation mit dem Titel "Therapeutischer Nutzen einer mitochondrialen KatalaseExpression in einem Mausmodell des Rett-Syndroms" eigenständig angefertigt und keine anderen als die von mir angegebenen Quellen und Hilfsmittel verwendet zu haben.

Göttingen, den

(Unterschrift) 
Die Daten, auf denen die vorliegende Arbeit basiert, wurden teilweise publiziert:

Adebayo OL, Dewenter I, Rinne L, Golubiani G, Solomonia R, Müller M (2020): Intensified mitochondrial hydrogen peroxide release occurs in all brain regions, affects male as well as female Rett mice, and constitutes a life-long burden. Arch Biochem Biophys 696, 10866 


\section{Inhaltsverzeichnis}

Abbildungsverzeichnis .......................................................................... III

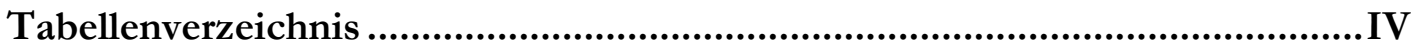

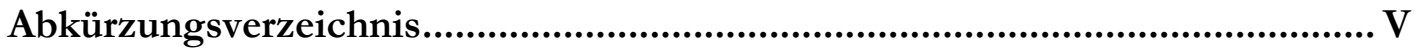

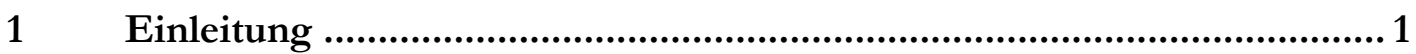

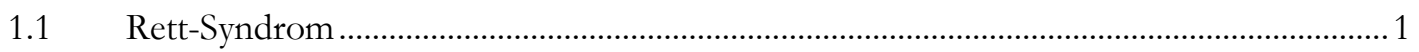

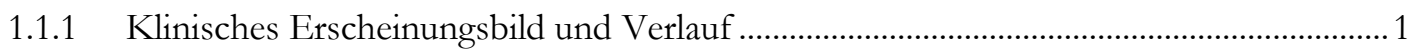

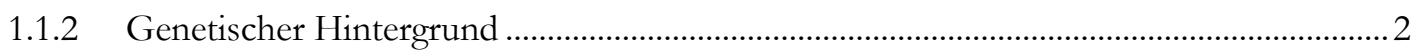

1.1.3 Mitochondriale Veränderungen im Rett-Syndrom ..................................................... 3

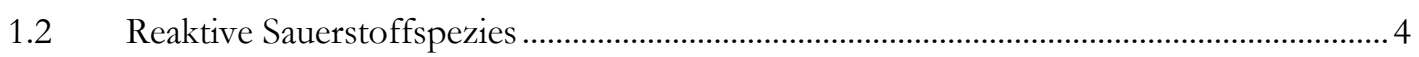

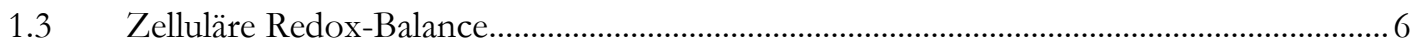

1.3.1 Enzymatische und antioxidative Regulation .................................................................

1.3.2 Redox-Imbalance und oxidativer Stress im Rett-Syndrom ............................................

$1.4 \quad$ Verbesserung der Redox-Homöostase als Therapieansatz.................................................. 9

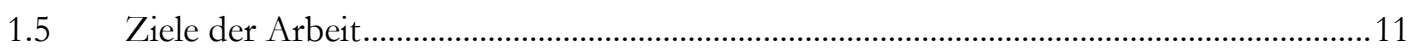

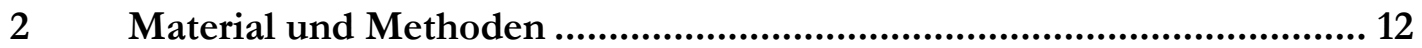

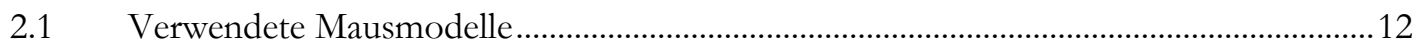

2.2 Bestimmung der allgemeinen Parameter ……………………...........................................13

2.3 Grundlagen der Absorptionsspektrometrie …………………..........................................

2.4 Grundlagen der Fluoreszenzspektrometrie............................................................. 15

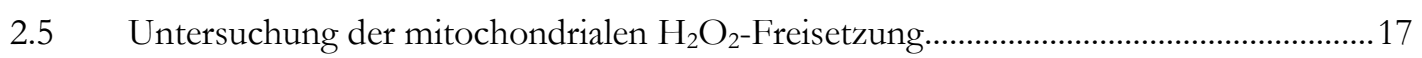

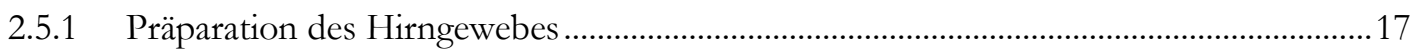

2.5.2 Isolierung der Mitochondrien und Proteinkonzentrationsbestimmung..........................17

2.5.3 Qualitätskontrolle isolierter Mitochondrien durch Western-Blots..................................18

2.5.4 Fluoreszenzspektrometrische $\mathrm{H}_{2} \mathrm{O}_{2}$-Messung.............................................................20

2.6 Zusammensetzung der verwendeten Chemikalien ...........................................................2

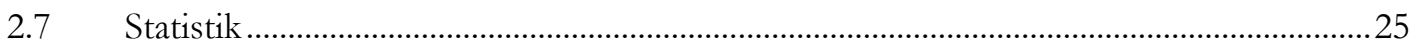

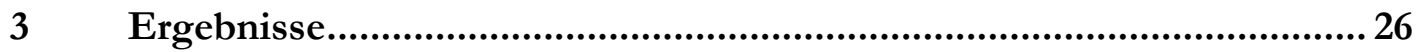

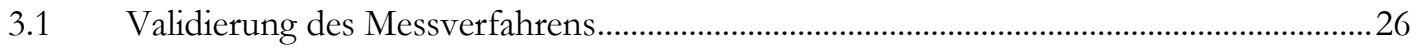

3.1.1 Qualitätskontrolle der isolierten Mitochondrien ...........................................................26

3.1.2 Kontrollen zur Überprüfung der Validität und Reliabilität des Küvetten-Assays ..........29

3.1.3 Konzentrationsbestimmung durch $\mathrm{H}_{2} \mathrm{O}_{2}$-Standards .....................................................

3.2 Fluoreszenzspektrometrische $\mathrm{H}_{2} \mathrm{O}_{2}$-Messungen in Abhängigkeit von Genotyp, Alter, Geschlecht und Hirnregion ................................................................................................. 31

3.2.1 Hirnregionen- und altersspezifische Unterschiede in der $\mathrm{H}_{2} \mathrm{O}_{2}$-Freisetzung..................32

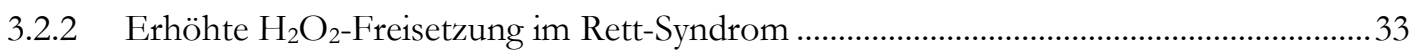


3.2.3 Einfluss der Expression einer mitochondrialen Katalase auf die $\mathrm{H}_{2} \mathrm{O}_{2}$-Freisetzung im

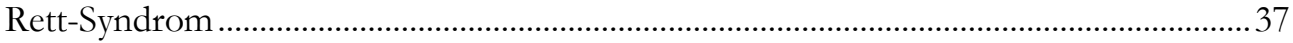

3.3 Auswertung der allgemeinen phänotypischen Parameter ..................................................46

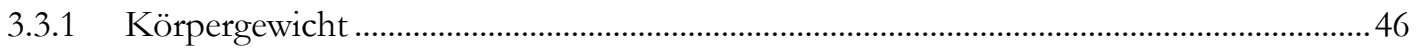

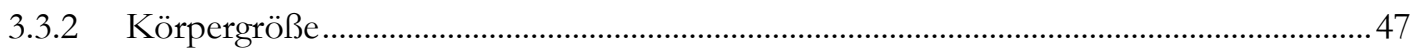

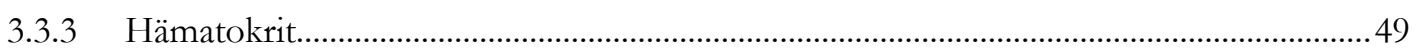

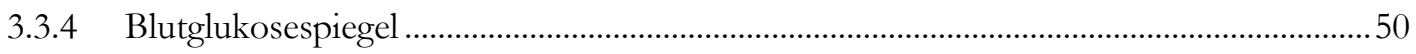

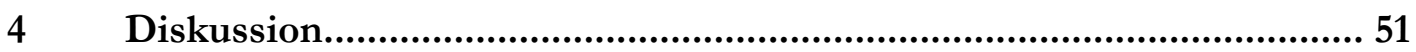

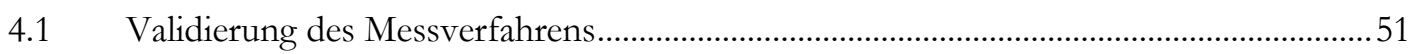

4.1.1 Qualitätskontrolle der isolierten Mitochondrien .............................................................51

4.1.2 Kontrollen zur Überprüfung der Validität und Reliabilität des Küvetten-Assays ..........52

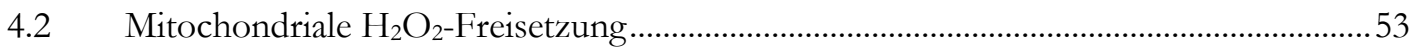

4.2.1 Mitochondriale $\mathrm{H}_{2} \mathrm{O}_{2}$-Freisetzung männlicher und weiblicher Wildtyp-Tiere.................53

4.2.2 Erhöhte mitochondriale $\mathrm{H}_{2} \mathrm{O}_{2}$-Freisetzung im Rett-Syndrom ........................................ 55

4.2.3 Positiver Einfluss einer mitochondrialen Katalase auf die Redox-Imbalance im Rett-

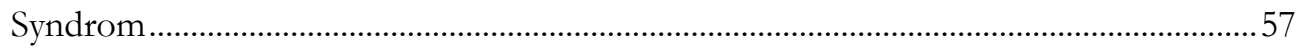

4.3 Veränderungen phänotypischer Parameter im Rett-Syndrom und deren Beeinflussung durch Expression einer mitochondrialen Katalase ............................................................55

4.4 Möglichkeiten der therapeutischen Anwendung der mitochondrialen Katalase-

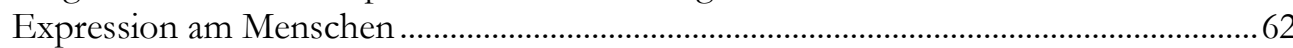

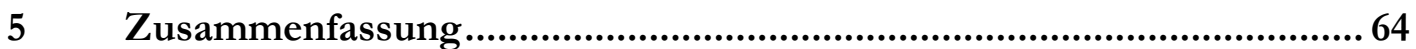

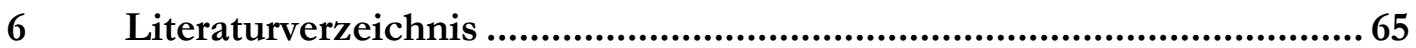




\section{Abbildungsverzeichnis}

Abbildung 1: Entstehungsorte radikaler Sauerstoffspezies im Mitochondrium ............................ 5

Abbildung 2: Enzymatische Regulationsmechanismen der zellulären Redox-Homöostase ...... 7

Abbildung 3: Zusammenhang zwischen der Progression des Krankheitsverlaufes und des Redox-Gleichgewichtes ................................................................................ 10

Abbildung 4: Bestimmung der Körpergröße .........................................................................13

Abbildung 5: Reaktion zur Detektion der $\mathrm{H}_{2} \mathrm{O}_{2}$-Freisetzung mittels Amplex UltraRed.............15

Abbildung 6: Aufbau und Funktionsweise des genutzten Fluoreszenzspektrometers ..............16

Abbildung 7: Zentrifugationsschema der Mitochondrien-Isolation ..........................................26

Abbildung 8: Western-Blots zur Klärung der zellulären Bestandteile der Mitochondriensuspensionen ................................................................................2

Abbildung 9: Densitometrische Analyse der Western-Blots......................................................28

Abbildung 10: Einfluss von CCCP und Substratreduktion auf die $\mathrm{H}_{2} \mathrm{O}_{2}$-Freisetzung...............29

Abbildung 11: Kalibrierung der Amplex UltroxRed-Fluoreszenz durch $\mathrm{H}_{2} \mathrm{O}_{2}$-Standards

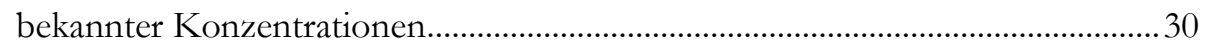

Abbildung 12: Mitochondriale $\mathrm{H}_{2} \mathrm{O}_{2}$-Freisetzung im zeitlichen Verlauf......................................... 31

Abbildung 13: Regionenspezifische $\mathrm{H}_{2} \mathrm{O}_{2}$-Freisetzung in Altersabhängigkeit bei Wildtyp-

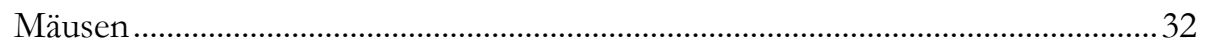

Abbildung 14: Überhöhte Mitochondriale $\mathrm{H}_{2} \mathrm{O}_{2}$-Freisetzung im Rett-Syndrom ........................... 35

Abbildung 15: Regionenspezifische Erhöhung der mitochondrialen $\mathrm{H}_{2} \mathrm{O}_{2}$-Freisetzung im

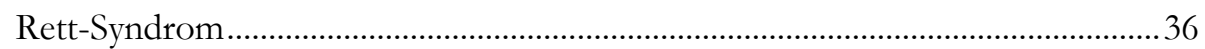

Abbildung 16: Senkung der mitochondrialen $\mathrm{H}_{2} \mathrm{O}_{2}$-Freisetzung in P50-Mecp2-1y-Männchen auf Wildtyp-Niveau durch die mitochondriale Katalase-Expression......................38

Abbildung 17: Deutliche Erhöhung der mitochondrialen $\mathrm{H}_{2} \mathrm{O}_{2}$-Freisetzung in den P50-Mecp 2+/-Weibchen und Reduktion der Freisetzung durch die mitochondriale Katalase-Expression

Abbildung 18: Reduktion der mitochondriale $\mathrm{H}_{2} \mathrm{O}_{2}$-Freisetzung in P200-Mecp2+/--Weibchen durch mitochondriale Katalase-Expression.

Abbildung 19: Verlust des therapeutisch wirksamen Effektes der mitochondrialen

Katalase-Expression bei den P400-Mecp 2+/--Weibchen

Abbildung 20: Einfluss der Expression der mitochondrialen Katalase auf die $\mathrm{H}_{2} \mathrm{O}_{2-}$

Freisetzung im Rett-Syndrom

Abbildung 21: Deutliche Reduktion der $\mathrm{H}_{2} \mathrm{O}_{2}$-Freisetzung im Rett-Syndrom durch

Expression einer mitochondrialen Katalase.

Abbildung 22: Reduziertes Körpergewicht im Rett-Syndrom in P50-Tieren beider

Geschlechter.

Abbildung 23: Initiale Reduktion der Körpergröße in P50-Tieren des Rett-Syndroms

Abbildung 24: Signifikante Erhöhung des Hämatokrits bei den P50-Männchen im

Rett-Syndrom

Abbildung 25: Blutglukose im Vergleich zwischen den Geschlechtern, Altersstufen und

Genotypen. 50 


\section{Tabellenverzeichnis}

Tabelle 1: Übersicht der genutzten Genotypen und der in nachfolgenden Diagrammen genutzten Farbcodierungen .......................................................................................13

Tabelle 2 :Im Rahmen der Western-Blots genutzte Antikörper .................................................19

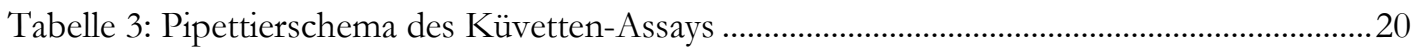

Tabelle 4: Parameter Einstellung des Fluoreszenzspektrometers................................................21

Tabelle 5: Zusammensetzung des Mitochondrien-Isolationspuffers ............................................22

Tabelle 6: Zusammensetzung des mitochondrialen Respirationsmediums ....................................23

Tabelle 7: Zusammensetzung des SDS-Probenpuffers............................................................24

Tabelle 8: Zusammensetzung des Tris-Tricin-Gradienten-Gels................................................24

Tabelle 9: Geschlechts-, alters- und regionenspezifische $\mathrm{H}_{2} \mathrm{O}_{2}$-Freisetzung bei Wildtyp-

Mäusen 


\section{Abkürzungsverzeichnis}

AAV

$\alpha-\mathrm{KDH}$

APS

BSA

cDNA

CMV

СССР

COX6a

DMSO

DNA

EDTA

EGTA

HEPES

HRP

IF

GAPDH

GSH

MAPK

mCAT

MECP2

MIRO5

NF-KB

NPBI

PAGE

PBS

PDH

PI3K

PMP70

PMSF

PVDF

$\mathrm{QH}_{2}$

roGFP

SDS

ROS

SOD

TBS-T

TEMED

Tris-Tricin
Adeno-assoziierte Virusvektoren

Alpha-Ketoglutaratdehydrogenase

Ammoniumperoxodisulfat

Bovines Serumalbumin

DNA der mitochondrialen Katalase

Cytomegalievirus

Carbonylcyanid-m-chlorphenylhydrazon

Cytochrome c oxidase subunit 6 a

Dimethylsulfoxid

Desoxyribonukleinsäure

Ethylendiamintetraacetat

Ethylenglycoltetraacetat

2-(4-(2-Hydroxyethyl)-1-piperazinyl)-ethansulfonsäure

horseradish peroxidase

Reduziertes Flavinmononukleotid

Glycerol-3-Phosphat Dehydrogenase

Gluthation

mitogen activated protein kinase

humane Katalase in Mitochondrien

methyl-CpG-binding protein 2

mitochondrial respiration medium 5

nuclear factor kappa-light-chain-enhancer of activated B-cells

non protein bound iron

Polyacrylamid-Gelelektrophorese

phosphate-buffered saline

Pyruvatdehydrogenase

Phosphoinositid-3-Kinase

70 kDa peroxisomal membrane protein

Phenylmethylsulfonylfluorid

Polyvinylidenfluorid

reduziertes Ubichinon

reduction-oxidation sensitive green fluorescent protein

Natriumdodecylsulfat

reactive oxygen species

Superoxiddismutase

Tris-buffered saline with Tween20

Tetramethylethylendiamin

Tromethamin-N-(Tri(hydroxymethyl)methyl)glycin 


\section{$1 \quad$ Einleitung}

\subsection{Rett-Syndrom}

\subsubsection{Klinisches Erscheinungsbild und Verlauf}

Das Rett-Syndrom ist eine schwer verlaufende, neurologische Entwicklungsstörung (Rett 1966) die hauptsächlich Mädchen mit einer Prävalenz von 1:10.000 bis 1:15.000 betrifft (Chahrour und Zoghbi 2007). Das klinische Erscheinungsbild ist komplex und äußert sich in vier Stadien der Erkrankung (Hagberg und Witt-Engerström 1986).

Das erste Stadium, auch als Phase der Stagnation und früher Symptome bezeichnet, tritt nach einer vermeintlich normalen Entwicklung nach ca. 6 bis 18 Monaten auf. Erste Entwicklungsschritte wie Sitzen, Krabbeln und Laufen sind verzögert, das Kopfwachstum verlangsamt sich und es kommt zur Mikrozephalie. Die betroffenen Mädchen zeigen reduzierten Augenkontakt und vermindertes Interesse am Spielen, außerdem kommt es zu Abweichungen von der normalen Sprachentwicklung (Hagberg et al. 1983). Diese Phase kann mehrere Monate andauern, zeigt eine eher milde Symptomatik und bleibt daher meist unentdeckt. Im Stadium zwei, der schnellen destruktiven Phase, die zwischen dem 1. und 4. Lebensjahr auftritt, kommt es zu einem Entwicklungsrückgang (Hagberg und WittEngerström 1986). Bereits erworbene Fähigkeiten wie Sprechen, Laufen oder zielgerichtete Handbewegungen gehen verloren. Es manifestieren sich stereotypische Handbewegungen; die Kinder nehmen die Hände in den Mund oder verrichten wringende, klatschende Bewegungen (Hagberg et al. 1983). Außerdem treten motorische Koordinationsprobleme und Atmungsirregularitäten im Wachzustand auf (Julu et al. 2001; Weese-Mayer et al. 2006; Stettner et al. 2008). Es kann des Weiteren zu Krampfanfällen kommen (Jian et al. 2006). Zudem vermeiden die Kinder soziale Interaktionen und ziehen sich sozial zurück. Der zeitliche Verlauf dieser Phase kann sehr unterschiedlich sein. Der Entwicklungsrückgang kann sich sehr abrupt innerhalb weniger Tage manifestieren oder über mehrere Wochen andauern. Das Stadium drei, das Plateau oder auch die pseudo-stationäre Phase genannt, tritt üblicherweise im Alter von 2 bis 10 Jahren auf. Das Verhalten und die physische Kondition stabilisieren oder verbessern sich sogar leicht. Die Handstereotypen werden deutlicher, Krampfanfälle treten häufiger auf (Hagberg et al. 1983). Außerdem manifestieren sich Apraxien. Diese Phase kann mehrere Jahre anhalten, die meisten Patienten befinden sich sogar den Großteil ihres Lebens in dieser Phase. Im Stadium vier, der späten motorischen Verschlechterung, charakterisiert sich der Mobilitätsverlust der Patientinnen, es kommt zu Muskelschwäche, Spasmen, Unbeweglichkeit und Skoliose. Diese Symptome können ab dem 10. Lebensjahr auftreten (Hagberg und Witt-Engerström 1986). Viele Patientinnen werden abhängig vom Rollstuhl. Das letzte Stadium kann Jahre oder Dekaden anhalten (Hagberg et al. 1983). 


\subsubsection{Genetischer Hintergrund}

Dem Rett-Syndrom liegen in 90 Prozent der Fälle De-novo-Mutationen im X-chromosomalen Gen MECP2 zugrunde, welches das metbyl-CpG-binding protein 2 codiert (Amir et al. 1999). $\mathrm{MeCP} 2$ ist ein chromosomenbindendes Protein, das selektiv 5-Methylcytosinreste in symmetrisch positionierten CpG-Dinucleotiden in Säugetiergenomen bindet (Lewis et al. 1992). MeCP2 fungiert somit als Transkriptionsregulator. Es kontrolliert die Transkription verschiedener Gene entweder positiv oder negativ (Chahrour et al. 2008). MECP2 besteht aus vier Exons (Reichwald et al. 2000), die für zwei verschiedene Isoformen des Proteins codieren, MeCP2e-1 (codiert von MECP2a) und MeCP2e-2 (codiert von MECP2ß). Die MECP2-Spleißvarianten unterscheiden sich nur in ihren $\mathrm{N}$-termini (Kriaucionis und Bird 2004). In der Literatur werden sowohl Missense- und Nonsense-Mutationen, als auch FrameshiftInsertionen und Deletionen beschrieben, wobei mehr als 400 verschiedene, pathologische Nukleotidänderungen beobachtet wurden (Christodoulou et al. 2003). Da viele Mutationen frühzeitig Stopp-Codons im Gen verursachen und in einem Nullallel enden, wird das RettSyndrom in den meisten Fällen durch einen Funktionsverlust von MeCP2 verursacht. Allerdings können auch hypomorphe Allele auftreten und in abgeschnittenen Formen von MeCP2 resultieren, die noch partielle Funktionen ausüben können (Chahrour und Zoghbi 2007).

Obwohl das MeCP2-Protein in vielen Regionen exprimiert wird, ist es relativ gesehen gehäufter im Gehirn vorkommend, primär in reifen Neuronen des Kortex, Hippocampus und Kleinhirns. Es wird vermutet, dass die verschiedenen Transkripte des Gens Gegenstand von Gewebe- und Entwicklungsstadien-spezifischer Regulation sein könnten (Jung et al. 2003). Da MeCP2 in reifen Neuronen exprimiert wird und die Konzentrationen während der postnatalen Entwicklung ansteigen, spielt es vielleicht auch eine Rolle in der Modulierung der Aktivität oder Plastizität von reifen Neuronen (Chahrour und Zoghbi 2007).

Allerdings resultieren sowohl der Funktionsverlust von MeCP2 als auch ein Anstieg der MeCP2-Konzentration in ähnlich klinisch-neurologischen Störungen. Studien von transgenen Mäusen, die MeCP2 in doppelter Menge exprimieren zeigen, dass diese Tiere nach vermeintlich normaler Entwicklung in den ersten zehn Wochen schließlich Phänotypen ähnlich denen des Rett-Syndroms aufweisen, wie phänotypische Bewegungen der vorderen Extremitäten, Hypoaktivität oder Krampfanfälle, wobei zwischen der 20. und 25. Woche auch von verbesserten Lernfähigkeiten und erhöhter synaptischer Plastizität berichtet wird. Dennoch kommt es auch bei diesen Tieren gegen Ende des ersten Lebensjahres zu Ataxie und Tod (Collins et al. 2004). Trotz der tiefgreifenden neurologischen Phänotypen im RettSyndrom sind die größten morphologischen Abnormalitäten, die im zentralen Nervensystem gefunden wurden eine einheitliche Verkleinerung des Gehirns und individueller Neurone. Außerdem wurde eine reduzierte dendritische Verzweigung in den Schichten III und V pyramidaler Neurone im frontalen und motorischen Kortex und im Subiculum beobachtet (Armstrong 2005). 
Eine verzögerte neuronale Reifung und Synaptogenese wurde im MeCP2-defizienten zerebralen Kortex beobachtet (Fukuda et al. 2005). Des Weiteren konnten auch Männer mit Rett-Syndrom identifiziert werden (Jan et al. 1999). Es konnte außerdem gezeigt werden, dass Jungen mit MECP2-Mutationen ähnliche Phänotypen wie die erkrankten Mädchen aufzeigen können (Dayer et al. 2007). Allerdings führen MECP2-Mutationen, die das klassische Rett-Syndrom bei Frauen auslösen, bei Männern mit normalem Karyotyp zu neonataler Enzephalopathie und Tod im ersten Lebensjahr (Chahrour und Zoghbi 2007).

Die Variabilitäten, die im Phänotyp der Patienten auftreten, können zum einen durch Unterschiede im Mutationstypus und der Mutationslokalisation zurückzuführen sein, zum andern auf das Muster der X-Chromosom-Inaktivierung (Young und Zoghbi 2004). In Studien konnte bereits gezeigt werden, dass Mecp2 von der X-Chromosom-Inaktivierung betroffen ist (Adler et al. 1995). Des Weiteren wurde im Rett-Mausmodell gezeigt, dass signifikant schwächere Phänotypen bei weiblichen Mäusen zu beobachten sind, die einen großen Prozentsatz der Neurone aufweisen, in denen das mutierte X-Chromosom inaktiviert wurde. Daher scheinen die Expressionsraten des Wildtyp-Mecp2 und des mutierten Mecp2 essentiell für die Schwere des Phänotypes verantwortlich zu sein. In Zellkulturen von Mecp2mutierten Mäuse-Neuronen konnte gezeigt werden, dass die Zellen, die das Wildtyp-Mecp2Allel exprimieren in der Zellpopulation dominieren, was suggeriert, dass es einen Selektionsvorteil für diese Zellen geben muss, bzw. einen Selektionsdruck für die Zellen, die das mutierte Allel exprimieren. Dies verdeutlicht, welchen enormen Einfluss MeCP2 auf das Überleben von Neuronen hat (Young und Zoghbi 2004). Jedoch ist darauf hinzuweisen, dass die Datenlage bei menschlichen Rett-Patienten unschlüssig ist, da sowohl von balancierter, ausgeglichener (Shahbazian et al. 2002) als auch von unbalancierter X-ChromosomInaktivierung berichtet wird (Renieri et al. 2003).

\subsubsection{Mitochondriale Veränderungen im Rett-Syndrom}

Obwohl mittlerweile festgestellt wurde, dass es sich beim Rett-Syndrom um eine Krankheit genetischen Ursprunges handelt (Amir et al. 1999), bestand anfänglich aufgrund der klinischen Erscheinung des Krankheitsbildes wie Hyperventilation und Apnoe die Vermutung einer metabolischen Störung (Haas et al. 1986; Matsuishi et al. 1994). Elektronenmikroskopische Untersuchungen von Muskel- und Frontallappenbiopsien bei Rett-Patientinnen zeigten in der Tat Veränderungen der mitochondrialen Morphologie. Elektronenmikroskopische Aufnahmen des Frontallappens zeigten große, kugelförmige Mitochondrien mit rudimentären Cristae (Cornford et al. 1994) sowie geschwollene, hanteloder zylinderförmige, akkumulierte Mitochondrien in Aufnahmen von Muskelbiopsien (EegOlofsson et al. 1990; Dotti et al. 1993). Post-mortem Untersuchungen von neuronalem Gewebe einer Patientin zwölf Jahre nach der ersten Hirnbiopsie zeigten runde, elektronendichte Einschlüsse in den Mitochondrien (Cornford et al. 1994), sodass die Vermutung besteht, dass die mitochondrialen, pathologischen Veränderungen trotz Stabilisierung der klinischen Symptome fortschreiten (Müller und Can 2014). 


\subsection{Reaktive Sauerstoffspezies}

Unter der Bezeichnung Reactive oxygen species (ROS) wird eine Gruppe reaktiver Sauerstoffverbindungen verstanden, die sowohl Sauerstoffradikale als auch nicht radikalische Verbindungen umfasst, die als Oxidationsmittel fungieren oder selbst leicht zu Radikalen reagieren (Miller et al. 1990; Khan und Wilson 1995; Halliwell 2006). Radikale besitzen ein oder mehrere ungepaarte Elektronen (Halliwell und Gutteridge 1984a) und streben an, durch Reaktionen mit anderen Molekülen Elektronen aufzunehmen. ROS repräsentieren eine der wichtigsten Radikalspezies in Lebewesen (Miller et al. 1990), da sie sowohl physiologisch als auch pathophysiologisch von großer Bedeutung sind. Sie entstehen als Produkte des normalen Zellmetabolismus (Boveris und Chance 1973) aus molekularem Sauerstoff $\left(\mathrm{O}_{2}\right)$. Wenn $\mathrm{O}_{2}$ ein Elektron hinzugefügt wird, entsteht das Superoxidanion $\mathrm{O}_{2}^{-}$, aus dem andere ROS wie Hydroxylanionen oder $\mathrm{H}_{2} \mathrm{O}_{2}$ entweder durch spontane oder enzym- bzw. metallkatalysierte Reaktionen entstehen können (Chance et al. 1979; Miller et al. 1990). Bereits 1975 wurde vermutet, dass die mitochondriale $\mathrm{H}_{2} \mathrm{O}_{2}$-Produktion mit der Atmungskette in Verbindung steht (Boveris et al. 1976). Später konnte nachgewiesen werden, dass Superoxide entstehen, wenn einzelne Elektronen während der Prozesse der Atmungskette auf molekularen Sauerstoff übertragen werden (Chance et al. 1979).

Insgesamt konnten sieben unterschiedliche Stellen mitochondrialer ROS Produktion lokalisiert werden (Brand 2010). Die höchsten ROS-Produktionskapazitäten konnten an Komplex I und Komplex III der Atmungskette identifiziert werden, genauer an den Komplexbestandteilen IF, IQ und IIIQo (Chen et al. 2003; Kudin et al. 2004) Wird der Komplex I der Atmungskette isoliert, zeigt das voll reduzierte Flavinmononukleotid (IF) die höchste Rate an produzierten Superoxidanionen (Kussmaul und Hirst 2006). Des Weiteren entstehen Superoxide durch rückwärtigen Elektronentransport vom reduzierten Ubichinon $\left(\mathrm{QH}_{2}\right)$ auf Nicotinamidadenindinukleotid $\left(\mathrm{NAD}^{+}\right)$(Votyakova und Reynolds 2001). An Komplex III entsteht im Rahmen des Q-Zyklus ein Pool an Semichinon (Hydrochinonradikal), welches Sauerstoff leicht zu Superoxidanionen reduzieren kann (Cape et al. 2007). Die an Komplex I produzierten ROS werden in die Mitochondrienmatrix freigesetzt, dagegen werden die an Komplex III entstandenen ROS sowohl in die Mitochondrienmatrix als auch in den Intermembranraum entlassen (Han et al. 2001; Muller et al. 2004). Auch andere mitochondriale Enzyme sind erheblich an der mitochondrialen ROS-Produktion beteiligt. Dazu gehören die Glycerol-3-Phosphatdehydrogenase (GPDH), die Superoxid zu beiden Seiten der inneren Mitochondrienmembran produziert (Miwa et al. 2003), die $\alpha$-Ketoglutaratdehydrogenase ( $\alpha-\mathrm{KDH}$ ) (Starkov et al. 2004; Tretter et al. 2004) die Pyruvatdehydrogenase (PDH) und die elektronentransferierende Flavoprotein-QOxidoreduktase (St-Pierre et al. 2002). Es wird angenommen, dass circa 0,15\% des mitochondrialen $\mathrm{O}_{2}$-Verbrauches auf die Produktion reaktiver Sauerstoffspezies zurückzuführen ist (St-Pierre et al. 2002). Die Zusammenhänge sind in Abbildung 1 dargestellt. 


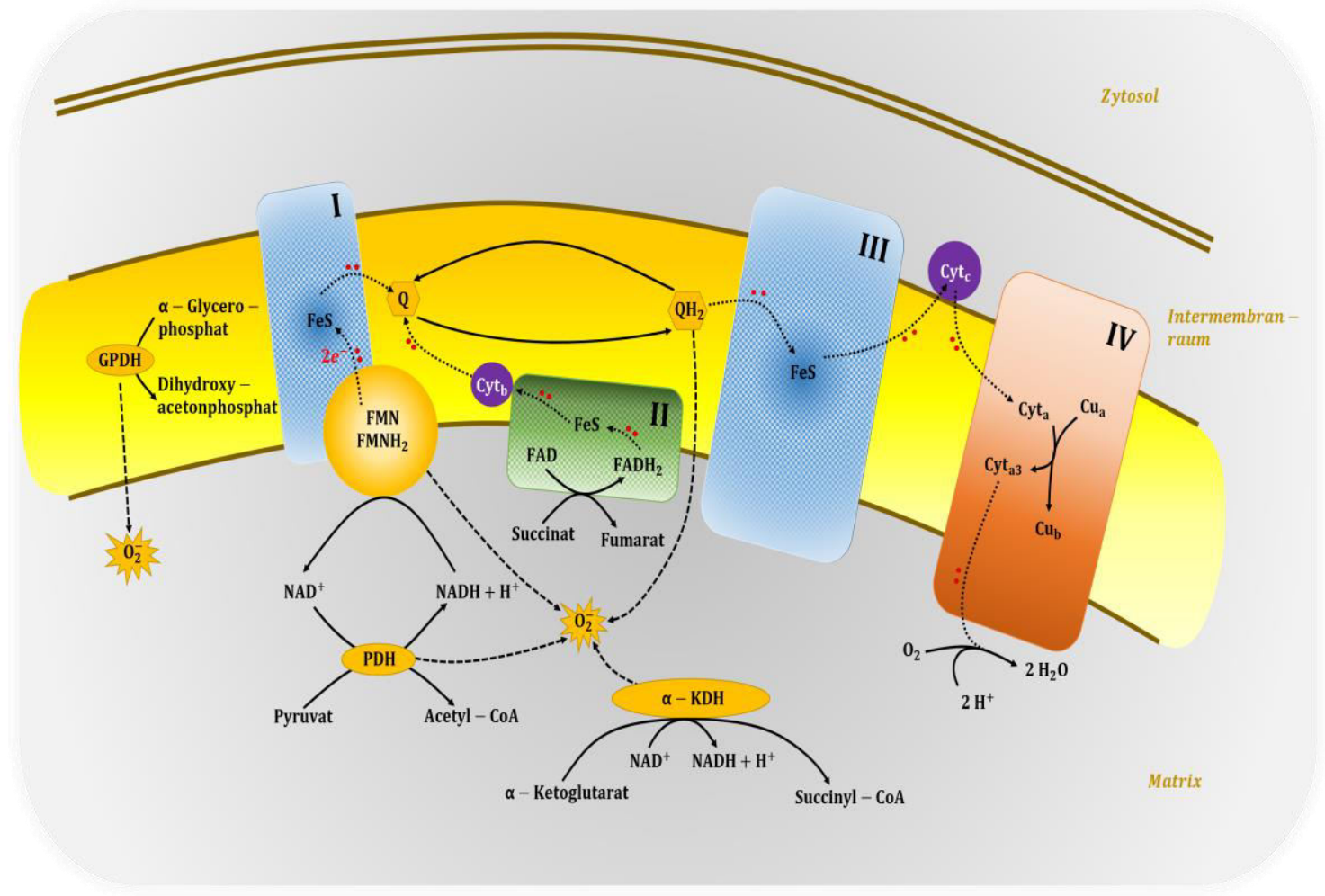

Abbildung 1: Entstehungsorte radikaler Sauerstoffspezies im Mitochondrium

Im Rahmen der Atmungskette entstehen radikale Sauerstoffspezies an Komplex I über das reduzierte Flavinmononukleotid und durch rückwärtigen Elektronentransport vom reduzierten Ubichinon (QH2) auf Nicotinamidadenindinukleotid $\left(\mathrm{NAD}^{+}\right)$. An Komplex III entsteht im Rahmen des Q-Zyklus Semichinon (Hydrochinonradikal), welches Sauerstoff leicht zu Superoxidanionen reduzieren kann. Auch andere mitochondriale Enzyme wie die Glycerol-3-Phosphatdehydrogenase (GPDH), welche Superoxid zu beiden Seiten der inneren Mitochondrienmembran produziert, die $\alpha$-Ketoglutaratdehydrogenase $(\alpha-\mathrm{KDH})$, die Pyruvatdehydrogenase (PDH) und die elektronentransferierende Flavoprotein-Q-Oxidoreduktase sind erheblich an der mitochondrialen ROS-Entstehung beteiligt.

Eine andere Quelle der ROS-Entstehung in physiologischen Zellprozessen sind die NADPH-abhängigen Oxidasen, die unter anderem in phagozytierenden Blutzellen wie Makrophagen und neutrophilen Granulozyten im Rahmen der Immunantwort aktiv sind. Das Enzym katalysiert den Elektronentransport von NADPH via FAD und Häm zu molekularem Sauerstoff, wodurch Superoxidanionen entstehen, die mikrobizid als Teil der angeborenen Immunität wirken (Segal und Shatwell 1997; Leto und Geiszt 2006). Mittlerweile konnten sieben verschiedene NADPH-Oxidasen (NADPH-Oxidase 1-5, DualOxidase 1-2) charakterisiert werden, deren produzierte ROS eine wichtige Rolle während der zellulären Signaltransduktion spielen (Brown und Griendling 2009). Signalmoleküle wie Protein-Tyrosin-Kinasen und Phosphatasen sowie Protein-Serin/Threonin-Kinasen und Phosphatasen können durch ROS-Freisetzung ihren Aktivitätszustand ändern (Kamata und Hirata 1999). Dies lässt sich dadurch erklären, dass viele solcher ROS-Effektorproteine häufig reaktive Cysteinreste besitzen, die reversibel durch ROS oxidiert werden können und damit die Funktion des Proteins verändert oder fehlreguliert wird (Miki und Funato 2012). 
Über unterschiedliche Signalkaskaden bzw. die Beeinflussung von Proteinen wie mitogen activated protein kinase (MAPK), Phosphoinositid-3-Kinasen (PI3K), nuclear factor kappa-lightchain-enhancer of activated B-cells (NF-KB) und p53 haben ROS somit erheblichen Einfluss auf physiologische Zellprozesse wie die zelluläre Signaltransduktion, Transkription und Induktion der Apoptose (Trachootham et al. 2008).

\subsection{Zelluläre Redox-Balance}

\subsubsection{Enzymatische und antioxidative Regulation}

In gewissen Konzentrationen sind ROS essentiell für den Ablauf physiologischer Zellprozesse, jedoch wurde früh vermutet, dass sie ebenso für Zellschäden, Mutationen, Tumoren und degenerative Prozesse im Rahmen der biologischen Alterung verantwortlich sind (Harman 1956). Mittlerweile wurde bestätigt, dass ROS in hohen Konzentrationen Zellschäden verursachen, insbesondere an Nukleinsäuren, Lipiden und Proteinen (Valko et al. 2006). So schädigen beispielsweise Hydroxylanionen DNA-Abschnitte, indem sie mit Purin- und Pyrimidinbasen sowie mit dem Desoxyribosegerüst reagieren (Halliwell und Gutteridge 1999) oder sie sind Initiatoren der Lipidperoxidation, in deren Folge die Membranfluidität herabgesetzt wird, die Membranpermeabilität erhöht, Membranproteine geschädigt und Rezeptoren oder Ionenkanäle inaktiviert oder fehlreguliert werden (Halliwell und Gutteridge 1984b; Halliwell 2006). Aufgrund dieser schädlichen Effekte von reaktiven Sauerstoffspezies wurden von Lebewesen unterschiedliche präventive bzw. reparierende Mechanismen und Antioxidantien entwickelt, um das Redoxsystem im physiologischen Gleichgewicht zu halten (Buonocore et al. 2010). Solche Antioxidantien sind als Substanzen definiert, die in der Lage sind, die Oxidation von Substraten zu verlangsamen oder zu verhindern, indem sie mit dem zu oxidierenden Substrat konkurrieren (Halliwell und Gutteridge 1984b). Diese Definition umfasst die Enzyme Superoxiddismutase, Glutathionperoxidase und Katalase, wie auch nicht enzymatische Moleküle wie $\alpha$ Tocopherol (Vitamin E), $\beta$-Carotin, Ascorbinsäure (Vitamin C) und Glutathion (Dröge 2002).

Die Superoxiddismutase (SOD) katalysiert die Disproportionierung von Superoxidanionen $\mathrm{zu} \mathrm{H}_{2} \mathrm{O}_{2}$ und molekularem Sauerstoff (McCord und Fridovich 1969).

$$
2 \mathrm{O}_{2}^{-}+2 \mathrm{H}^{+} \rightarrow \mathrm{H}_{2} \mathrm{O}_{2}+\mathrm{O}_{2}
$$

[Formel 1]

Die Enzymaktivität konnte in den subzellulären Kompartimenten nachgewiesen werden, in denen Superoxidanionen produziert werden (Peeters-Joris et al. 1975). Im Zytosol und dem Mitochondrienintermembranraum befindet sich eine SOD mit Zink und Kupfer im aktiven Zentrum (SOD1), in der Mitochondrienmatrix besitzt die SOD dagegen Mangan im aktiven Zentrum (SOD2) (Panchenko et al. 1975; Fridovich 1995). Da $\mathrm{H}_{2} \mathrm{O}_{2}$ als Endprodukt der katalysierten Reaktion immer noch in der Lage ist Zellschäden zu verursachen, muss die Superoxiddismutase mit Enzymen oder Molekülen gekoppelt sein, die $\mathrm{H}_{2} \mathrm{O}_{2}$ eliminieren. Das 
Enzym Katalase, das vor allem in den Peroxisomen vorkommt, katalysiert den Abbau von $\mathrm{H}_{2} \mathrm{O}_{2}$ zu molekularem Sauerstoff und Wasser (De Duve und Baudhuin 1966; Deisseroth und Dounce 1970). Als tetrameres Enzym mit Häm im aktiven Zentrum (Murthy et al. 1981) ist es wichtiger Bestandteil der zellulären Redox-Homöostase.

$$
\mathrm{H}_{2} \mathrm{O}_{2} \rightarrow 2 \mathrm{H}_{2} \mathrm{O}+\mathrm{O}_{2}
$$

[Formel 2]

Auch Glutathion ist in der Lage, $\mathrm{H}_{2} \mathrm{O}_{2}$ zu eliminieren. Glutathion (2 GSH/GSSG) gilt als wesentlicher intrazellulärer Redox-Regulator, indem es einen großen Pool an Reduktionsäquivalenten liefert (Schafer und Buettner 2001). Wichtig für seine Funktion ist die Sulfhydrylgruppe (-SH) des Cysteins, die unter Oxidation eine Disulfidbrücke mit einem weiteren Glutathionmolekül ausbilden kann (Mills 1957; Gilbert 1995), sodass folgende von der Glutathionperoxidase katalysierte Reaktion zustande kommt:

$$
2 \mathrm{GSH} \rightarrow \mathrm{GSSG}+2 \mathrm{H}^{+}+2 \mathrm{e}^{-}
$$

[Formel 3]

Das Gleichgewicht zwischen reduziertem und oxidiertem Glutathion wird durch die Gluthationreduktase erhalten, die die Reduktion von Glutathiondisulfid zu Glutathion mit Hilfe des Coenzyms NADPH $/ \mathrm{H}^{+}$katalysiert (Shan et al. 1990). Alle an diesem System beteiligten Komponenten sind in Abbildung 2 dargestellt. Übersteigt die ROS-Produktion die Kapazität des antioxidativen Systems entsteht oxidativer Stress (Milton und Sweeney 2011).

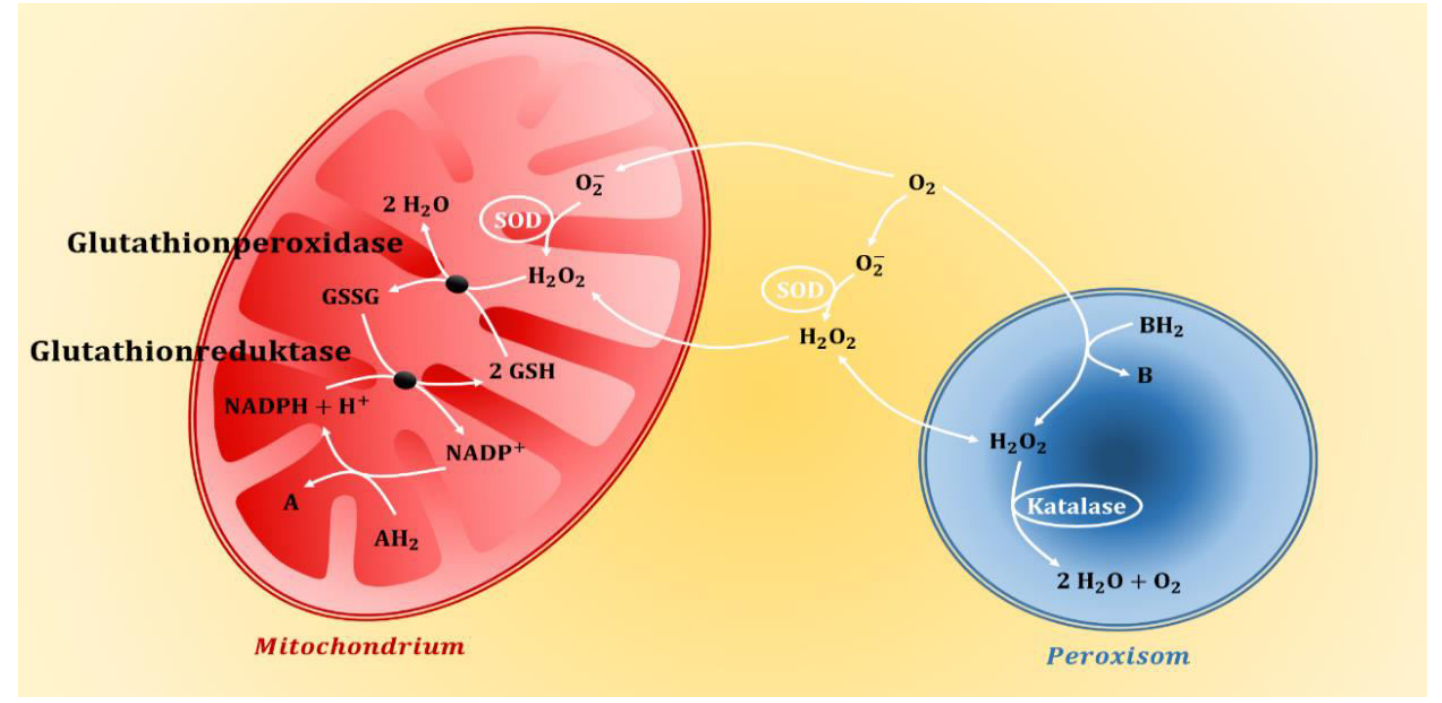

Abbildung 2: Enzymatische Regulationsmechanismen der zellulären Redox-Homöostase

Schlüsselenzyme der zellulären Redox-Homöostase stellen im Mitochondrium die Superoxiddismutase, die die Disproportionierung von Superoxidanionen $\mathrm{zu} \mathrm{H}_{2} \mathrm{O}_{2}$ und molekularem Sauerstoff katalysiert, sowie das Glutathionsystem dar. Durch Oxidation des Glutathions kann $\mathrm{H}_{2} \mathrm{O}_{2}$ unter Katalyse der Glutathionperoxidase zu Wasser reduziert werden. Die Reduktion des so entstandenen Glutathiondisulfid zu Glutathion erfolgt über die Glutathionreduktase mit Hilfe des Coenzyms NADPH $/ \mathrm{H}^{+}$. Zusätzlich erfolgt der Abbau von im Zellmetabolismus entstandenem $\mathrm{H}_{2} \mathrm{O}_{2}$ in den Peroxisomen durch das Enzym Katalase. Abbildung angelehnt an Chance B (1979): Hydroperoxide metabolism in mammalian organs. Physiol Rev $\underline{59}$, 527-605 


\subsubsection{Redox-Imbalance und oxidativer Stress im Rett-Syndrom}

Da der klinische Phänotyp im Rett-Syndrom Ähnlichkeiten mit Symptomen mitochondrialer Erkrankungen und Störungen des oxidativen Stoffwechsels aufweist wie Hyperventilation und Apnoe, wurde lange vermutet, dass es sich beim Rett-Syndrom um eine metabolische Störung handelt (Matsuishi et al. 1994; Haas et al. 1995). Die in 1.1.3 beschriebenen Veränderungen lieferten erste Beweise mitochondrialer Defekte. Passend zu den morphologischen Veränderungen werden in der Literatur auch pathophysiologische Veränderungen der Mitochondrienfunktion beschrieben. So konnten in Sauerstoffmessungen bis zu $30 \%$ erhöhte mitochondriale Atmungsraten bei Mecp2-nullMäusen nachgewiesen werden (Müller und Can 2014). Zudem wurde eine Überexpression des Gens Uqcr1 beobachtet, welches für das Protein Uqcrc1 exprimiert, das Bestandteil von Komplex III der Atmungskette ist und mit dessen Promotor MeCP2 interagiert (Kriaucionis et al. 2006). Microarray-Daten, die die Genregulation in Blutzellen von Rett-Patientinnen untersuchten, ergänzen diese Ergebnisse. Viele Transkripte, die für verschiedene ProteinUntereinheiten der Atmungskettenkomplexe codieren, waren bei Rett-Patientinnen im Vergleich zur Kontrollgruppe signifikant hochreguliert. Diese veränderte Genregulation ist daher direkt mit der mitochondrialen ATP-Produktion und indirekt mit der potentiellen Entstehung reaktiver Sauerstoffspezies verbunden (Pecorelli et al. 2013). Die Tatsache, dass trotz Hypoxie bei Rett-Mäusen in Hippocampus-Proben von adulten Mecp $2^{-1 y}$-Mäusen normale ATP-Spiegel beobachtet wurden (Fischer et al. 2009) suggeriert, dass die mitochondriale Atmung kompensatorisch stimuliert wird, um eine ausreichende ATPVersorgung der Gewebe zu gewährleisten (Müller und Can 2014). Da 80 \% der zellulären Superoxide in Mitochondrien produziert werden (Boveris und Chance 1973), besteht die Vermutung, dass diese metabolische Kompensation in einer erhöhten Freisetzung reaktiver Sauerstoffspezies und somit in oxidativem Stress im Rett-Syndrom resultiert. Diese Theorie wird dadurch bestätigt, dass viele Gene, die für die zelluläre Redox-Homöostase verantwortlich sind, im Rett-Syndrom ebenfalls hochreguliert werden. Dazu gehören die Gene der Superoxiddismutase, Katalase und Peroxiredoxin 1. So könnte die erhöhte Expression des Gens der SOD1 eine Reaktion auf erhöhte Superoxidanionproduktion an den Komplexen I und III sein und die Expression der Gene der Katalase und des Peroxiredoxin 1 als Kompensation der daraus resultierenden erhöhten $\mathrm{H}_{2} \mathrm{O}_{2}$-Konzentration ansteigen (Großer et al. 2012; Pecorelli et al. 2013).

Dennoch scheint dieser Kompensationsmechanismus nicht suffizient genug zu sein, um die ROS-Produktion im Rett-Syndrom auf einem physiologischen Level zu halten, da verschiedene Studien von erhöhten ROS-Konzentrationen und systemischem oxidativem Stress im Rett-Syndrom berichten (De Felice et al. 2009; Pecorelli et al. 2011). Fluoreszenzspektrometrische Messungen isolierter Mitochondrien des Hippocampus und Kortex zeigen erhöhte $\mathrm{H}_{2} \mathrm{O}_{2}$-Freisetzung in Mecp2-/y-Mäusen im Vergleich zu WildtypKontrollgruppen (Can et al. 2019). Mit Hilfe des redoxsensitiven Biosensors roGFP1 (reduction-oxidation sensitive green fluorescent protein) konnten außerdem erhöhte oxidative baseline- 
Konditionen im Zytosol Mecp2-defizienter Mäuse sowie eine vulnerablere Redox-Balance und reduzierte Aktivität des ROS Scavengers SOD1 nachgewiesen werden (Großer et al. 2012). Auch humane Studien bestätigen diese Datenlage, da oxidative Stressmarker wie intraeerythrozytäres, nicht proteingebundenes Eisen (NPBI), Plasma NPBI und Proteincarbonyle bei Rett-Patientinnen erhöht sind. Somit wird bestätigt, dass oxidativer Stress an der Pathogenese des klassischen Rett-Syndroms beteiligt ist (De Felice et al. 2009). Interessant ist die Erkenntnis, dass sowohl erhöhter oxidativer Stress als auch der daraus resultierende oxidative Schaden am Hirngewebe bei Mecp2-null-Mäusen nach Reaktivierung von Mecp2 vollständig reversibel ist (De Felice et al. 2014). Dies veranschaulicht, dass erhöhter oxidativer Stress im Rett-Syndrom direkt aus dem Funktionsverlust des Mecp2-Gens resultiert und keinen irreversiblen Zustand darstellen muss (Müller und Can 2014; Can et al. 2019), was für therapeutische Ansätze von großem Interesse ist (Müller 2019).

\subsection{Verbesserung der Redox-Homöostase als Therapieansatz}

Da sich sowohl die mitochondrialen Veränderungen als auch der durch oxidativen Stress entstandene Hirnschaden bereits einige Wochen vor dem Auftreten klinischer Symptome manifestieren, besteht die Vermutung, dass die mitochondriale Beeinträchtigung für die Progression der Krankheit von größerer Bedeutung ist (De Felice et al. 2014). Therapeutische Ansätze, die die mitochondriale Funktion verbessern oder das RedoxGleichgewicht stabilisieren, könnten daher möglicherweise das Auftreten von Symptomen verzögern oder den Schweregrad des Krankheitsverlaufes mildern (Shulyakova et al. 2017). Es gibt bereits erste Studien, die mit dahingehenden Therapieansätzen erste Erfolge erzielen konnten: So konnte in akuten Hippocampus-Schnitten von $M e c p 2^{-1 y}$-Mäusen durch das Vitamin E Derivat Trolox die synaptische Kurz- und Langzeitplastizität verbessert werden sowie die neuronale Hypererregbarkeit gedämpft werden (Janc und Müller 2014). In weiterführenden in vivo Studien, in denen $M e c p 2^{-1 y}$-Mäusen intraperitoneal alle 48 Stunden Trolox injiziert wurde, konnten durch diese Therapiemaßnahme sowohl die oben beschriebene Kurz-und Langzeitplastizität verbessert, als auch Blutglukosespiegel und Lipidperoxidation positiv beeinflusst werden (Janc et al. 2016). Des Weiteren konnten vaskuläre Dysfunktionen im Mausmodell des Rett-Syndroms, die auf eine erhöhte ROSFreisetzung zurückzuführen sind, durch Curcumin-Fütterung aufgehoben werden (Panighini et al. 2013). Zudem konnte ein signifikanter Rückgang oxidativer Stressmarker bei RettPatientinnen unter sechsmonatiger oraler Gabe mehrfach ungesättigter $\omega$-3-Fettsäuren beobachtet werden, ebenso wie eine signifikante Reduktion des klinischen Schweregrades der Erkrankung. Insbesondere haben sich durch die Therapie Atemstörungen und auch motorische Fähigkeiten der Patientinnen wie aufrechtes Sitzen, Handbewegungen oder nonverbale Kommunikation verbessert (De Felice et al. 2012). 


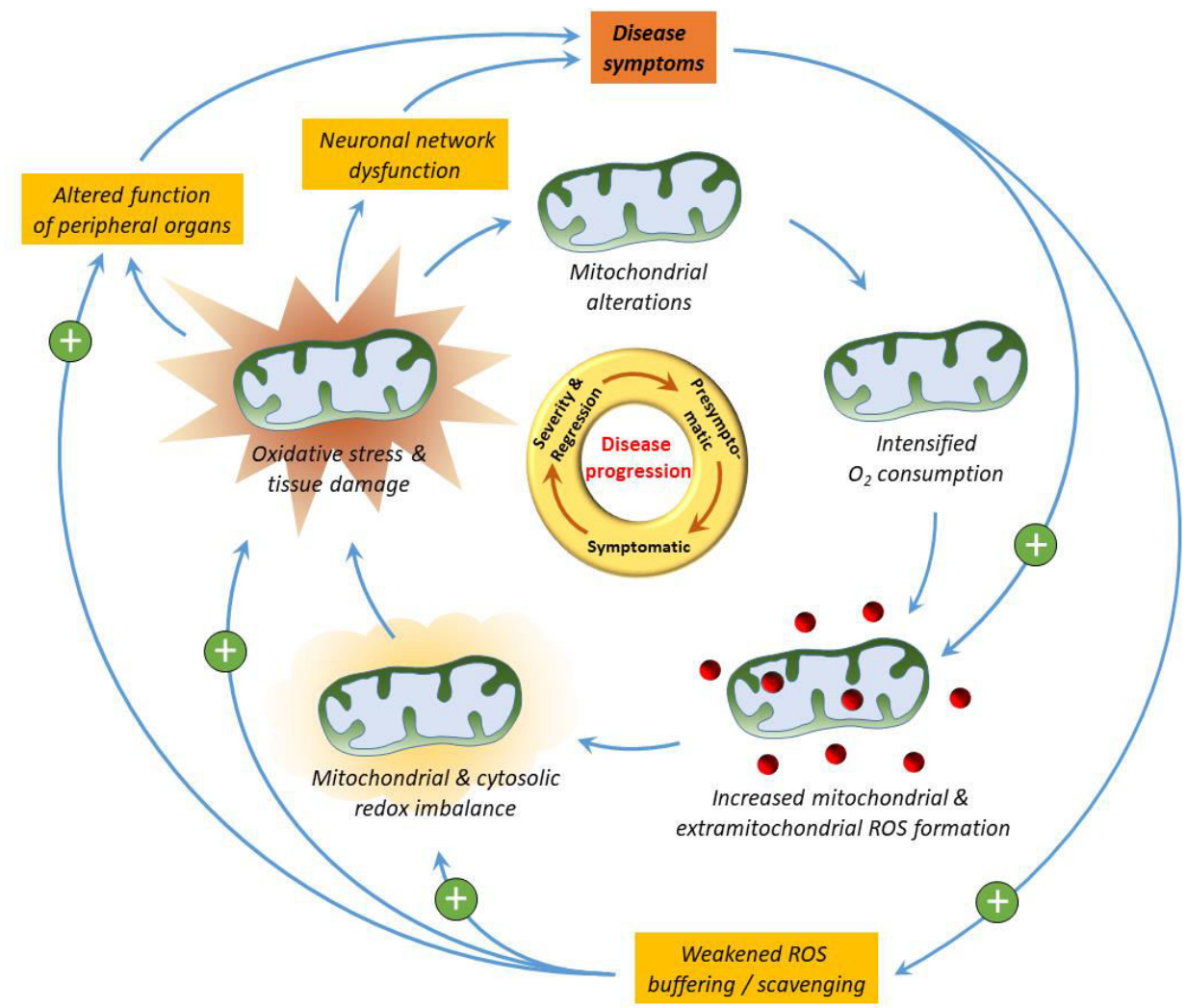

Abbildung 3: Zusammenhang zwischen der Progression des Krankheitsverlaufes und des RedoxGleichgewichtes

Mitochondriale Veränderungen und die systemische Hypoxie im Rett-Syndrom resultieren in einer erhöhten ROS-Freisetzung und Redox-Imbalance. Der oxidative Stress verändert die Aktivität Redox-abhängiger Signalkaskaden und kann zu Veränderungen der Proteinaktivität und Dysfunktionen zerebraler Aktivitäten führen. Mögliche Therapieansätze versuchen diesen Kreis zu durchbrechen und eine physiologische RedoxBalance widerherzustellen. Abbildung entnommen aus Müller M (2019): Disturbed redox homeostasis and oxidative stress: potential players in the developmental regression in Rett syndrome. Neurosci Biobehav Rev 98, 154-163 mit freundlicher Genehmigung des Verlags Elsevier.

Auch die orale Gabe von EPI-743, das die Glutathion-Synthese anregt, zeigt erste positive Effekte in Bezug auf die Redox-Balance und die Entwicklung der am Rett-Syndrom erkrankten Kinder. So konnte im Rahmen einer explorativen Phase-II-Studie durch die orale EPI-743 Substitution das Kopfwachstum im Rett-Syndrom positiv beeinflusst werden (Pozzo-Miller et al. 2015). Diese Studien suggerieren ein hohes therapeutisches Potential von Antioxidantien im Rett-Syndrom (Abbildung 3). Allerdings ist durch die antioxidative Therapie keine Heilung zu erreichen, es können lediglich einzelne Symptome des komplexen klinischen Erscheinungsbildes verbessert werden. 


\subsection{Ziele der Arbeit}

In der aktuellen Literatur wurde hauptsächlich der Effekt nicht enzymatischer Antioxidantien auf die Redox-Imbalance im Rett-Syndrom untersucht. In wie weit sich jedoch eine erhöhte Expression antioxidativ wirkender Enzyme auswirkt steht bislang noch aus. Mit der Entwicklung transgener Mäuse, die humane Katalase in Mitochondrien $(m C A T)$ exprimieren, konnte bereits eine geringere $\mathrm{H}_{2} \mathrm{O}_{2}$-Produktion sowie ein geringerer oxidativer Schaden bei $m C A T$-Mäusen im Vergleich zu den Wildtyp-Kontrollgruppen nachgewiesen werden (Schriner et al. 2005). Andere Studien berichten von gesteigertem Gedächtnisvermögen und reduzierten Angstzuständen bei diesen Tieren (Olsen et al. 2013). Im physiologischen Zellmetabolismus ist die Katalase vor allem in den Peroxisomen lokalisiert, um $\mathrm{H}_{2} \mathrm{O}_{2}$, das im Rahmen der peroxisomalen $\beta$-Oxidation entsteht, abzubauen (Chance et al. 1979). In den Mitochondrien wird überschüssiges $\mathrm{H}_{2} \mathrm{O}_{2}$ über die Glutathionperoxidase abgebaut. Dieser Abbau ist abhängig von der Verfügbarkeit reduzierten Glutathions und somit auch vom Gesamt-Redoxstatus. Der Vorteil der Katalase ist, dass sie $\mathrm{H}_{2} \mathrm{O}_{2}$ auch ohne die Verfügbarkeit von Elektronendonatoren abbauen kann. Damit bleibt ihre Funktion auch im bereits veränderten Redoxmilieu (wie z.B. im Rett Syndrom nachgewiesen) erhalten (Dai et al. 2017). Durch das Einkreuzen der transgenen $m C$ AT-Mäuse in das Mausmodell des Rett-Syndroms, sollten im Rahmen dieser Arbeit potentiell positive Auswirkungen der mitochondrialen Katalase auf die Redox-Imbalance im Rett-Syndrom untersucht werden. Dafür wurden Mitochondrien der Hirnregionen Kortex, Hippocampus, Kleinhirn, Mittelhirn und Hirnstamm isoliert und in fluoreszenzspektrometrischen Analysen deren $\mathrm{H}_{2} \mathrm{O}_{2}$-Freisetzung quantifiziert. Parallel dazu sollten auch mögliche Verbesserungen des phänotypischen Erscheinungsbildes der Tiere bewertet werden, indem Größe, Gewicht, Blutglukosespiegel und Hämatokrit untersucht wurden. Im Rahmen dieser Experimente wurden sowohl männliche als auch weibliche Tiere genutzt, um auch geschlechtsspezifische Unterschiede zu untersuchen. Bei den hemizygoten Männchen fehlt Mecp2 vollständig (Mecp2-ly). Aufgrund des ausgeprägten Phänotyps der Mecp 2-ly-Männchen konnten diese lediglich 50 Tage postnatal im Zuge der Messungen untersucht werden, da diese in der Regel eine Lebenserwartung von nur 50 bis 70 Tage verzeichnen. Bei den weiblichen, heterozygoten Tieren $\left(M e c p 2^{+/-}\right)$, die das klinisch relevante Erscheinungsbild wiederspiegeln, war es aufgrund der milderen Symptomatik, der langsameren Krankheitsprogression und der damit verbundenen höheren Lebenserwartung möglich, den therapeutischen Nutzen der mitochondrialen Katalase-Expression im zeitlichen Verlauf bis ins höhere Lebensalter untersuchen zu können. Die Messungen wurden bei den Weibchen 50, 200 und 400 Tage postnatal durchgeführt. Ziel dieser Arbeit war es daher, den therapeutischen Nutzen einer erhöhten Katalase-Expression im RettSyndrom in Bezug auf Alter, Geschlecht und vor allem für die unterschiedlichen Hirnregionen zu evaluieren. 


\section{Material und Methoden}

\subsection{Verwendete Mausmodelle}

Im Zuge dieser Arbeit wurde die Mauslinie B6.129P2(C)-Mecp2 ${ }^{\text {tm-1-1Bid }}$ genutzt, die ein Mausmodell für die human-relevante Erkrankung des Rett-Syndroms darstellt. Mit Hilfe des Cre/loxP-Systems wurden bei diesen Mäusen das Exon 3 und 4 des X-chromosomalen Mecp2-Gens mit loxP-Stellen markiert, was in einer Deletion der beiden Exons resultiert und somit zum Funktionsverlust des Gens führt (Guy et al. 2001). Die heterozygoten Zuchtweibchen dieser Linie wurden von der Firma The Jackson Laboratory (Bar Harbor, Maine) bezogen. Durch anschließende Verpaarung mit Wildtyp-Männchen der Zuchtlinie C57BL/6J wurden heterozygote Weibchen $\left(M e c p 2^{+/-}\right)$, Wildtyp-Weibchen $\left(M e c p 2^{+/+}\right)$, knockout-Männchen $\left(M e c p 2^{-/ y}\right)$ und Wildtyp-Männchen $\left(M e c p 2^{+/ y}\right)$ erzeugt und vor Ort entsprechend weiter gezüchtet. Außerdem wurde die Mauslinie C57BL/6.mCAT 4033 genutzt. Bei diesen Tieren wurde das Gen der humanen peroxisomalen Katalase dahingehend verändert, dass die Peroxisom-Lokalisationsfrequenz deletiert wurde und durch die ersten 25 Aminosäuren der Ornithintranscarbamylase-Sequenz ersetzt wurde. Durch diese an den N-Terminus angehängte Sequenz wird das Proteinprodukt des Gens zum Mitochondrium geleitet. Das so veränderte humane Gen wurde anschließend in das Mausgenom integriert (Schriner et al. 2005). Als Resultat exprimieren die Tiere in allen Körperzellen eine mitochondriale Katalase. Diese Mäuse wurden ebenfalls von der Firma The Jackson Laboratory (Bar Harbor, Maine) bezogen.

Anschließend wurden männliche Tiere dieser Mauslinie mit heterozygoten Weibchen der Rett-Linie B6.129P2(C)- Mecp2 ${ }^{\text {tm-1-1Bid }}$ verpaart, um Mäuse zu erhalten, die sowohl den Xchromosomalen Mecp2-Gendefekt tragen, als auch die mitochondriale Katalase exprimieren $\left(m C A T^{+/ T}\right)$. Die im Rahmen dieser Arbeit verwendeten Weibchen wurden nach 50, 200 und 400 Lebenstagen für die Messungen genutzt. Aufgrund des ausgeprägteren Phänotyps des Rett-Syndroms bei den Männchen und der daraus resultierenden geringeren Lebenserwartung, wurden die Männchen lediglich 50 Tage postnatal für die Messungen genutzt.

Die Zucht der Rett-Mäuse, das Einkreuzen der $m C A T$ Linie sowie alle anderen Prozeduren wurden dem Tierschutzbeauftragten der Universitätsmedizin Göttingen vorgelegt und vom Niedersächsischen Landesamt für Verbraucherschutz und Lebensmittelsicherheit (LAVES) genehmigt (Aktenzeichen G16/2177). Tabelle 1 zeigt die in der Arbeit genutzten Genotypen als Übersicht. 
Tabelle 1: Übersicht der genutzten Genotypen und der in nachfolgenden Diagrammen genutzten Farbcodierungen

\begin{tabular}{|c|c|c|c|c|c|}
\hline \multicolumn{2}{|c|}{ Männchen } & Farbcodierung & \multicolumn{2}{c|}{ Weibchen } & Farbcodierung \\
\hline Mecp2 & mCAT & - & Mecp2 & mCAT & - \\
\hline$+/ y$ & $+/+$ & $\square$ & $+/+$ & $+/+$ & $\square$ \\
\hline$-/ y$ & $+/+$ & $\square$ & $+/-$ & $+/+$ & $\square$ \\
\hline$-/ y$ & $+/ T$ & $\square$ & $+/-$ & $+/ T$ & $\square$ \\
\hline$+/+$ & $+/ T$ & $\square$ & $+/+$ & $+/ T$ & $\square$ \\
\hline
\end{tabular}

\subsection{Bestimmung der allgemeinen Parameter}

Zur Bestimmung der allgemeinen Parameter der Tiere wurden die Mäuse in Bezug auf Gewicht, Größe, Blutglukosespiegel und Hämatokrit untersucht. Zunächst wurde das zu untersuchende Tier nach Entnahme aus dem Käfig gewogen. Für die Gewichtsbestimmung wurde die Kleintierwaage Kern PCB 1000-2 genutzt. Anschließend wurde die zu untersuchende Maus zunächst in einem Exsikkator mit Hilfe von Diethylether narkotisiert. Die Körperlänge des Tieres konnte anschließend mit Hilfe eines Lineals bestimmt werden, wobei von Nasenspitze bis zur Schwanzwurzel gemessen wurde (Abbildung 4). Anschließend wurde mit Hilfe einer chirurgischen Schere die Dekapitation durchgeführt und Blutproben durch das Nutzen von Natrium-heparinisierten Mikro-Hämatokritkapillaren entnommen. Der Hämatokrit wurde durch fünfminütige Zentrifugation (13000 rpm) bestimmt. Hierfür wurde die Mikroliterzentrifuge MIKRO 220 der Firma Hettich ${ }^{\text {TM }}$ verwendet. Die Messung des Blutglukosespiegels erfolgte mit einem Blutzuckermessgerät (Contour XT, Bayer) und Sensoren (Ascensia Diabetes Care Deutschland GmbH). Sowohl die Ethernarkose als auch die Dekapitation wurden von entsprechend authorisierten Mitgliedern der Arbeitsgruppe durchgeführt.

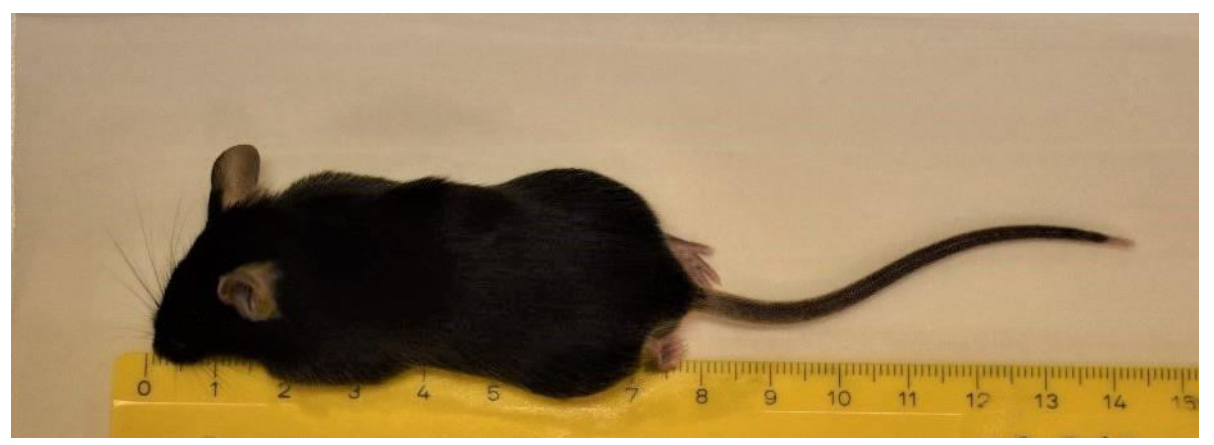

Abbildung 4: Bestimmung der Körpergröße

Die Bestimmung der Körpergröße erfolgte bei den anästhesierten Tieren mittels Lineal. Bezugspunkte stellten dabei die Nasenspitze und die Schwanzwurzel des Tieres dar. 


\subsection{Grundlagen der Absorptionsspektrometrie}

Da im Zuge dieser Arbeit die Proteinkonzentration der Mitochondriensuspension mit Hilfe eines Absorptionsspektrometers gemessen wurde, soll nun kurz auf den theoretischen Hintergrund der Absorptionsspektroskopie eingegangen werden. Bei der Absorptionsspektroskopie wird die zu untersuchende Probe mit annähernd monochromatischer Strahlung durchleuchtet und anschließend die Differenz zwischen Emission und Absorption der Probe, die Nettoabsorption, gemessen. Bei der Spektroskopie im visuellen Lichtbereich handelt es sich um eine elektronische Anregung der Moleküle. Die dafür aufzubringende Energie erhält das System aus dem eingestrahlten Licht. Licht ist elektromagnetische Strahlung, die durch die Frequenz $v$ und die Wellenlänge $\lambda$ definiert ist. Der Zusammenhang lässt sich durch folgende Formel darstellen (c = Lichtgeschwindigkeit):

$$
c=\lambda \cdot v
$$

[Formel 4]

Die Energie E des dazugehörigen Lichtquants lässt sich über die Frequenz und das Planck'sche Wirkungsquantum $h$ berechnen:

$$
\mathrm{E}=h \cdot v
$$

[Formel 5]

Kommt es zur Absorption des sichtbaren Lichtes, bewirkt dies im absorbierenden Molekül einen Übergang zwischen den elektronischen Energieniveaus. Durch die einfallende Strahlung kann ein Elektron von einem energetisch niedrigen in ein energetisch höher liegendes Orbital angehoben werden. Um von der Absorption auf die Konzentration der Probe zurückschließen zu können, nutzt man das Lambert-Beer'sche Gesetz:

$$
\mathrm{E}=\log \frac{\mathrm{I}_{0}}{\mathrm{I}}=\varepsilon \cdot \mathrm{c} \cdot \mathrm{d}
$$

[Formel 6]

Dabei ist $\mathrm{I}_{0}$ die Intensität des eingestrahlten Lichtes, I die Intensität des transmittierten Lichtes. $\varepsilon$ ist der dekadische Extinktionskoeffizient, welcher eine für die absorbierende Substanz spezifische Größe darstellt. Die Schichtdicke des durchstrahlten Körpers d beträgt bei konventionellen Küvetten üblicherweise einen Zentimeter. Durch Umstellung des Lambert-Beer'schen Gesetzes kann anschließend die Konzentration der Substanz in der Küvette berechnet werden. Eine weitere Option, die im Zuge dieser Arbeit genutzt wurde, ist die Verwendung einer Standardkurve bekannter Stoffkonzentrationen. Dafür werden Küvetten mit bekannten Konzentrationen des zu bestimmenden Stoffes befüllt und anschließend im Spektrometer gemessen und gegen die Absorption aufgetragen. Proben mit unbekannten Stoffkonzentrationen können anhand der gemessenen Absorptionen auf der Standardkurve der korrespondierenden Stoffkonzentration zugeordnet werden (Galla und Müller 1988). 
Im Rahmen dieser Arbeit wurde das Spektrometer DU 800 der Firma Beckmann Coulter genutzt, zusammen mit der von der Firma bereitgestellten, gleichnamigen Software. Für die Messungen wurden 1,5 ml Küvetten der Firma Sarstedt GmbH \& Co. Kg verwendet.

\subsection{Grundlagen der Fluoreszenzspektrometrie}

$\mathrm{Da}$ die finale Messung der $\mathrm{H}_{2} \mathrm{O}_{2}$-Freisetzung in Mitochondrien mit Hilfe des Fluoreszenzspektrometer Xenius der Firma SAFAS durchgeführt wurde, soll im Folgenden ein kurzer Überblick über den theoretischen Hintergrund und den Versuchsaufbau gegeben werden.

Für die Detektion der $\mathrm{H}_{2} \mathrm{O}_{2}$-Produktion in den Küvetten wurde der Farbstoff Amplex UltraRed der Firma Thermo Fisher Scientific genutzt. Dieser reagiert in einer 1:1 stöchiometrischen Reaktion mit $\mathrm{H}_{2} \mathrm{O}_{2}$ zu dem fluoreszierenden Farbstoff Amplex UltroxRed (Zhou et al. 1997). Katalysiert wird diese Reaktion von dem Enzym horseradish peroxidase (HRP). Die Reaktion ist in Abbildung 5 dargestellt. Der fluoreszierende Farbstoff Amplex UltroxRed emittiert Strahlung der Wellenlänge $581 \mathrm{~nm}$, welche vom Detektor des Fluoreszenzspektrometers registriert wird. Über die detektierte Fluoreszenzintensität konnte anschließend Rückschluss auf die Menge freigesetzten $\mathrm{H}_{2} \mathrm{O}_{2}$ gezogen werden.<smiles>CC(=O)N1c2ccc(O)cc2Oc2cc(O)ccc21</smiles>

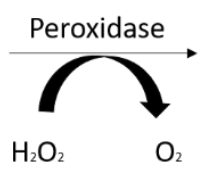<smiles>O=c1ccc2nc3ccc(O)cc3oc-2c1</smiles>

Abbildung 5: Reaktion zur Detektion der $\mathrm{H}_{2} \mathrm{O}_{2}$-Freisetzung mittels Amplex UltraRed

Amplex UltraRed reagiert mit $\mathrm{H}_{2} \mathrm{O}_{2}$ unter Katalyse des Enzyms HRP zum fluoreszierenden Resorufin (Amplex UltroxRed).

Abbildung 6 zeigt den schematischen Aufbau des zur Messung genutzten Fluoreszenzspektrometers. Im Rahmen bereits erfolgreich durchgeführter Vorversuche der Arbeitsgruppe wurden die idealen Parameter der Spektrometereinstellung ermittelt und für den im Folgenden beschriebenen Versuchsaufbau übernommen. Aus der Strahlung einer Xenonlichtquelle wird mittels Anregungsmonochromator sichergestellt, dass die Probe mit der ausgewählten Exzitationswellenlänge (568nm) belichtet wird. Angeregt wird die Probe durch den Küvettenboden. Die emittierte Strahlung $(581 \mathrm{~nm})$ wird im $90^{\circ}$ Winkel versetzt zur einfallenden Exzitationsstrahlung gemessen. Zwischen Küvette und Detektor ist ein 
Emissionsmonochromator zwischengeschaltet, welcher Strahlung mit einer von $581 \mathrm{~nm}$ abweichenden Wellenlänge eliminiert. Um auch noch sehr geringe Strahlungsintensitäten zuverlässig erfassen zu können, handelt es sich bei den Detektoren um hochsensitive Photomultiplier. Die Küvetten inklusive der Proben werden während der gesamten Messung durch ein Zirkulationswasserbad auf konstante $35^{\circ} \mathrm{C}$ erwärmt. Ein großer Vorteil des genutzten Fluoreszenzspektrometers ist die Möglichkeit, bis zu zehn Küvetten in einem Zeitverlauf von mehreren Minuten gleichzeitig in einem Experiment zu analysieren. Ein weiterer Vorteil der Fluoreszenzmessung gegenüber der Absorptionsmessung bei Konzentrationsbestimmungen ist, dass durch Fluoreszenzmessungen bereits sehr kleine Strahlungsintensitäten zuverlässig registriert und somit auch noch geringste Quantitäten eines Fluorophors erfasst werden können.

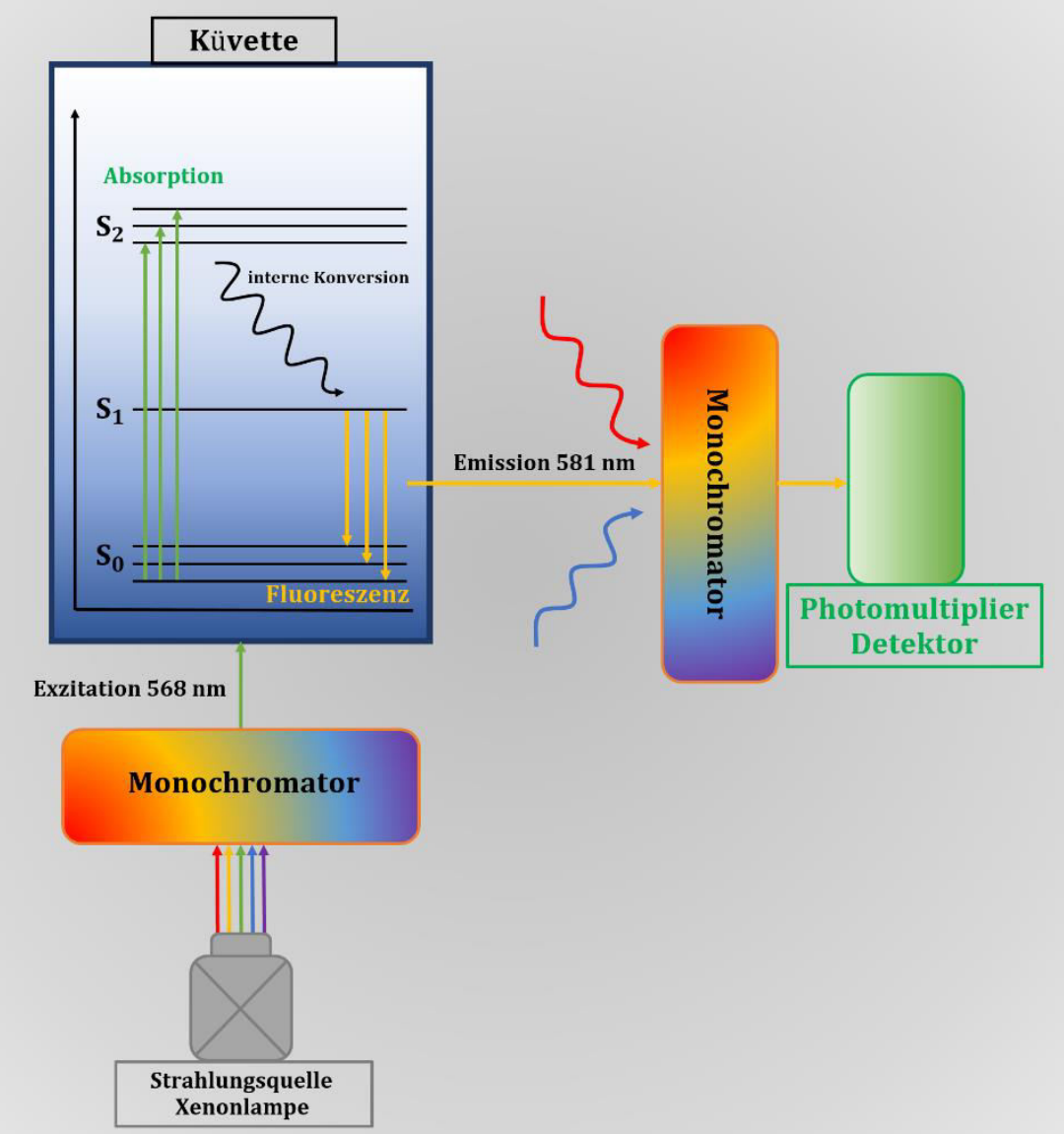

Abbildung 6: Aufbau und Funktionsweise des genutzten Fluoreszenzspektrometers

Die von der Xenonlichtquelle entsendete Exzitationstrahlung wird über einen Anregungsmonochromator gefiltert. Die Anregung erfolgt dabei über den Küvettenboden. Im $90^{\circ}$ Winkel wird nachfolgend die emittierte Strahlung über einen Emissionsmonochromator gefiltert und von Photomultiplier-Detektoren registriert. Die Küvetten werden während der gesamten Messung über ein Zirkulationswasserbad auf konstante $35^{\circ} \mathrm{C}$ erwärmt. 


\subsection{Untersuchung der mitochondrialen $\mathrm{H}_{2} \mathrm{O}_{2}$-Freisetzung}

\subsubsection{Präparation des Hirngewebes}

Nachdem die zu untersuchende Maus zunächst in einem Exsikkator mit Hilfe von Diethylether narkotisiert wurde, wurde anschließend mit Hilfe einer chirurgischen Schere die Dekapitation durchgeführt. Diese initialen Schritte der Präparation wurden von Personen mit der entsprechenden tierexperimentellen Autorisierung durchgeführt. Um das Gehirn zu extrahieren, musste anschließend die Kopfhaut durch einen Schnitt vom Nacken bis zur Nase durchtrennt werden. Danach wurde durch zwei horizontale Schnitte kaudal und einen vertikalen Schnitt der Schädelknochen eröffnet, der dann mit Hilfe einer Pinzette entfernt wurde. Das freiliegende Hirngewebe wurde anschließend mit einer eiskalten Phosphatgepufferten Salzlösung (PBS-Lösung) überspült, das Gehirn mit einem runden Spatel aus dem Schädel gelöst und in PBS-Lösung zum Kühlen gegeben. Anschließend wurde das Gehirn in die Regionen Kortex, Hippocampus, Mittelhirn, Kleinhirn und Hirnstamm separiert und in eisgekühlte Reaktionsgefäße mit Mitochondrien-Isolationspuffer überführt.

\subsubsection{Isolierung der Mitochondrien und Proteinkonzentrationsbestimmung}

Die Gewebe wurden anschließend zusammen mit $700 \mu$ l Mitochondrien-Isolationspuffer auf Eis mit Mikropistillen homogenisiert (ca. 30-40 Stöße). Diese Lösung wurde dann mit Hilfe einer Glaspipette in Eppendorf Reaktionsgefäße überführt. Die Gewebe wurden in drei Durchgängen zentrifugiert. Im ersten Durchgang wurde über 15 Minuten bei $4{ }^{\circ} \mathrm{C}$ und $800 \times \mathrm{g}$ zentrifugiert, um grobe Zellbestandteile sedimentieren zu lassen. Der dabei entstandene Überstand wurde anschließend 30 Minuten bei $4^{\circ} \mathrm{C}$ und $800 \times \mathrm{g}$ zentrifugiert, um die Nuclei zu sedimentieren. Ein weiteres Mal wurde der Überstand entfernt und über 10 Minuten bei $4^{\circ} \mathrm{C}$ und $10.000 \times \mathrm{g}$ zentrifugiert. Das dabei entstandene Pellet enthielt die Mitochondrien. Der Überstand wurde entfernt und das Mitochondrienpellet in $100 \mu \mathrm{l}$ Mitochondrien-Isolationspuffer mit Hilfe einer Pipette gelöst. Da bei jeder fluoreszenzspektrometrischen Messung reproduzierbar je $30 \mu \mathrm{g}$ Mitochondrien pro Küvette genutzt werden sollten, musste nach jeder Mitochondrien-Isolation die Proteinkonzentration mit Hilfe des Bradford Assays bestimmt werden. Dafür wurde das Protein-Assay der Firma Bio-Rad genutzt, welches auf dem Farbwechsel des Coomassie brilliant blue G-250 in Abhängigkeit von unterschiedlichen Proteinkonzentrationen basiert. Der Farbstoff bindet vorwiegend an basische und aromatische Aminosäurereste. Durch Erstellung einer ProteinStandardkurve konnte anschließend die Proteinkonzentration der Probe anhand der gemessenen Absorption auf der Standardkurve der korrespondierenden Stoffkonzentration zugeordnet werden.

Zunächst wurden Proteinstandards mit Rinderserum Albumin (BSA) für die Standardkurve in den Konzentrationen 0, 0,2, 0,5, 0,7 und 0,9 $\mathrm{mg} / \mathrm{ml}$ hergestellt. 
Von den Proteinstandards wurden je $20 \mu \mathrm{l}$ in eine Küvette pipettiert und mit $1 \mathrm{ml}$ der Bradford-Farblösung aufgefüllt. Der Inhalt wurde mit Hilfe von Parafilm durchmischt und bei Raumtemperatur für 5 Minuten inkubiert. Die Küvetten wurden mit Hilfe des Absorptionsspektrometers DU 800 zeitgleich gemessen. Die Messung erfolgte unter einer analytischen Wellenlänge von $595 \mathrm{~nm}$ und einer Durchschnittsmessdauer von 0,5 Sekunden, wobei je Probe zwei Replikate genutzt wurden.

Zunächst wurde eine Leerprobe gemessen, dann wurde die Messung gestartet und die Standardkurve erstellt. Anschließend wurden je zwei Küvetten pro Hirnregion mit $10 \mu \mathrm{l}$ Mitochondrien-Isolationspuffer und $10 \mu \mathrm{l}$ der Mitochondriensuspension bestückt und mit $1 \mathrm{ml}$ der Bradford-Farblösung aufgefüllt. Vor der Messung wurden die Proben durchmischt und bei Raumtemperatur für fünf Minuten inkubiert. Anhand der Mittelwerte der Gewebeproben konnte anschließend die Menge an Mitochondriensuspension berechnet werden, die $30 \mu \mathrm{g}$ Protein entsprach.

\subsubsection{Qualitätskontrolle isolierter Mitochondrien durch Western-Blots}

Im Rahmen der Mitochondrien-Isolation wurde ein Protokoll genutzt, welches schlussendlich keine reine Mitochondriensuspension lieferte. Um das Ausmaß anderer Zellbestandteile quantifizieren zu können, wurden diese Anteile der anderen Zellorganellen oder zytosolischen Bestandteile im Rahmen von Western-Blots dargestellt. Die Versuche wurden in Kooperation mit dem Zentrum für Biochemie der Universitätsmedizin Göttingen durchgeführt. Exemplarisch wurde für dieses Vorhaben Gewebe des Kortex von vier Wildtyp-Männchen $\left(M e c p 2^{+/ y}, m C A T^{+/+}\right)$der Altersstufe P50 genutzt. Nach Dekapitation wurden alle Schritte der Mitochondrien-Isolation protokollgemäß durchgeführt. Die Rückstände (Pellets) der Zentrifugationsschritte eins und zwei wurden zusätzlich aufbewahrt und in $100 \mu \mathrm{l}$ Mitochondrien-Isolationspuffer resuspendiert. Der Überstand, der aus der dritten Zentrifugation resultierte, wurde bei $73^{\circ} \mathrm{C}$ auf $100 \mu \mathrm{l}$ eingedampft. Nach Durchführung des Bradford Assays zur Proteinkonzentrationsbestimmung wurden alle Proben in korrekter, zuvor bestimmter Konzentration entsprechend $30 \mu \mathrm{g}$ (Proteinmenge je Geltasche) Mitochondriensuspension in Eppendorf Röhrchen gefüllt und erneut für 5 min bei $10.000 \times g$ zentrifugiert. Die entstandenen Pellets wurden anschließend in Natriumdodecylsulfat (SDS)-Puffer gelöst und lysiert und bei $95^{\circ} \mathrm{C}$ für fünf Minuten aufgekocht. Die Proben sollten in Bezug auf Verunreinigung durch zytosolische Proteine, endoplasmatisches Retikulum und Peroxisomen-Kontamination untersucht werden. Die dazu verwendeten Antikörper sind in Tabelle 2 aufgelistet. 
Tabelle 2 : Im Rahmen der Western-Blots genutzte Antikörper

\begin{tabular}{|c|c|c|c|}
\hline Zellorganell & Antikörper & Molekülmasse & Antikörperursprung \\
\hline Mitochondrien & Anti-COX 6a & $12 \mathrm{kDa}$ & $\alpha$-Hase \\
\hline $\begin{array}{c}\text { Endoplasmatisches } \\
\text { Retikulum }\end{array}$ & $\begin{array}{c}\text { Anti- } \\
\text { Calreticulin }\end{array}$ & $44 \mathrm{kDa}$ & $\alpha$-Hase \\
\hline Peroxisomen & Anti-PMP70 & $75 \mathrm{kDa}$ & $\alpha$-Hase \\
\hline Zytosol & Anti-GAPDH & $36 \mathrm{kDa}$ & $\alpha$-Maus \\
\hline
\end{tabular}

Nach Beendigung der Probenaufbereitung wurde das Gel für die SDS-Polyacrylamid Gel Elektrophorese (SDS-PAGE) hergestellt. Aufgrund der unterschiedlich großen Molekülmassen wurde ein Tromethamin-N-(Tri(hydroxymethyl)methyl)glycin (Tris-Tricin) Gradienten-Gel gewählt. Die Gele wurden in den Konzentrationen von $10 \%$ und $18 \%$ hergestellt (Inhalt siehe 2.6) und in den Gradienten-Mixer gegeben. Durch Hinzufügen von Tetramethylethylendiamin (TEMED) und 10-\%igem Ammoniumperoxodisulfat (APS) wurde die Polymerisation gestartet, das Gel gegossen und anschließend mit einem Film Isopropanol benetzt. Nach abgeschlossener Polymerisation wurde das 4-\%ige Sammelgel hinzugefügt. Da die Fraktion des endoplasmatischen Retikulums (44 kDa) und die zytosolische Fraktion ( $36 \mathrm{kDa}$ ) sehr nah beieinanderlagen, wurden zwei Gele gegossen, um die jeweiligen Banden ohne Interaktionen klar getrennt darstellen zu können. Anschließend wurden Kathoden-und Anodenpuffer in die Messvorrichtung hinzugefügt. Jedes Gel enthielt alle Rückstände der Zentrifugationen inklusive der finalen Mitochondriensuspension der vier Versuchstiere. Die Gele wurden an eine Spannung von $80 \mathrm{~V}$ und eine Stromstärke von $25 \mathrm{~mA}$ für 14,5 Stunden angelegt. Anschließend wurden die Proteine des Gels nach dem Prinzip des semi-dry-blots auf die Polyvinylidenfluorid (PVDF) Membran übertragen.

Die Membranen wurden getrocknet und entsprechend der in Tabelle 2 dargestellten Molekülmassen zurechtgeschnitten. Die Stellen der Membran, die proteinungebunden vorlagen, wurden anschließend mit $5 \%$ Milchpulver, welches in TBS-T (Tris-buffered saline with Tween20) gelöst wurde, blockiert. Die Antikörper wurden ebenfalls in TBS-T und $5 \%$ Milch gelöst und die Membranabschnitte in den jeweiligen Primärantikörper-Lösungen innerhalb einer Inkubationszeit von 12 Stunden bei Raumtemperatur getränkt. Nachfolgend wurden die Membranen dreimal für zehn Minuten in TBS-T gewaschen. Anschließend wurden die Membranen für eine Stunde in den Sekundär-Antikörper enthaltenden Lösungen inkubiert und erneut dreimal für zehn Minuten in TBS-T gewaschen. Der sekundäre Antikörper wurde an HRP gekoppelt. Im Folgenden wurde das Pierce ${ }^{\mathrm{TM}}$ ECL Western Blotting Substrat der Firma Thermo Fisher genutzt, das einem hochempfindlichen, nicht radioaktiven Chemilumineszenzsubstrat auf Luminolbasis zum Nachweis von HRP entspricht. 
Detektionsreagenzien 1 und 2 wurden im Verhältnis 1:1 gemischt, auf die PVDF-Membran gegeben und über eine Minute inkubiert. Überschüssiges Reagenz wurde abgelassen und die Membran mit einer durchsichtigen Plastikfolie bedeckt. Die Chemilumineszenz WesternBlot-Detektion wurde mit dem Gerät Amersham $^{\mathrm{TM}}$ ImageQuant $^{\mathrm{TM}} 800$ Biomolecular Imager der Firma Bioke durchgeführt, wobei eine Belichtungszeit von 30 Sekunden je Bild gewählt wurde.

\subsubsection{Fluoreszenzspektrometrische $\mathrm{H}_{2} \mathrm{O}_{2}$-Messung}

Für die finale Messung der $\mathrm{H}_{2} \mathrm{O}_{2}$-Freisetzung wurde das Fluoreszenzspektrometer SAFAS Xenius XC der Firma SAFAS Monaco genutzt. Dieses ermöglichte es, zehn Gewebeproben gleichzeitig als Zeitverlauf zu messen. Jede Küvette wurde insgesamt mit $512 \mu$ l Flüssigkeit befüllt. Zunächst wurde jede Küvette jeweils mit MiRO5 (Mitochondrial Respiration Medium 5) befüllt. Die Menge musste je nach Menge der benötigten Mitochondriensuspension für jede Hirnregion individuell berechnet werden $(500 \mu l-$ Mitochondriensuspenion in $\mu \mathrm{l}=$ MiRO5 Menge). Anschließend wurden die Substrate Pyruvat, Malat und Succinat sowie der Katalysator HRP und der Farbstoff Amplex UltraRed hinzugefügt (Pipettierschema inklusive Konzentrationen siehe Tabelle 3).

Tabelle 3: Pipettierschema des Küvetten-Assays

\begin{tabular}{|c|c|c|c|}
\hline Substanz & $\begin{array}{c}\text { Konzentration } \\
\text { Stammlösung }\end{array}$ & Hinzugefügte Menge & $\begin{array}{c}\text { Endkonzentration } \\
\text { Küvette }\end{array}$ \\
\hline Pyruvat & $1 \mathrm{M}$ & $2,5 \mu \mathrm{l}$ & $5 \mathrm{mM}$ \\
\hline Malat & $0,4 \mathrm{M}$ & $2,5 \mu \mathrm{l}$ & $2 \mathrm{mM}$ \\
\hline Succinat & $1 \mathrm{M}$ & $5 \mu \mathrm{l}$ \\
\hline HRP & $500 \mathrm{U} / \mathrm{ml}$ & $1 \mu \mathrm{l}$ & $1 \mathrm{U} / \mathrm{ml}$ \\
\hline Amplex UltraRed & $5 \mathrm{mM}$ & $1 \mu \mathrm{l}$ & $10 \mu \mathrm{M}$ \\
\hline
\end{tabular}

Abschließend wurde die pro Gewebe errechnete Menge an Mitochondriensuspension, die $30 \mu \mathrm{g}$ Mitochondrien entsprach, in die Küvetten pipettiert. Im Rahmen jeder Messung wurden außerdem zwei Leerproben als Kontrollen integriert. Leerprobe 1 enthielt MiRO5 und die in Tabelle 3 dargestellten Substanzen. Leerprobe 2 entsprach Leerprobe 1 abzüglich des Farbstoffes Amplex UltraRed. Der Inhalt wurde mittels Kunststoff-Mikrospatel vermischt und die Küvetten in das Spektrometer gesetzt. Mit Hilfe der Kontrollsoftware SP2000V7 der Firma Safas wurde die Messung unter den in Tabelle 4 aufgeführten Parametern gestartet. Der Fluoreszenzanstieg wurde über eine Zeitspanne von 30 Minuten gemessen, wobei die Küvetten jeweils nacheinander alle 30 Sekunden in Zyklen gemessen wurden. Die Belichtungszeit betrug jeweils eine Sekunde pro Küvette und Messzyklus. 
Tabelle 4: Parameter Einstellung des Fluoreszenzspektrometers

\begin{tabular}{|c|c|c|c|}
\hline Messgröße & Fluoreszenzintensität & Belichtungszeit in Sekunden & 1 \\
\hline Exzitationswellenlänge & $555 \mathrm{~nm}$ & Exzitationsspaltbreite & $10 \mathrm{~nm}$ \\
\hline Emissionswellenlänge & $581 \mathrm{~nm}$ & Emissionsspaltbreite & $5 \mathrm{~nm}$ \\
\hline Zyklus Intervall & $30 \mathrm{~s}$ & PMT-Spannung & $500 \mathrm{~V}$ \\
\hline Dauer der Messung & $30 \mathrm{~min}$ & Leerprobe & Nein \\
\hline
\end{tabular}

Um leichte Differenzen in der absoluten Fluoreszenzintensität zwischen den einzelnen Küvetten zu berücksichtigen, die durch Ungenauigkeit kleiner Pipettiervolumina sowie durch das sukzessive Befüllen der Küvetten im leichten zeitlichen Versatz entstanden sind, wurden alle Fluoreszenzmessungen auf den Startpunkt der jeweiligen Küvette $\left(\mathrm{F}_{0}\right)$ normalisiert. Die Auswertung der Daten erfolgte nach einer Messdauer von 15 Minuten.

Anschließend wurde die normalisierte Leerprobe 1 aller durchgeführten Messungen zum Messzeitpunkt 15 Minuten gemittelt und im Rahmen einer Leerprobe-Korrektur von den normalisierten Daten der Hirnregionen subtrahiert. 


\subsection{Zusammensetzung der verwendeten Chemikalien}

Alle verwendeten Chemikalien wurden von der Firma Sigma-Aldrich Chemie GmbH bezogen. Im Falle der Nutzung Chemikalien anderer Firmen, ist dies im Folgenden kenntlich gemacht.

Die für die Präparation des Hirngewebes genutzte PBS-Lösung enthielt $137 \mathrm{mM} \mathrm{NaCl}$, 2,7 mM KCl und $12 \mathrm{mM}$ Phosphatpuffer $\left(\mathrm{HPO}_{4}{ }^{2-}\right.$ und $\left.\mathrm{H}_{2} \mathrm{PO}_{4}{ }^{-}\right)$. Die Lösung wurde als 10fach konzentrierte Stammlösung hergestellt und mit $1 \mathrm{M}$ Natronlauge auf einen pH-Wert von 7,4 eingestellt. Für die Präparation wurde diese Stammlösung auf einfache Konzentration mit destilliertem Wasser verdünnt, anschließend wurde der $\mathrm{pH}$-Wert der Lösung erneut auf 7,4 eingestellt.

Die Zusammensetzung des Mitochondrien-Isolationspuffers ist in der folgenden Tabelle 5 aufgeführt. Alle Substanzen außer dem Phenylmethylsulfonylfluorid (PMSF) wurden in destilliertem Wasser gelöst. Der pH-Wert wurde anschließend mit $1 \mathrm{M} \mathrm{KOH}$ auf 7,4 eingestellt. Die so entstandene Lösung wurde in Aliquots von je $10 \mathrm{ml}$ eingefroren. Das PMSF wurde in Ethanol als 0,1 $\mathrm{M}$ Lösung angesetzt und diese bei $4^{\circ} \mathrm{C}$ gelagert. Am Versuchstag wurden nach Auftauen des Isolationspuffers $50 \mu \mathrm{l}$ der 0,1 M PMSF-Lösung zum Puffer hinzugefügt, sodass eine Konzentration von 0,5 mM PMSF entstand.

Tabelle 5: Zusammensetzung des Mitochondrien-Isolationspuffers

\begin{tabular}{|c|c|}
\hline Substanz & Konzentration \\
\hline Hepes (pH 7,6) & $20 \mathrm{mM}$ \\
\hline Mannitol & $220 \mathrm{mM}$ \\
\hline Sucrose & $70 \mathrm{mM}$ \\
\hline EDTA & $1 \mathrm{mM}$ \\
\hline PMSF & $0,5 \mathrm{mM}$ \\
\hline
\end{tabular}

Das in den fluoreszenzspektrometrischen Messungen genutzte mitochondriale Respirationsmedium 5 (MiRO5) enthielt die in Tabelle 6 aufgelisteten Substanzen. 
Tabelle 6: Zusammensetzung des mitochondrialen Respirationsmediums

\begin{tabular}{|c|c|c|c|}
\hline Substanz & Molare Masse & $\begin{array}{c}\text { Einwaage für 250 ml } \\
\text { Endvolumen [g] }\end{array}$ & Finale Konzentration \\
\hline EGTA & $380,4 \mathrm{~g} / \mathrm{mol}$ & 0,047 & $0,5 \mathrm{mM}$ \\
\hline $\mathbf{M g C l}_{2}$ & $95,2 \mathrm{~g} / \mathrm{mol}$ & 0,071 & $3 \mathrm{mM}$ \\
\hline Lactobionsäure & $358,3 \mathrm{~g} / \mathrm{mol}$ & 5,375 & $60 \mathrm{mM}$ \\
\hline Taurin $_{\text {KH}} \mathbf{P O}{ }_{4}$ & $125,1 \mathrm{~g} / \mathrm{mol}$ & 0,625 & $20 \mathrm{mM}$ \\
\hline HEPES & $136,1 \mathrm{~g} / \mathrm{mol}$ & 0,340 & $10 \mathrm{mM}$ \\
\hline D-Sucrose & $238,3 \mathrm{~g} / \mathrm{mol}$ & 1,191 & $20 \mathrm{mM}$ \\
\hline BSA, fettsäurefrei & $342,3 \mathrm{~g} / \mathrm{mol}$ & 9,413 & $110 \mathrm{mM}$ \\
\hline
\end{tabular}

Alle Substanzen wurden in $230 \mathrm{ml}$ destilliertem Wasser gelöst und bei $30{ }^{\circ} \mathrm{C}$ mit einem Magnetrührer verrührt. Anschließend wurden 3,75 ml einer $1 \mathrm{M} \mathrm{KOH-Lösung} \mathrm{hinzugefügt}$ und dies für 90 Minuten unter dem Magnetrührer verrührt. Der $\mathrm{pH}$-Wert wurde anschließend mit $5 \mathrm{M} \mathrm{KOH-Lösung} \mathrm{auf} \mathrm{7,1} \mathrm{eingestellt,} \mathrm{wobei} \mathrm{dieser} \mathrm{für} \mathrm{mindestens} \mathrm{fünf}$ Minuten stabil sein sollte. Anschließend wurden ca. $50 \mathrm{ml}$ dieser Lösung in ein Glasgefäß überführt und $0,25 \mathrm{~g}$ BSA hinzugefügt.

Die BSA-Lösung wurde zu der Hauptlösung hinzugefügt und der pH-Wert auf 7,1 rejustiert. Anschließend wurde mit Wasser das Endvolumen auf $250 \mathrm{ml}$ aufgefüllt. Die Lösung wurde in Aliquots bei $-20^{\circ} \mathrm{C}$ eingefroren.

Der Farbstoff Amplex UltraRed wurde von der Firma Thermo Fisher Scientific bezogen. Für die Messungen wurden Aliquots der Konzentration von $5 \mathrm{mM}$ genutzt. Dafür wurden $1 \mathrm{mg}$ Amplex UltraRed in $680 \mu \mathrm{l}$ Dimethylsulfoxid (DMSO) gelöst und bei $-20{ }^{\circ} \mathrm{C}$ gelagert.

Für die HRP Suspension wurden Aliquots als Stammlösung in Konzentrationen von $500 \mathrm{U} \mathrm{HRP} / \mathrm{ml}$ in MiRO5 hergestellt, welche bei $-20{ }^{\circ} \mathrm{C}$ gelagert werden konnten.

Die Substrate Succinat $(1 \mathrm{M})$ und Malat $(0,4 \mathrm{M})$ wurden entsprechend ihrer Molaritäten in Wasser gelöst, der $\mathrm{pH}$-Wert auf $\mathrm{pH}$ 7,0 rejustiert und in $0,5 \mathrm{ml}$ Volumina in EppendorffReaktionsgefäßen bei $-20^{\circ} \mathrm{C}$ eingefroren. Das Substrat Pyruvat $(1 \mathrm{M})$ wurde an jedem Messtag frisch hergestellt, als Lösungsmittel wurde Wasser verwendet und der $\mathrm{pH}$-Wert auf 7,0 justiert. 
Die Zusammensetzung des im Rahmen der Western-Blots genutzten SDS-Probenpuffers wurde in Tabelle 7 aufgelistet.

Tabelle 7: Zusammensetzung des SDS-Probenpuffers

\begin{tabular}{|c|c|}
\hline SDS-Proben Puffer & $\mathbf{1 0 0 ~} \mathrm{ml}$ \\
\hline $\mathbf{2} \%$ SDS & $2 \mathrm{~g}$ \\
\hline $\mathbf{1 0} \%$ Glycerol & $10 \mathrm{ml}$ \\
\hline $\mathbf{6 0} \mathbf{~ m M ~ T r i s ~ p H ~ 6 , 8}$ & $727 \mathrm{mg}$ \\
\hline $\mathbf{0 , 2} \mathbf{- 1} \% \boldsymbol{\beta}$-Mercaptoethanol & $0,2-1 \mathrm{ml}$ \\
\hline $\mathbf{0 , 1} \%$ Bromphenolblau & $0,1 \mathrm{ml}$ \\
\hline
\end{tabular}

Der Kathodenpuffer wurde aus $1 \mathrm{M}$ Tricin, $1 \mathrm{M}$ Tris und $1 \%$ SDS hergestellt, der pH-Wert auf 8,25 adjustiert. Der Anodenpuffer bestand aus $2 \mathrm{M}$ Tris, welches auf einen pH-Wert von 8,45 adjustiert wurde. Die Inhaltstoffe des Tris-Tricin-Gradienten-Geles sind in Tabelle 8 dargestellt. Der in dieser Tabelle aufgelistete Gel Puffer bestand aus $3 \mathrm{M}$ Tris und 0,3\% SDS (pH: 8,45). Der Acrylamid-Mix wurde aus $96 \%$ Acrylamid und 3 g Bis-Acrylamid/200 ml zusammengesetzt. Der Lösungspuffer bestand aus 1,87 M Tris (pH: 8,8).

Tabelle 8: Zusammensetzung des Tris-Tricin-Gradienten-Gels

\begin{tabular}{|c|c|c|c|}
\hline Gelkomponenten & $\mathbf{1 0} \mathbf{0}$ & $\mathbf{1 8} \mathbf{\%}$ & $\mathbf{4} \mathbf{\%}$ (Sammelgel) \\
\hline Acrylamid-Mix & $1,65 \mathrm{ml}$ & $2,97 \mathrm{ml}$ & $0,5 \mathrm{ml}$ \\
\hline Gel Puffer & $2,67 \mathrm{ml}$ & $2,67 \mathrm{ml}$ & $2 \mathrm{ml}$ \\
\hline $\mathbf{5 0} \% \mathbf{G l y c e r o l}$ & - & $2,08 \mathrm{ml}$ & $3,5 \mathrm{ml}$ \\
\hline $\mathbf{d H}_{\mathbf{2}} \mathbf{O}$ & $3,68 \mathrm{ml}$ & $0,28 \mathrm{ml}$ & $6 \mathrm{ml}$ \\
\hline Endvolumen & $8 \mathrm{ml}$ & $8 \mathrm{ml}$ & $6 \mu \mathrm{l}$ \\
\hline TEMED & $3 \mu \mathrm{l}$ & $3 \mu \mathrm{l}$ & $60 \mu \mathrm{l}$ \\
\hline $\mathbf{1 0} \%$ APS & $40 \mu \mathrm{l}$ & $40 \mu \mathrm{l}$ & \\
\hline
\end{tabular}

Für die in 3.1 beschriebenen Qualitätskontrollen wurde das genutzte CCCP in $100 \%$ absoluten Ethanol als $1 \mathrm{M}$ Lösung gelöst und bei $-20{ }^{\circ} \mathrm{C}$ gelagert. Das $\mathrm{H}_{2} \mathrm{O}_{2}$ wurde am Nutzungstag aus wässriger 8,8 M (30\% $\left.\mathrm{H}_{2} \mathrm{O}_{2}\right)$ Stammlösung angesetzt, welche für die Verdünnung zu niedrigeren Konzentrationen für die Standards in MiRO5 gelöst wurde. 


\subsection{Statistik}

Im Rahmen der Datenerhebung wurden 126 Tiere für die Messungen genutzt, wobei für die Messungen der allgemeinen Parameter (Größe, Gewicht etc.) und die fluoreszenzspektrometrischen Messungen zum größten Teil dieselben Tiere verwendet wurden. Der Stichprobenumfang (n) bezieht sich bei den Daten der allgemeinen Parameter auf die Anzahl der Tiere, wobei mindestens vier Tiere je Genotypgruppe verwendet wurden. Die Daten wurden durch eine Einweg-Varianzanalyse (One-way-ANOVA) mit Hilfe des Programmes SigmaStat 3.5 auf ihre Signifikanz überprüft. Für normalverteilte Daten wurde als posthoc test der Holm-Sidak Test genutzt. Für nicht normalverteilte Daten wurde der Dunn's Test genutzt.

Bei den fluoreszenzspektrometrischen Messungen bezieht sich die Anzahl (n) auf die Anzahl der verwendeten Küvetten. Abhängig von der verfügbaren Proteinmenge konnten pro Hirnregion eines Tieres zwei bis acht Küvetten mit Probeninhalt für die Datenerhebung genutzt werden. Auch hier wurden prinzipiell mindestens vier verschiedene Tiere je Genotyp verwendet. Die angegebenen Daten sind als Mittelwerte \pm Standardabweichung dargestellt. Die Auswertung erfolgte zunächst durch Normalisierung der Daten mit Hilfe von Microsoft Excel. Die normalisierten Daten wurden anschließend einer Leerwert-Korrektur (Blank) unterzogen. Die relativen Fluoreszenzintensitäten wurden mit Hilfe der $\mathrm{H}_{2} \mathrm{O}_{2}-$ Kalibrierungskurve in absolute $\mathrm{H}_{2} \mathrm{O}_{2}$-Freisetzungsraten umgerechnet. Diese wurden im Vergleich zwischen allen vier Gruppen einer Einweg-Varianzanalyse unterzogen. Für normalverteilte Daten wurde als posthoc Test ebenfalls der Holm-Sidak Test und für nicht normalverteilte Daten der Dunn's Test genutzt.

Der absolute Vergleich zwischen zwei Phänotypgruppen erfolgte mittels ungepaartem Zweistichproben t-Test. Die Signifikanzprüfung der auf die Kontrolltiere normierten Daten erfolgte durch einen zweiseitigen Einstichproben-t-Test. Die Signifikanzniveaus sind durch ein Sternchen $(*)$ für das $5 \%$ Niveau $(\mathrm{p}<0,05)$, zwei Sternchen $(* *)$ für das $1 \%$ Niveau $(\mathrm{p}<0,01)$ und drei Sternchen $(* * *)$ für das $0,1 \%$ Niveau $(\mathrm{p}<0,001)$ gekennzeichnet. 


\section{Ergebnisse}

Ziel dieser Arbeit war es, potentiell positive Auswirkungen der mitochondrialen Katalase auf die Redox-Imbalance im Rett-Syndrom zu untersuchen. Dafür wurden im entsprechenden Mausmodell Mitochondrien der Hirnregionen Kortex, Hippocampus, Kleinhirn, Mittelhirn und Hirnstamm isoliert und in fluoreszenzspektrometrischen Messungen deren $\mathrm{H}_{2} \mathrm{O}_{2}$ Freisetzung quantifiziert. Um die Validität des Messverfahrens sicherzustellen, wurden Qualitätskontrollen durchgeführt, deren Ergebnisse zunächst beschrieben werden. Darauffolgend werden die Ergebnisse der fluoreszenzspektrometrischen Messungen in Bezug auf Genotyp, Alter, Geschlecht und Hirnregionen der Tiere dargestellt und in Relation gesetzt. Anschließend werden mögliche Verbesserungen des Erscheinungsbildes der Tiere evaluiert, indem Größe, Gewicht, Blutglukosespiegel und Hämatokrit betrachtet werden.

\subsection{Validierung des Messverfahrens}

\subsubsection{Qualitätskontrolle der isolierten Mitochondrien}

Um die Qualität der isolierten Mitochondriensuspension zu evaluieren, wurden die genutzten Proben im Rahmen von Western-Blots auf ihre Reinheit untersucht. Die Versuche wurden gemäß der Angabe in 2.5.3 durchgeführt. Bestimmt wurde der Anteil zusätzlicher zytosolischer Bestandteile (Antikörper: GAPDH), Bestandteile des endoplasmatischen Retikulums (Antikörper: Calreticulin) und der Peroxisomen (Antikörper: PMP70) in den isolierten Mitochondriensuspensionen. Zusätzlich wurden die Inhalte der nach den Zentrifugationsschritten eins und zwei entstandenen Pellets betrachtet, sowie der Inhalt des Überstandes, der nach der dritten Zentrifugation entstand.

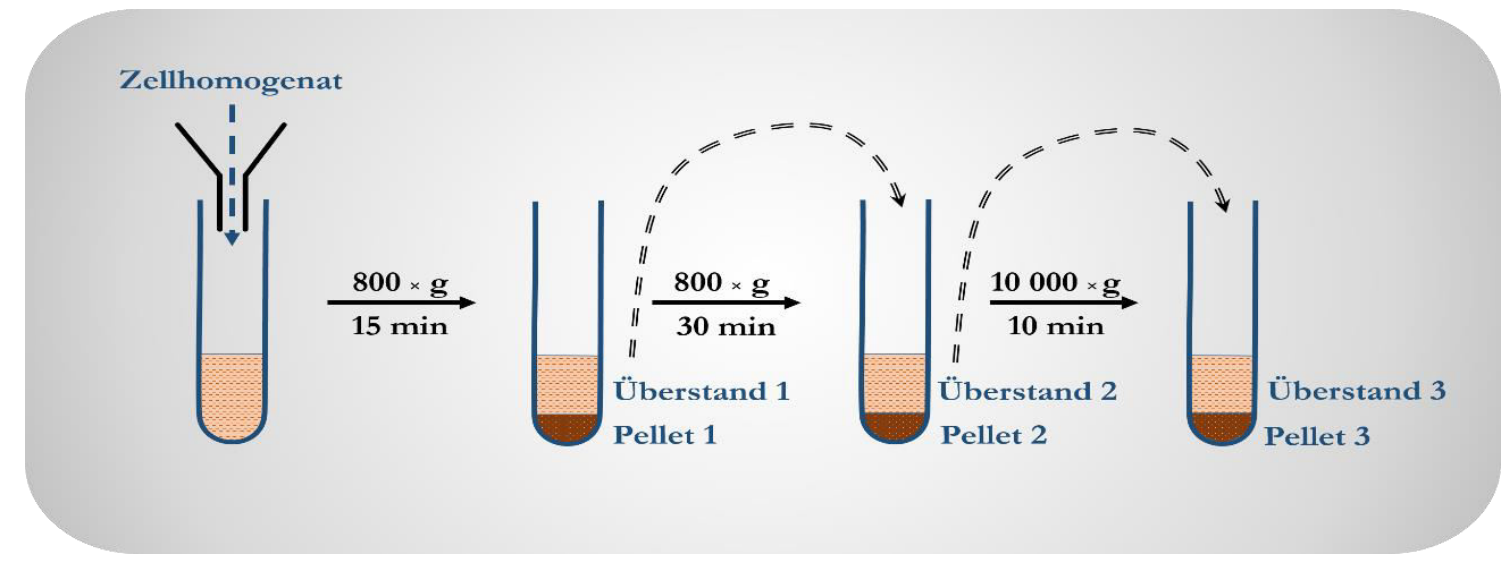

\section{Abbildung 7: Zentrifugationsschema der Mitochondrien-Isolation}

Im Rahmen der Mitochondrien-Isolation wurde das Zellhomogenat zunächst für 15 Minuten bei $800 \times \mathrm{g}$ zentrifugiert. Der dabei entstandene Überstand wurde entnommen und erneut für 30 Minuten bei $800 \times \mathrm{g}$ zentrifugiert. Die letzte Zentrifugation erfolgte bei $10.000 \times \mathrm{g}$ für zehn Minuten, das dabei entstandene Pellet enthielt die Mitochondrien. 
Die Chemilumineszenz Aufnahme der beiden Gele ist für die vier genutzten Tiere in Abbildung 8 gezeigt. Zu betonen ist die Tatsache, dass zwei identische Gele angefertigt und mit den gleichen Proben beladen wurden, um die jeweiligen Banden ohne Interaktionen klar getrennt darstellen zu können. Für die Antikörperinkubation wurde jeweils eine Membran zur Detektion mittels Anti-PMP70 (75 kDa) und Anti-Calreticulin (44 kDa) genutzt, die andere Membran wurde mit den Antikörpern Anti-COX6a (12 kDa) und Anti-GAPDH $(36$ $\mathrm{kDa}$ ) inkubiert.

Es konnte deutlich gezeigt werden, dass sich in den Pellets der Zentrifugationsschritte eins und zwei sowohl zytosolische Bestandteile, endoplasmatisches Retikulum und Peroxisomen durch den Western-Blot nachweisen ließen, jedoch ebenfalls auch eine starke Bande im Bereich des Antikörpers COX6a bei allen Kortexproben beobachtet wurde. Somit werden erhebliche Anteile der Mitochondrien bereits nach den Zentrifugationsschritten eins und zwei verworfen und können schlussendlich nicht im Rahmen der fluoreszenzspektrometrischen Messungen genutzt werden.

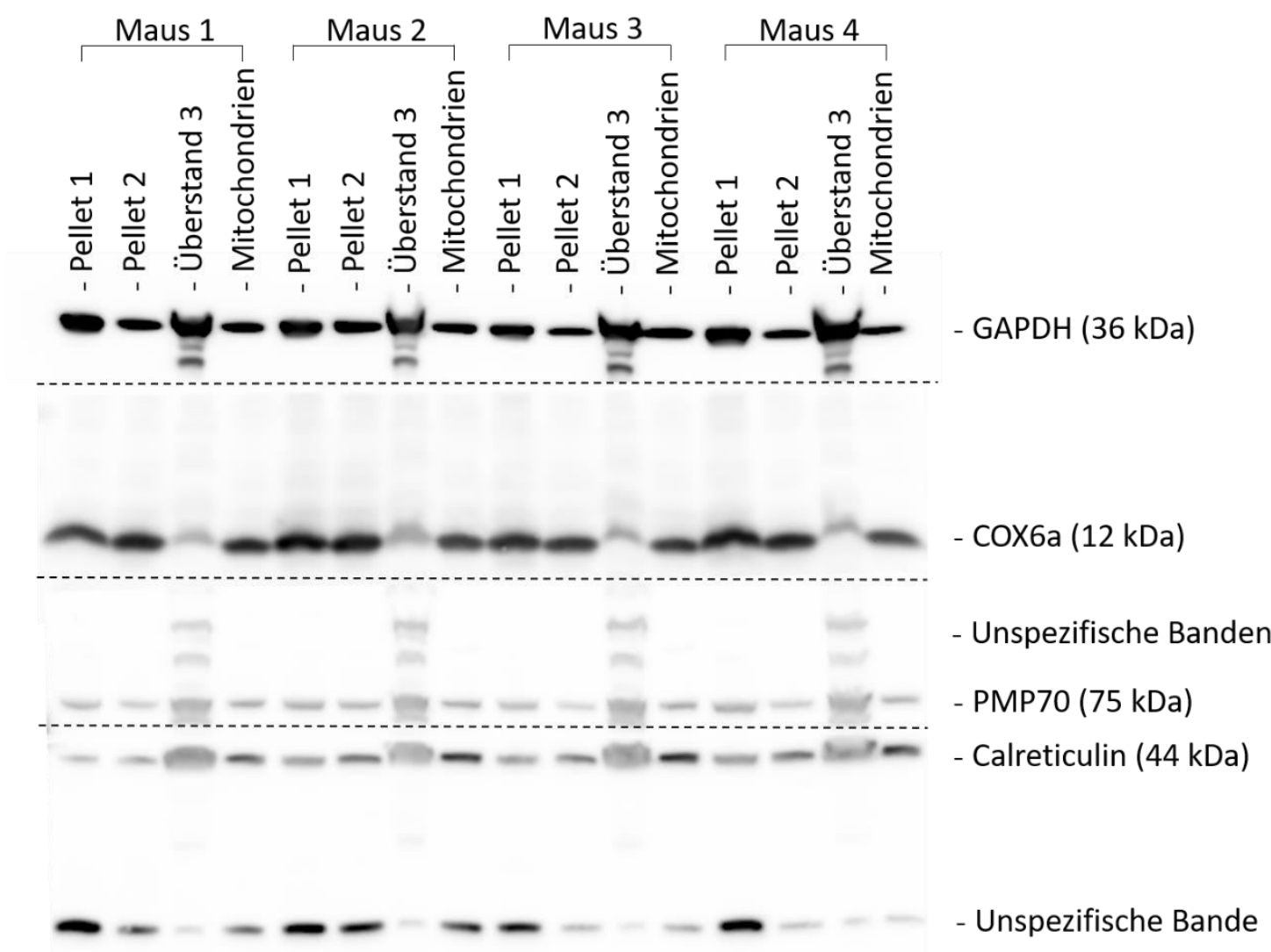

Abbildung 8: Western-Blots zur Klärung der zellulären Bestandteile der Mitochondriensuspensionen

Für die Antikörperinkubation wurde jeweils eine Membran zur Detektion mittels Anti-PMP70 (75 kDa) und Anti-Calreticulin (44 kDa) genutzt, die andere Membran wurde mit den Antikörpern gegen COX6a (12 kDa) und GAPDH (36 kDa) inkubiert. Die Trennlinien, an denen die Membranen für die Detektion geschnitten wurden, sind als gestreifte Linien in der Abbildung kenntlich gemacht worden. Im letzten mit Mitochondrien angereicherten Pellet ließen sich neben Mitochondrien auch zytosolische Proteine, Peroxisomen und Bestandteile des endoplasmatischen Retikulums nachweisen. 
Im Überstand, der nach der dritten Zentrifugation protokollgemäß ebenfalls verworfen wird, befinden sich vor allem zytosolische Proteine, Peroxisomen und endoplasmatisches Retikulum. Der Antikörper COX6a ließ sich in diesen Proben deutlich schwächer nachweisen, somit ist die Verlustrate an Mitochondrien in diesem dritten Zentrifugationsschritt als geringfügig einzustufen. In den Spuren, in die die isolierten Mitochondrien beladen wurden, ließen sich über die entsprechenden Antikörper neben den Mitochondrien sowohl zytosolische Bestandteile, als auch Peroxisomen und endoplasmatisches Retikulum nachweisen. Die Banden der Antikörper GAPDH und COX6a wiesen eine höhere Dichte als die Banden der Antikörper PMP70 und Calreticulin auf. Daher ließ sich zeigen, dass die im Bradford Assay aus 2.5.4 genutzten $30 \mu \mathrm{g}$ Protein je Küvette überwiegend Mitochondrien und zytosolische Proteine darstellen. Die nicht näher spezifizierten Banden stellen unspezifische Banden dar, die im Rahmen der Nutzung von Anti-PMP70 und Anti-Calreticulin zu beobachten sind und von den Herstellern (abcam) ebenfalls als additionelle Banden unbekannten Ursprungs beschrieben werden.

Um die Ergebnisse des Western-Blots quantifizieren zu können, wurden die betreffenden Banden densitometrisch mit Hilfe des Programmes ImageJ analysiert (Abbildung 9). Betrachtet wurden jeweils die Bandendichten der Mitochondriensuspension (Spur 4 jeder Maus). Nach Bestimmung der Dichte wurden die Werte auf die entsprechenden GAPDHBanden jeder Probe normiert. Somit handelt es sich bei der isolierten Mitochondrienfraktion um eine Mitochondrien-angereicherte Suspension, die zudem geringfügige Anteile der Peroxisomen und des endoplasmatischen Retikulums enthielten.

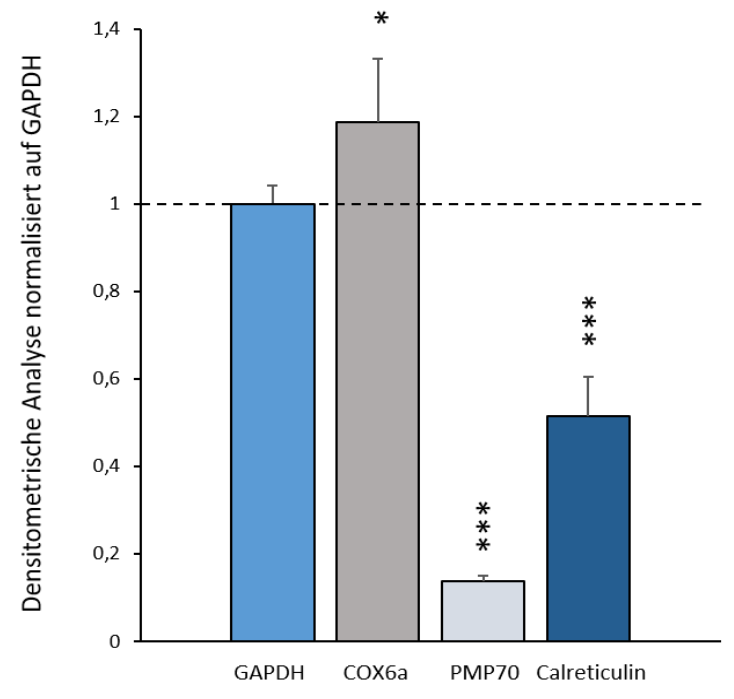

\section{Abbildung 9: Densitometrische Analyse der Western-Blots}

In der densitometrischen Analyse zeigte sich nach Normierung auf die Anti-GAPDH-Banden im zweiseitigen Einstichproben-t-Test eine signifikant höhere COX6a ( $p<0,05)$, sowie signifikant niedrigere PMP70 und Calreticulin Dichte $(\mathrm{p}<0,001)$. Somit handelt es sich bei der genutzten Probensuspension um eine Mitochondrien-angereicherte Lösung mit geringfügigen Anteilen von Peroxisomen, ER und zytosolischen Bestandteilen. Gezeigt sind die Mittelwerte und Standardabweichungen aus Proben von vier Wildtyp-Tieren. 


\subsubsection{Kontrollen zur Überprüfung der Validität und Reliabilität des Küvetten-} Assays

Um sicherzustellen, dass in der verwendeten fluoreszenzspektrometrischen Messmethode tatsächlich nur das aus Mitochondrien freigesetzte $\mathrm{H}_{2} \mathrm{O}_{2}$ nachgewiesen wurde, wurden verschiedene Kontrollen durchgeführt. Zunächst wurden für die Kontrollmessungen alle Schritte der Mitochondrien-Isolation und der Proteinkonzentrationsbestimmung protokollgemäß durchgeführt. Für alle folgenden Messungen wurden zunächst Küvetten gemäß Pipettierschema (Tabelle 3) komplett mit MiRO5, den Substraten Pyruvat, Malat und Succinat, HRP, Amplex UltraRed und $30 \mu \mathrm{g}$ Mitochondriensuspension befüllt und als Referenzgruppe genutzt. Zudem wurden weitere Küvetten mit Mitochondrien, jedoch ohne die Substrate Pyruvat, Malat und Succinat befüllt. Weitere Küvetten wurden nach Pipettierschema befüllt, ausgenommen der horseradish peroxidase. Außerdem wurde bei einigen Küvetten nach vollständigem Befüllen nach Pipettierschema Carbonylcyanid-mchlorphenyllhydrazon (CCCP) hinzugefügt. CCCP ist ein Entkoppler, der den Protonengradienten zwischen Mitochondrienmatrix und Intermembranraum aufhebt. Alle Kontrollmessungen wurden im 30-minütigen Verlauf aufgezeichnet und sind in Abbildung 10 dargestellt.
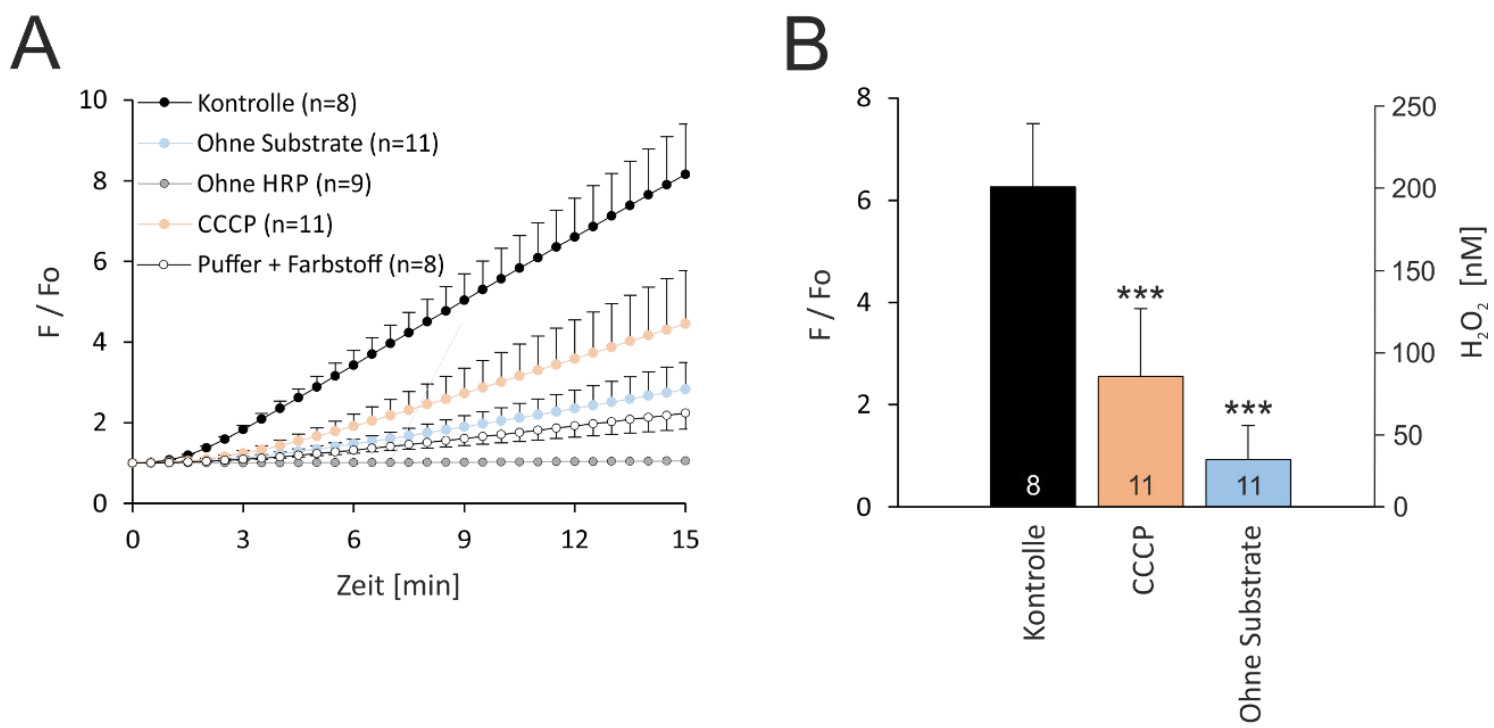

Abbildung 10: Einfluss von CCCP und Substratreduktion auf die $\mathrm{H}_{2} \mathrm{O}_{2}$-Freisetzung

A) In den initialen Tests wurde der Einfluss der Substratentfernung, des Fehlens des Enzyms HRP sowie das Hinzufügen des Entkopplers CCCP auf die relative Fluoreszenzintensität im zeitlichen Verlauf untersucht. Die dargestellten Daten sind Durchschnittswerte multipler Messungen, in denen das Hirngewebe des Kortex genutzt wurde. B) Durch die Substratreduktion und das Hinzufügen eines Entkopplers ist die Oxidation des fluoreszierenden Farbstoffes Amplex UltraRed (relative Fluoreszenzintensität) nach 15 Minuten signifikant reduziert.

Die Referenzgruppe zeigte den Datenverlauf einer Wildtyp-Messung des Kortex. Im Vergleich dazu war die $\mathrm{H}_{2} \mathrm{O}_{2}$-Freisetzung der Probensuspensionen ohne Substrate signifikant niedriger $(\mathrm{p}<0,001)$, ebenso waren die Probensuspensionen, denen CCCP 
hinzugefügt wurde, signifikant niedriger als die Kontrollen ( $\mathrm{p}<0,001)$. Die Probensuspensionen ohne HRP zeigten in der 30-minütigen Kinetik eine signifikant niedrigere, gegen null strebende $\mathrm{H}_{2} \mathrm{O}_{2}$-Freisetzung $(\mathrm{p}<0,001)$ und keinen Anstieg der Werte im zeitlichen Verlauf.

\subsubsection{Konzentrationsbestimmung durch $\mathrm{H}_{2} \mathrm{O}_{2}$-Standards}

Da im Xenius Fluoreszenzspektrometer nur die relative Fluoreszenzintensität des oxidierten Amplex UltraRed gemessen werden konnte und keine absoluten $\mathrm{H}_{2} \mathrm{O}_{2}$-Konzentrationen, konnten die Daten nach Normalisierung nur miteinander in Relation gesetzt werden und Aussagen getroffen werden, welche Hirnregion relativ gesehen mehr $\mathrm{H}_{2} \mathrm{O}_{2}$ freisetzen. Um einen Eindruck zu erhalten, in welchen Konzentrationen sich die Messungen bewegten, wurden unter exakt gleichen Messbedingungen $\mathrm{H}_{2} \mathrm{O}_{2}$-Standards von $20 \mathrm{nM}, 50 \mathrm{nM}, 100 \mathrm{nM}$, $200 \mathrm{nM}$ und $500 \mathrm{nM} \mathrm{H} \mathrm{H}_{2} \mathrm{O}_{2}$ zur Kalibrierung einer Standardkurve erstellt und im Spektrometer gemessen. Zusätzlich wurden, wie bei jeder Messung, eine Leerprobe mit allen Substraten inklusive HRP und Amplex UltraRed gemessen, sowie eine Leerprobe mit allen Substraten und HRP jedoch ohne Amplex UltraRed. Die Ergebnisse sind in Abbildung 11 dargestellt. Es ließ sich feststellen, dass im Rahmen der mitochondrialen, fluoreszenzspektrometrischen Messungen $\mathrm{H}_{2} \mathrm{O}_{2}$ auch in einer Konzentration von nur $20 \mathrm{nM}$ noch zuverlässig detektierbar ist und zwischen $20 \mathrm{nM}$ und $500 \mathrm{nM} \mathrm{H} \mathrm{H}_{2} \mathrm{O}_{2}$ ein linearer Antwortbereich von Amplex UltraRed vorliegt (Abbildung 11).

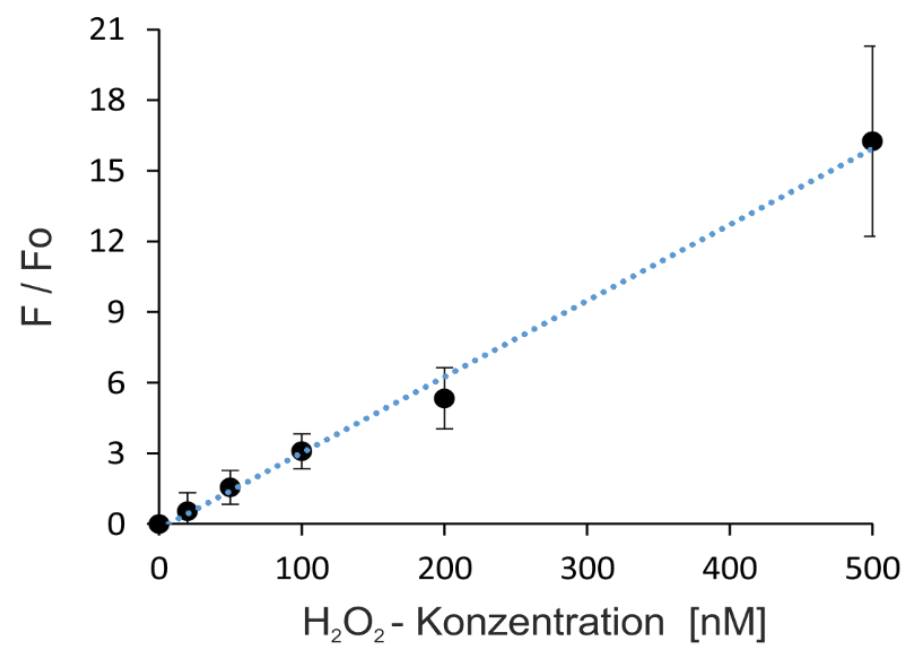

Abbildung 11: Kalibrierung der Amplex UltroxRed-Fluoreszenz durch $\mathrm{H}_{2} \mathrm{O}_{2}$-Standards bekannter Konzentrationen

Die $\mathrm{H}_{2} \mathrm{O}_{2}$-Standards wurden auf die im jeweiligen Messset mitgelaufene Leerprobe mit Amplex UltraRed normalisiert und anschließend die Mittelwerte und Standardabweichungen errechnet. Je bekannter Standardkonzentration wurden die Durchschnittswerte von sechs bis neun Messproben ermittelt. Obwohl die Reaktion bereits sofort nach Hinzufügen des $\mathrm{H}_{2} \mathrm{O}_{2}$ stattfindet, wurden in Analogie zu den anderen Messungen die Werte zum Zeitpunkt 15 Minuten ausgewertet. 


\subsection{Fluoreszenzspektrometrische $\mathrm{H}_{2} \mathrm{O}_{2}$-Messungen in Abhängigkeit von Genotyp, Alter, Geschlecht und Hirnregion}

Im Zuge der fluoreszenzspektrometrischen $\mathrm{H}_{2} \mathrm{O}_{2}$-Analysen wurden pro Messzyklus neun Gewebeproben gleichzeitig über einen zeitlichen Verlauf von 30 Minuten gemessen. Die normalisierten Daten der Messung eines Wildtyp-Weibchens sind in Abbildung 12 zur Veranschaulichung dargestellt. In jedem Messzyklus wurden stets alle Hirnregionen einbezogen, um eine bessere Vergleichbarkeit der Daten zu gewährleisten. Im zeitlichen Verlauf zeigte sich, dass einige Gewebeproben im Zuge der fluoreszenzspektrometrischen Messung bereits nach 16 bis 18 Minuten aufgrund einer Überbelichtung des Photomultipliertube-Detektors in die Sättigung liefen und somit kein weiterer Anstieg der $\mathrm{H}_{2} \mathrm{O}_{2}$-Freisetzung registriert werden konnte. In Abbildung 12 zeigt sich, dass obwohl die Proben nicht in die Sättigung liefen, zudem auch ein Abflachen der Kurve zu beobachten war. Es bestand die Vermutung, dass die Sauerstoffverfügbarkeit in den Küvetten ein limitierender Faktor für zeitlich längere Messungen darstellt. Aus diesem Grund wurde entschieden, in den folgenden Messungen die vergleichende Quantifizierung der $\mathrm{H}_{2} \mathrm{O}_{2}$ Freisetzung der jeweiligen Proben grundsätzlich nach jeweils 15 Minuten durchzuführen.

\section{Fluoreszenzkinetik im 30 Minuten Verlauf}

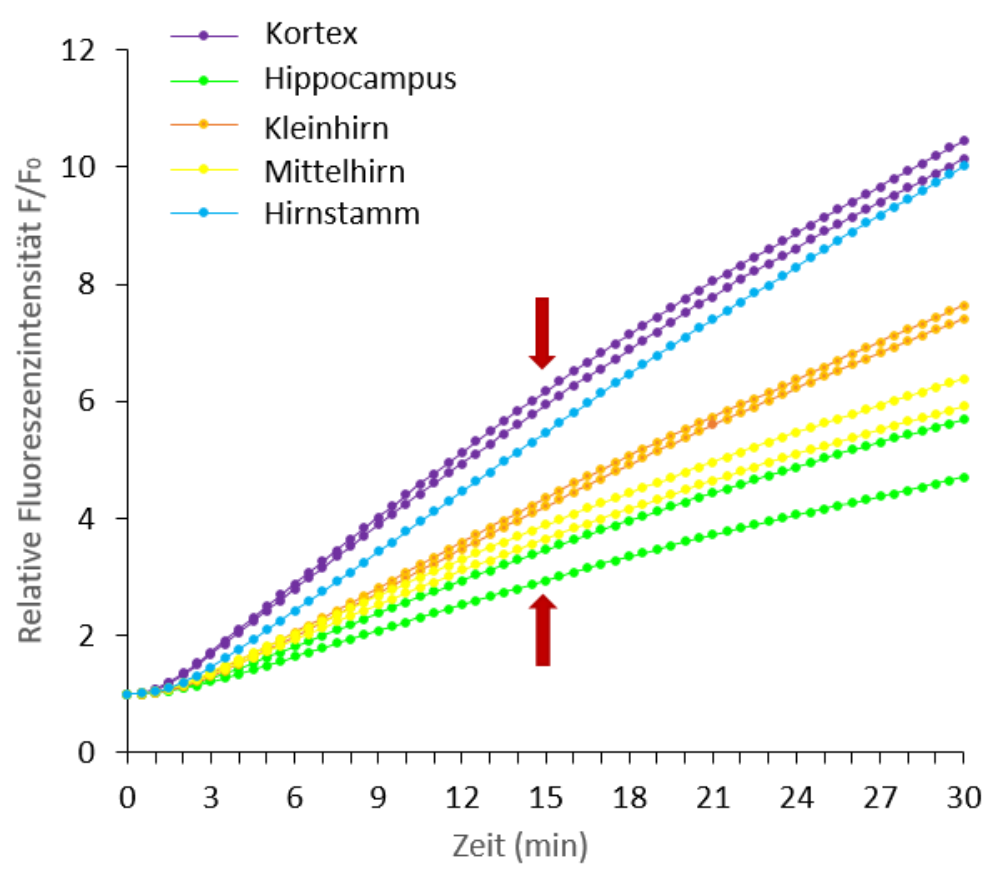

Abbildung 12: Mitochondriale $\mathrm{H}_{2} \mathrm{O}_{2}$-Freisetzung im zeitlichen Verlauf

Im zeitlichen Verlauf zeigt sich eine Zunahme des fluoreszierenden, oxidierten Farbstoffes Amplex UltroxRed $\left(\mathrm{F} / \mathrm{F}_{0}\right)$ in allen betrachteten Hirnregionen einer Wildtyp-Messung in neun Küvetten. Die initialen Messwerte wurden auf den Startpunkt der Messung $\left(\mathrm{F}_{0}\right)$ normalisiert. Ein Abflachen der Kurve konnte nach 16-18 Minuten in der Großzahl der Messungen beobachtet werden, sodass in den nachfolgenden Versuchen eine Analyse der Daten nach 15 Minuten erfolgte, da zu diesem Zeitpunkt noch alle Proben einen linearen Zeitverlauf zeigten. 


\subsubsection{Hirnregionen- und altersspezifische Unterschiede in der $\mathrm{H}_{2} \mathrm{O}_{2}$-Freisetzung}

Zunächst wurden spezifische Unterschiede in der $\mathrm{H}_{2} \mathrm{O}_{2}$-Freisetzung zwischen den Hirnregionen Kortex, Hippocampus, Kleinhirn, Mittelhirn und Hirnstamm bei der WildtypKontrollgruppe untersucht, bevor weitere Messungen zur Untersuchung des Einflusses des Rett-Syndroms und der mitochondrialen Katalase-Expression durchgeführt wurden. Analysiert wurden Männchen der Altersstufe P50 sowie Weibchen der Altersstufen P50, P200 und P400. Sowohl bei den Männchen, als auch bei den Weibchen konnten signifikante und reproduzierbare Unterschiede der $\mathrm{H}_{2} \mathrm{O}_{2}$-Freisetzung zwischen den einzelnen Hirnregionen festgestellt werden (Abbildung 13). Es ließ sich beobachten, dass die höchsten Freisetzungsraten im Kortex, Hirnstamm und Mittelhirn zu verzeichnen waren, die niedrigsten Freisetzungsraten waren im Hippocampus zu beobachten. Altersabhängig zeigten sich die höchsten $\mathrm{H}_{2} \mathrm{O}_{2}$-Freisetzungsraten bei den Tieren der Altersstufe P50, diese sanken im Alter von 200 Tagen geringfügig und zeigten im Alter von 400 Tagen erneut einen leichten Anstieg im Kortex, Hirnstamm und Hippocampus. Die Freisetzungsraten inklusive Standardabweichungen und Stichprobenumfang ( $\mathrm{n}$ ) der Messungen sind in Tabelle 9 einzusehen.

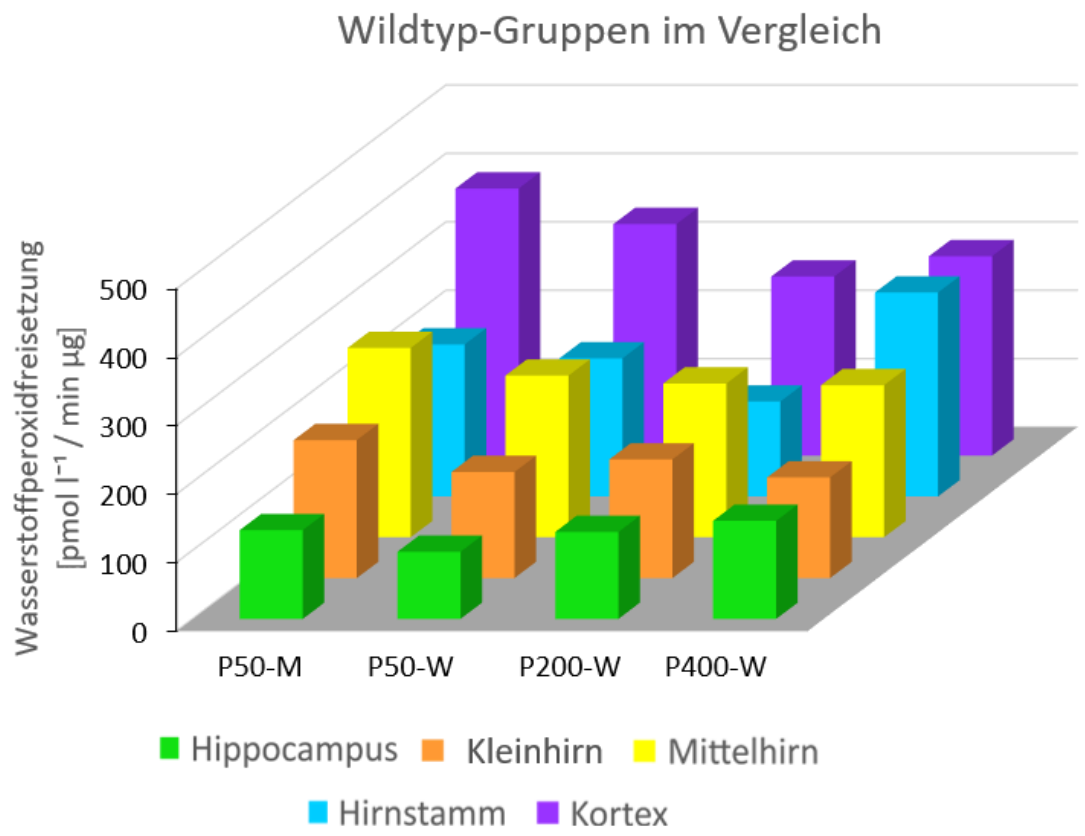

\section{Abbildung 13: Regionenspezifische $\mathrm{H}_{2} \mathrm{O}_{2}$-Freisetzung in Altersabhängigkeit bei Wildtyp-Mäusen}

Anhand der Mittelwerte der $\mathrm{H}_{2} \mathrm{O}_{2}$-Freisetzung in den WT-Mäusen sind alters- und regionenspezifische Unterschiede zu beobachten. Aus Übersichtlichkeitsgründen wurden die Fehlerbalken und Signifikanzniveaus exkludiert. Die höchste $\mathrm{H}_{2} \mathrm{O}_{2}$-Freisetzung konnte bei den 50 Tage alten Männchen und Weibchen festgestellt werden. Im zeitlichen Verlauf sank die $\mathrm{H}_{2} \mathrm{O}_{2}$-Freisetzung geringfügig ab, um im Alter von 400 Tagen einen erneuten Anstieg zu verzeichnen. Die Hirnregionen mit der höchsten $\mathrm{H}_{2} \mathrm{O}_{2}$-Freisetzung stellten Kortex, Hirnstamm und Mittelhirn dar, die geringste Freisetzung wurde im Kleinhirn und Hippocampus beobachtet. Der Stichprobenumfang (n) umfasste je nach Gruppe 13-28 Küvetten, wobei vier bis sechs Tiere je Gruppe für die Messungen verwendet wurden. 
Tabelle 9: Geschlechts-, alters- und regionenspezifische $\mathrm{H}_{2} \mathrm{O}_{2}$-Freisetzung bei Wildtyp-Mäusen

\begin{tabular}{|c|c|c|c|c|c|}
\hline \multirow{6}{*}{ 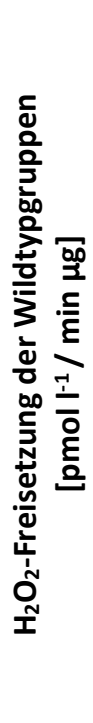 } & & P50-M & P50-W & P200-W & P400-W \\
\hline & Kortex & $\begin{array}{c}390,3 \pm 138,4 \\
(n=27)\end{array}$ & $\begin{array}{c}338,4 \pm 123,0 \\
(n=24)\end{array}$ & $\begin{array}{c}261,7 \pm 86,9 \\
(n=28)\end{array}$ & $\begin{array}{c}291,4 \pm 117,7 \\
(n=25)\end{array}$ \\
\hline & Hirnstamm & $\begin{array}{c}222,1 \pm 80,5 \\
(n=18)\end{array}$ & $\begin{array}{c}201,7 \pm 91,5 \\
(n=14)\end{array}$ & $\begin{array}{c}138,7 \pm 138,7 \\
(n=16)\end{array}$ & $\begin{array}{c}298,0 \pm 113,1 \\
(n=19)\end{array}$ \\
\hline & Mittelhirn & $\begin{array}{c}276,6 \pm 128,6 \\
(n=19)\end{array}$ & $\begin{array}{c}236,2 \pm 114,5 \\
(n=19)\end{array}$ & $\begin{array}{c}224,6 \pm 97,7 \\
(n=17)\end{array}$ & $\begin{array}{c}222,2 \pm 104,3 \\
(n=15)\end{array}$ \\
\hline & Kleinhirn & $\begin{array}{c}201,6 \pm 91,6 \\
(n=17)\end{array}$ & $\begin{array}{c}155,1 \pm 71,6 \\
(n=15)\end{array}$ & $\begin{array}{c}173,3 \pm 67,6 \\
(n=14)\end{array}$ & $\begin{array}{c}147,1 \pm 38,1 \\
(n=13)\end{array}$ \\
\hline & Hippocampus & $\begin{array}{c}129,6 \pm 49,6 \\
(n=15)\end{array}$ & $\begin{array}{c}98,0 \pm 55,2 \\
(n=16)\end{array}$ & $\begin{array}{c}127,0 \pm 65,8 \\
(n=16)\end{array}$ & $\begin{array}{c}143,3 \pm 26,6 \\
(n=17)\end{array}$ \\
\hline
\end{tabular}

\subsubsection{Erhöhte $\mathrm{H}_{2} \mathrm{O}_{2}$-Freisetzung im Rett-Syndrom}

Da bereits in vergangenen Studien von Veränderungen in der Mitochondrien-Morphologie, der Redox-Homöostase und deren Einfluss auf die Progression des Krankheitsverlaufes des Rett-Syndromes berichtet wurde, wurde im Rahmen der fluoreszenzspektrometrischen Messungen die $\mathrm{H}_{2} \mathrm{O}_{2}$-Freisetzung heterozygoter Rett-Weibchen $\left(\mathrm{Mecp}^{2 /-} m \mathrm{CAT}^{+/+}\right)$und hemizygoter Rett-Männchen (Mecp2 $\left.{ }^{-1 y} m \mathrm{CAT}^{+/+}\right)$untersucht. Die bei den Wildtyp-Tieren beschriebenen Unterschiede in der $\mathrm{H}_{2} \mathrm{O}_{2}$-Freisetzung zwischen den Hirnregionen fanden sich ebenfalls an den am Rett-Syndrom erkrankten Tieren. Die Regionen mit den höchsten Freisetzungsraten waren auch hier Kortex und Hirnstamm, die Hirnregion Hippocampus zeigte auch bei den erkrankten Tieren die niedrigste $\mathrm{H}_{2} \mathrm{O}_{2}$-Freisetzung. Da die hemizygoten Rett-Männchen einen schwerwiegenderen Krankheitsverlauf aufweisen, liegt die Lebenserwartung dieser Tiere bei circa 70 Tagen. Aus diesem Grund konnten die Altersstufen 200 und 400 Tage alter Tiere nicht untersucht werden. Bei den 50 Tage alten Rett-Tieren konnte sowohl bei den Männchen $\left(\operatorname{Mecp}^{-1 y} m C A T^{+/+}\right)$, als auch bei den Weibchen $\left(\mathrm{Mecp}^{+/-} m \mathrm{CAT}^{+/+}\right)$in allen Hirnregionen eine signifikant erhöhte mitochondriale $\mathrm{H}_{2} \mathrm{O}_{2}$-Freisetzung im Vergleich $\mathrm{zu}$ den Wildtyp-Tieren beobachtet werden. Dies traf ebenfalls auf die 200 und 400 Tage alten weiblichen Tiere in allen Hirnregionen zu (Abbildung 13).

Um genauere Aussagen über den Einfluss der Rett-Erkrankung auf die mitochondriale $\mathrm{H}_{2} \mathrm{O}_{2}$-Freisetzung treffen zu können, wurden sämtliche Daten der erkrankten Rett-Tiere auf die durchschnittliche $\mathrm{H}_{2} \mathrm{O}_{2}$-Freisetzungsrate der entsprechenden Wildtyp-Kontrollgruppe normiert. Im Vergleich zu den Wildtyp-Kontrollgruppen zeigte sich eine Erhöhung der mitochondrialen $\mathrm{H}_{2} \mathrm{O}_{2}$-Freisetzung um 33-72 \% bei den Männchen, und um 38-270 \% bei 
den Weibchen. Die stärksten Differenzen zur Wildtyp-Kontrolle konnten bei der Gruppe der 50 Tage alten Weibchen beobachtet werden. Besonders im Hippocampus, Hirnstamm und Kleinhirn ließen sich Freisetzungsraten mit einer Steigerung von mehr als $200 \%$ feststellen $(\mathrm{p}<0,001)$. Diese Zusammenhänge wurden in den Abbildungen 14 und 15 dargestellt. Im geschlechtsspezifischen Vergleich ließ sich zudem bei den heterozygoten Weibchen eine signifikant höhere $\mathrm{H}_{2} \mathrm{O}_{2}$-Freisetzungsrate als in den hemizygoten Männchen beobachten.

Somit konnte eindeutig bewiesen werden, dass sich oxidativer Stress im Rett-Syndrom in allen Hirnregionen und allen Altersstufen manifestiert. Diese Feststellung gilt sowohl für die heterozygoten Weibchen, als auch für die hemizygoten Männchen. 


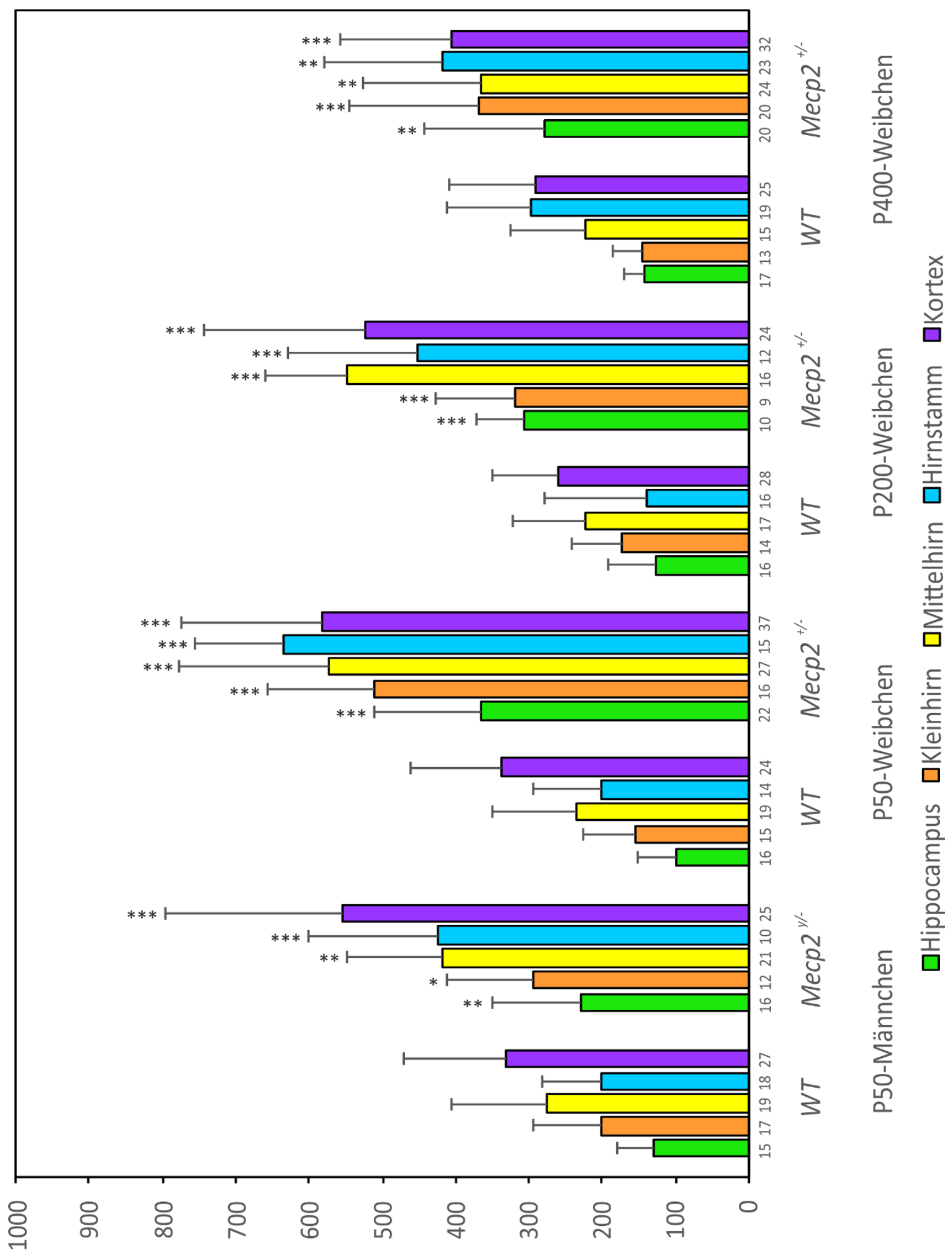

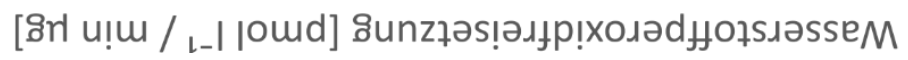

\section{Abbildung 14: Überhöhte Mitochondriale $\mathrm{H}_{2} \mathrm{O}_{2}$-Freisetzung im Rett-Syndrom}

Die absolute $\mathrm{H}_{2} \mathrm{O}_{2}$-Freisetzung aller Altersgruppen und aller Hirnregionen ist in beiden Geschlechtern im RettSyndrom im Vergleich zu den WT-Kontrollgruppen signifikant erhöht. Die Signifikanzprüfung erfolgte mittels Einwegvarianzanalyse $(A N O V A)$ und ungepaartem Zweistichproben t-Test. Der Stichprobenumfang (n) ist unter den Balken als Zahlenwert dargestellt. Je Gruppe wurden mindestens vier Tiere für die Messungen genutzt. 


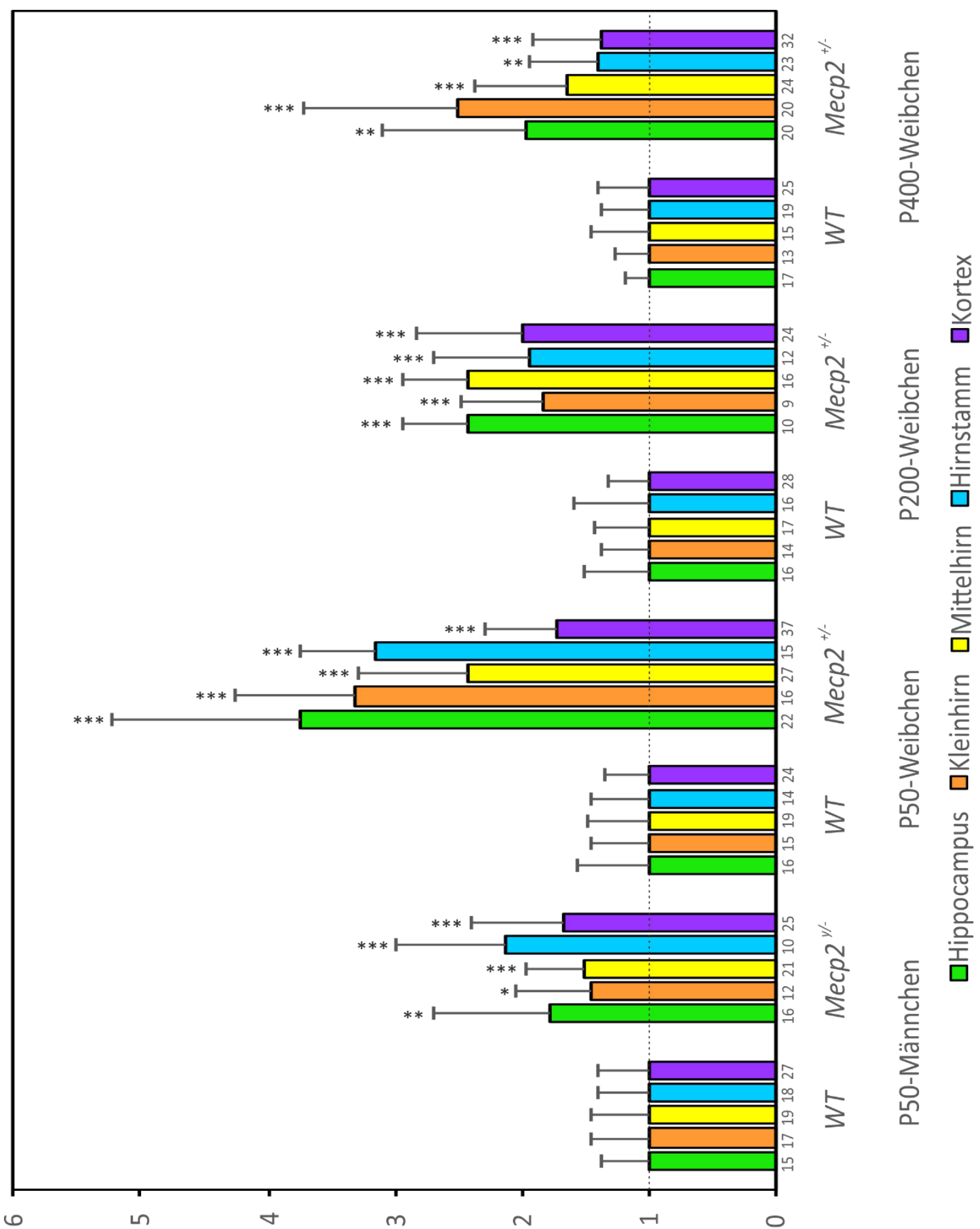

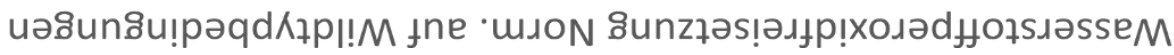

Abbildung 15: Regionenspezifische Erhöhung der mitochondrialen $\mathrm{H}_{2} \mathrm{O}_{2}$-Freisetzung im RettSyndrom

Normierung auf die jeweilige Wildtyp-Gruppe offenbart Rett-spezifische Defekte in den einzelnen Hirnregionen. Es zeigte sich eine eindeutige Erhöhung der mitochondrialen $\mathrm{H}_{2} \mathrm{O}_{2}$-Freisetzung im RettSyndrom um 33-72 \% bei den Männchen, und um 38-270 \% bei den Weibchen. Die Erhöhung war in allen Hirnregionen und Altersgruppen signifikant. Die Signifikanzprüfung erfolgte mittels zweiseitigem Einstichproben t-Test. Der Stichprobenumfang (n) ist unter den Balken als Zahlenwert dargestellt. Je Gruppe wurden mindestens vier Tiere für die Messungen genutzt. 


\subsubsection{Einfluss der Expression einer mitochondrialen Katalase auf die $\mathrm{H}_{2} \mathrm{O}_{2-}$ Freisetzung im Rett-Syndrom}

Aufgrund der nachgewiesenen erhöhten mitochondrialen $\mathrm{H}_{2} \mathrm{O}_{2}$-Freisetzung im RettSyndrom und der damit einhergehenden Redox-Imbalance sollte ein möglicher Therapieansatz zur Wiederherstellung der Redox-Homöostase untersucht werden. Zu diesem Zweck wurden Tiere, die eine mitochondriale Katalase exprimieren in die Mauslinie B6.129P2(C)- Mecp2 ${ }^{\text {tm-1-1Bid }}$ eingekreuzt, die ein Mausmodell für das humane Rett-Syndrom darstellt. Untersucht wurden außerdem auch Wildtyp-Tiere, die ebenfalls die mitochondriale Katalase exprimieren.

In den folgenden Abbildungen wurden zunächst die absoluten $\mathrm{H}_{2} \mathrm{O}_{2}$-Freisetzungsraten der vier Genotypen einer Altersstufe dargestellt, im nachfolgenden Diagramm wurden die normalisierten Daten der Genotypen $\mathrm{Mecp}^{+/-} m \mathrm{CAT}^{+/+}, \mathrm{Mecp}^{+/-} m \mathrm{CA} \mathrm{T}^{+/ T}$ und $\mathrm{Mecp} 2^{+/+}$ $m C A T^{+/ T}$ bzw. Mecp2-ly $m C A T^{+/+}, M_{e c p 2^{-1 y}} m C A T^{+/ T}$ und $M e c p 2^{+/ y} m C A T^{+/ T}$ auf die durchschnittliche $\mathrm{H}_{2} \mathrm{O}_{2}$-Freisetzungsrate der entsprechenden Wildtyp-Kontrollgruppe normiert. Um eine bessere Übersichtlichkeit zu gewährleisten, wurde auf die Signifikanzniveaus zwischen Wildtyp-Gruppe und hemi- bzw. heterozygoten Rett-Tieren ohne mitochondriale Katalase verzichtet, da diese bereits in den Abbildungen 14 und 15 dargestellt wurden und in allen Altersstufen und Hirnregionen signifikant erhöhte Freisetzungsraten aufwiesen.

In der Altersstufe P50 konnte bei den Rett-Männchen durch die Expression der mitochondrialen Katalase (Mecp $\left.2^{-1 y} m C A T^{+/ T}\right)$ eine signifikante Reduktion $(\mathrm{p}<0,001)$ der mitochondrialen $\mathrm{H}_{2} \mathrm{O}_{2}$-Freisetzung im Vergleich $\mathrm{zu}$ den erkrankten Tieren ohne mitochondriale Katalase $\left(\mathrm{Mecp}^{-/ y} \mathrm{mCAT^{+/+ }}\right.$ ) in allen Hirnregionen beobachtet werden (Abbildung 15). Die $\mathrm{H}_{2} \mathrm{O}_{2}$-Freisetzung der Mecp $2^{-1 y} m C A T^{+/ T}$-Tiere konnte somit erfolgreich auf das Niveau der Wildtyp-Kontrollgruppe in allen Hirnregionen gesenkt werden, sodass zwischen den $M e c p 2^{-1 y} m C A T^{+/ T}$-Tieren und den $M e c p 2^{+/ y} m C A T^{+/+}$-Tieren kein signifikanter Unterschied mehr zu verzeichnen war.

Hinsichtlich der regionenspezifischen Unterschiede zeigten sich auch bei den erkrankten Tieren mit mitochondrialer Katalase-Expression ebenfalls die höchsten Freisetzungsraten in den Hirnregionen Kortex und Hirnstamm und die niedrigste Freisetzungsrate im Hippocampus. Auffällig war jedoch, dass die Wildtyp-Tiere mit mitochondrialer KatalaseExpression $\left(\mathrm{Mecp}^{+/ y} \mathrm{mCA} T^{+/ T}\right)$ signifikant höhere mitochondriale $\mathrm{H}_{2} \mathrm{O}_{2}$-Freisetzungsraten im Kortex $(p<0,05)$, Hippocampus $(p<0,01)$ und Mittelhirn $(p<0,01)$ aufwiesen, als die Wildtyp-Kontrollgruppe $\left(M e c p 2^{+/ y} m C A T^{+/+}\right)$. Im Kleinhirn und Hirnstamm ließen sich jedoch keine signifikanten Unterschiede zu den Wildtyp-Tieren beobachten. 
A

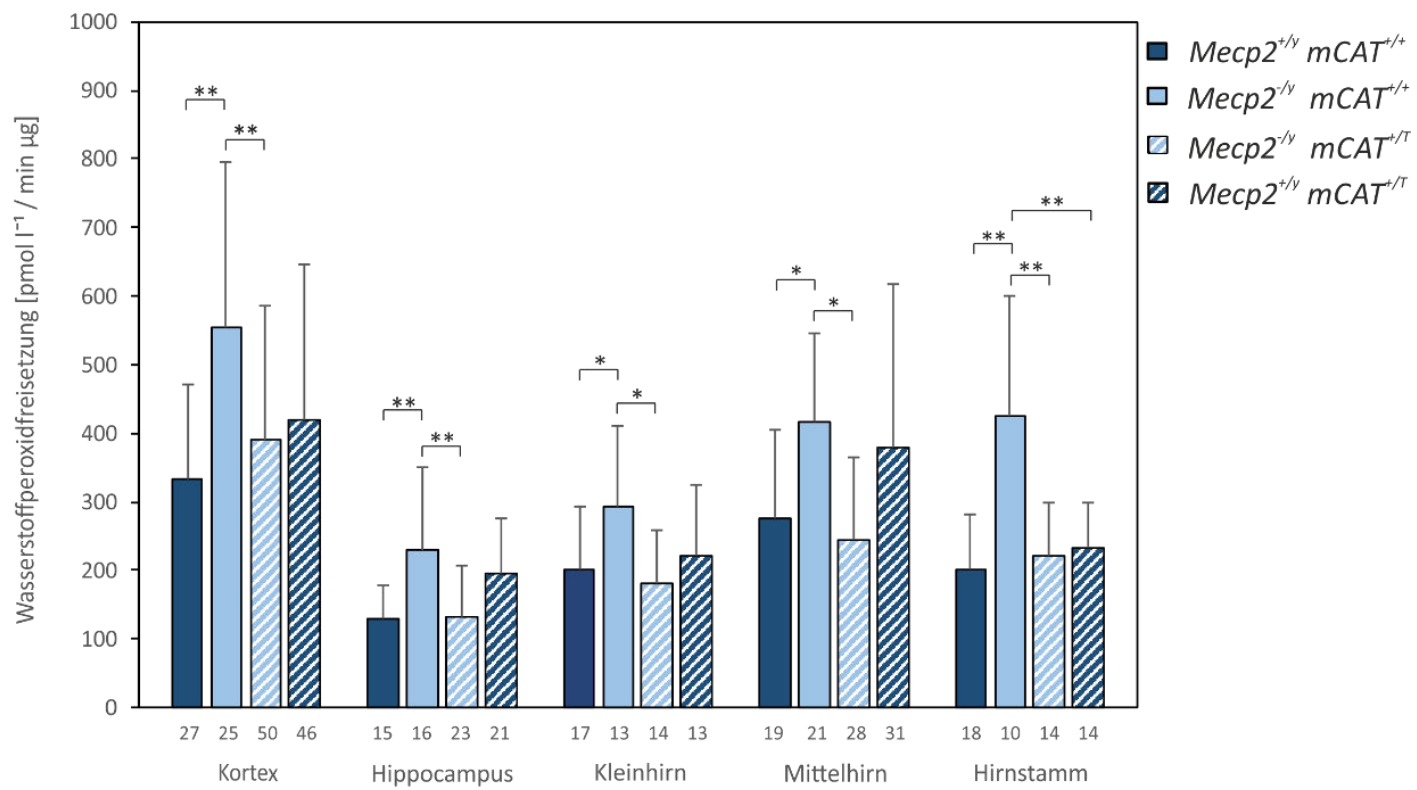

B

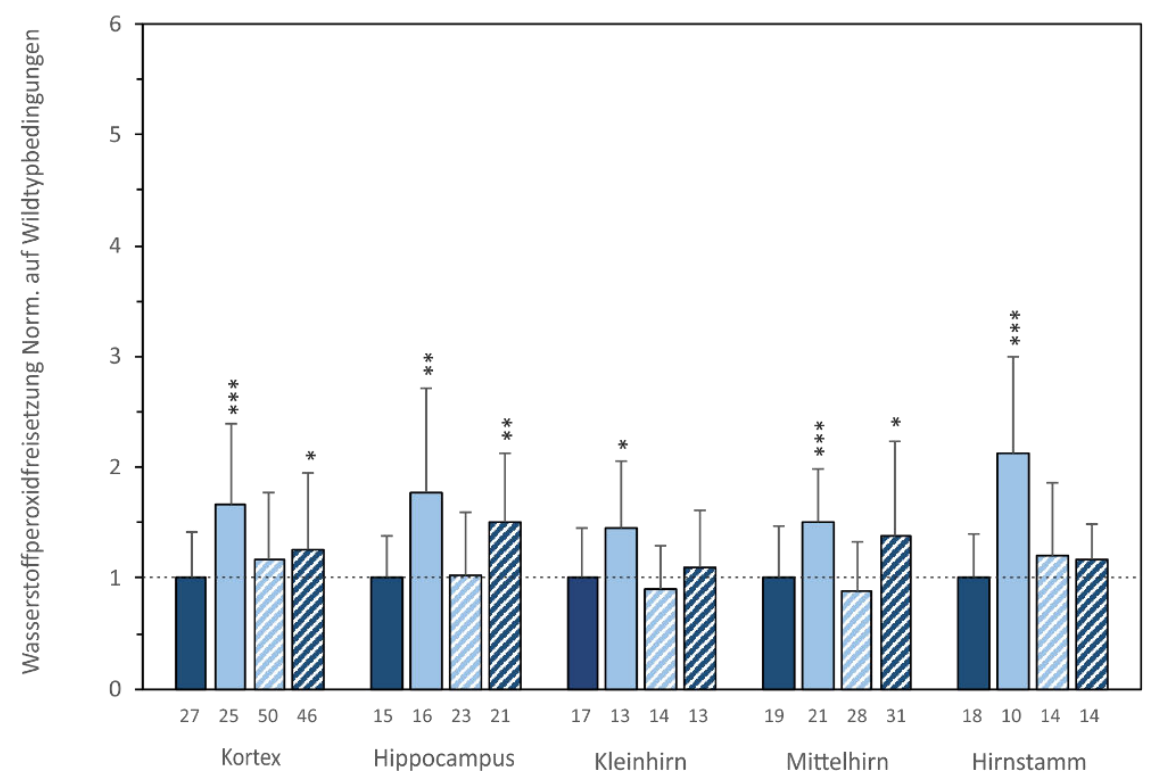

Abbildung 16: Senkung der mitochondrialen $\mathrm{H}_{2} \mathrm{O}_{2}$-Freisetzung in P50-Mecp2-y-Männchen auf Wildtyp-Niveau durch die mitochondriale Katalase-Expression

A) In allen Hirnregionen ist eine signifikant erhöhte $\mathrm{H}_{2} \mathrm{O}_{2}$-Freisetzung im Rett-Syndrom im Vergleich zur WTKontrollgruppe zu beobachten. Die Anzahl der Küvetten (n) ist unter den Balken dargestellt. Die Signifikanzprüfung erfolgte mit Hilfe einer Einweg-Varianzanalyse (ANOVA). Für normalverteilte Daten wurde als posthoc test der Holm-Sidak Test und für nicht normalverteilte Daten der Dunn's Test genutzt. B) Nach Normierung auf die entsprechende Wildtyp-Gruppe zeigt sich eine signifikante Senkung der $\mathrm{H}_{2} \mathrm{O}_{2-}$ Freisetzung auf WT-Niveau in allen Hirnregionen durch die mitochondriale Katalase-Expression. Die Signifikanzprüfung erfolgte mittels zweiseitigem Einstichproben t-Test. 
Die Ergebnisse der fluoreszenspektrometrischen Messungen der weiblichen Tiere der Altersstufe P50 zeigten ähnliche protektive Effekte der mitochondrialen KatalaseExpression (Abbildung 17).

P50-Weibchen

A
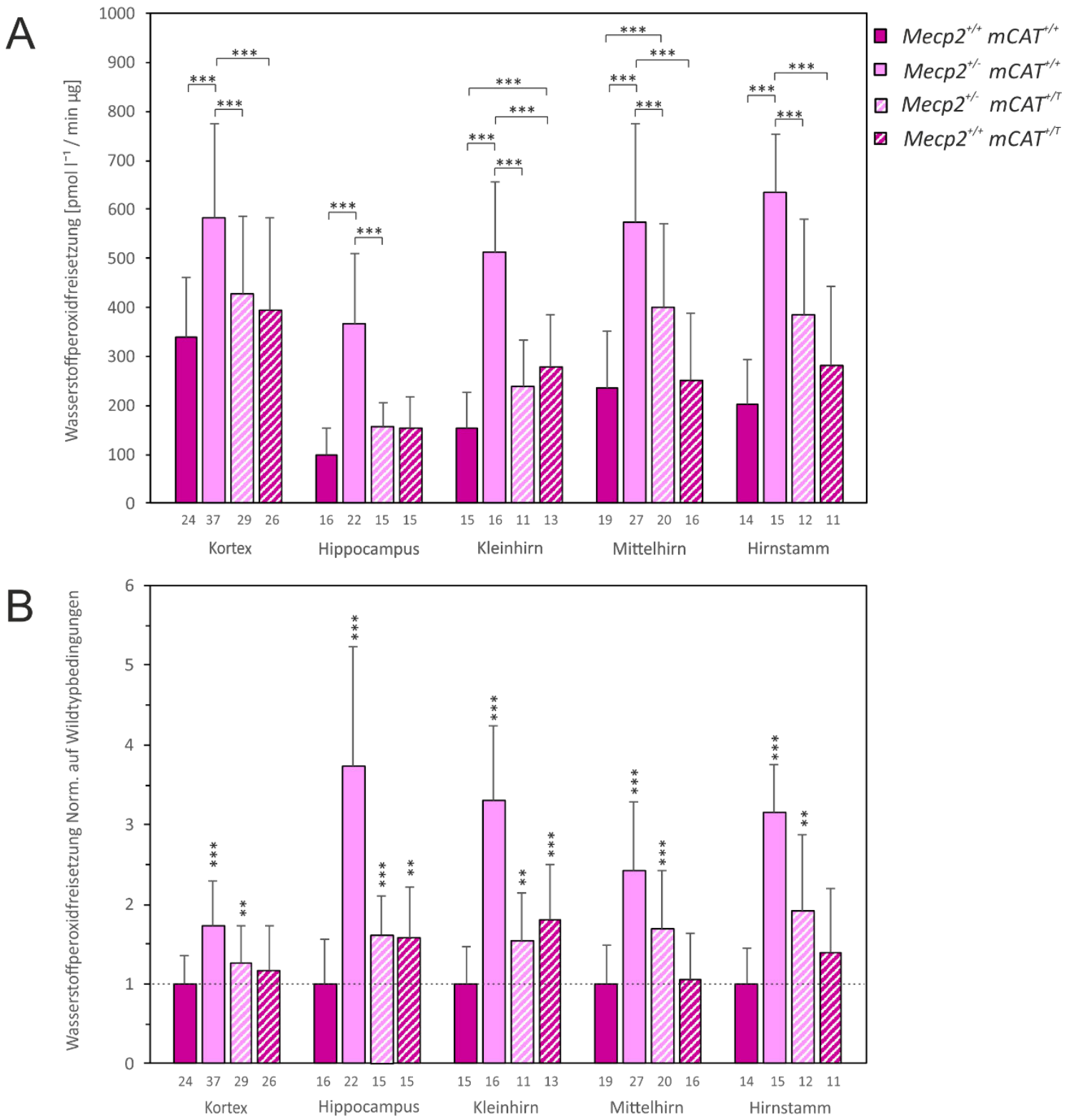

Abbildung 17: Deutliche Erhöhung der mitochondrialen $\mathrm{H}_{2} \mathrm{O}_{2}$-Freisetzung in den P50-Mecp $2^{+/-}$ Weibchen und Reduktion der Freisetzung durch die mitochondriale Katalase-Expression

A) Auch bei den Weibchen konnte in allen Hirnregionen eine signifikant erhöhte $\mathrm{H}_{2} \mathrm{O}_{2}$-Freisetzung im RettSyndrom im Vergleich zur WT-Kontrollgruppe beobachtet werden. Die Anzahl der Küvetten (n) ist unter den Balken dargestellt. Die Signifikanzprüfung erfolgte mit Hilfe einer Einweg-Varianzanalyse. B) Bei Betrachtung der relativen $\mathrm{H}_{2} \mathrm{O}_{2}$-Freisetzung der unterschiedlichen Genotyp-Gruppen, die jeweils auf die Wildtyp-Gruppen normiert wurden, zeigt sich durch die mitochondriale Katalase-Expression eine signifikante Senkung der $\mathrm{H}_{2} \mathrm{O}_{2-}$ Freisetzung. Jedoch konnte das WT-Niveau nicht komplett erreicht werden. Zudem zeigten die WT-Tiere mit Expression der mitochondrialen Katalase-Expression teilweise signifikant höhere Werte im Vergleich zur WTKontrollgruppe. 
Durch die Expression der mitochondrialen Katalase in den am Rett-Syndrom erkrankten Weibchen $\left(\right.$ Mecp $\left.^{+/-} m C A T^{+/ T}\right)$ konnte die mitochondriale $\mathrm{H}_{2} \mathrm{O}_{2}$-Freisetzung im Vergleich zu den erkrankten Tieren ohne mitochondriale Katalase $\left(M e c p 2^{+/-} m C A T^{+/+}\right)$in allen Hirnregionen signifikant gesenkt werden $(\mathrm{p}<0,001)$.

Allerdings wurde die $\mathrm{H}_{2} \mathrm{O}_{2}$-Freisetzungsrate durch die Expression der mitochondrialen Katalase nicht komplett bis auf das Wildtyp-Niveau gesenkt. Nach Normierung auf die entsprechende Wildtyp-Kontrollgruppe zeigte sich, dass die $\mathrm{H}_{2} \mathrm{O}_{2}$-Freisetzungsrate durch die Expression der mitochondrialen Katalase zwar signifikant reduziert werden konnte, sie bei den $\mathrm{Mecp}^{+/-} m C A T^{+/ T}$-Weibchen dennoch im Mittel $26 \%$ höher in der Hirnregion Kortex, $61 \%-70 \%$ höher im Hippocampus, Kleinhirn und Mittelhirn und sogar 92 \% höher im Hirnstamm als in den Wildtyp-Kontrollgruppen war. Jedoch zeigte sich auch in der Untersuchungsgruppe der 50 Tage alten Weibchen, dass die Wildtyp-Tiere mit mitochondrialer Katalase-Expression $\left(\mathrm{Mecp}^{+/+} \mathrm{mCAT^{+/T }}\right)$ signifikant höhere mitochondriale $\mathrm{H}_{2} \mathrm{O}_{2}$-Freisetzungsraten im Hippocampus $(\mathrm{p}<0,01)$ und Kleinhirn $(\mathrm{p}<0,001)$ aufwiesen, als die reinen Wildtyp-Tiere $\left(\mathrm{Mecp}^{+/+} m \mathrm{CAT}^{+/+}\right)$.

In der Altersstufe der 200 Tage alten Weibchen konnte ähnlich der P50-Altersstufe eine signifikante Senkung der mitochondrialen $\mathrm{H}_{2} \mathrm{O}_{2}$-Freisetzung $(\mathrm{p}<0,001$ in den Regionen Kortex, Hirnstamm und Mittelhirn, $\mathrm{P}<0,05$ im Hippocampus und $\mathrm{p}<0,01$ im Kleinhirn) in allen Hirnregionen durch die mitochondriale Katalase in den am Rett-Syndrom erkrankten P200-Weibchen $\left(\mathrm{Mecp}^{+/-} m C A T^{+/ T}\right)$ im Vergleich zu den erkrankten Tieren ohne mitochondriale Katalase (Mecp $2^{+/-} m C A T^{+/+}$) beobachtet werden (Abbildung 18). Die $\mathrm{H}_{2} \mathrm{O}_{2^{-}}$ Freisetzung konnte durch die Expression der Katalase um $35 \%$ im Kortex, um $25 \%$ im Hippocampus und Kleinhirn, $45 \%$ im Mittelhirn, und $37 \%$ im Hirnstamm gesenkt werden. Allerdings wurde auch in dieser Altersstufe die $\mathrm{H}_{2} \mathrm{O}_{2}$-Freisetzungsrate durch die Expression der mitochondrialen Katalase nicht auf Wildtyp-Niveau gesenkt. Signifikante Erhöhungen $(\mathrm{p}<0,05)$ der $\mathrm{H}_{2} \mathrm{O}_{2}$-Freisetzung durch die mitochondriale Katalase bei den Wildtyp-Tieren $\left(M e c p 2^{+/+} m C A T^{+/ T}\right)$ konnten in den Hirnregionen Kortex und Mittelhirn verzeichnet werden (Abbildung 18). 


\section{P200-Weibchen}

A

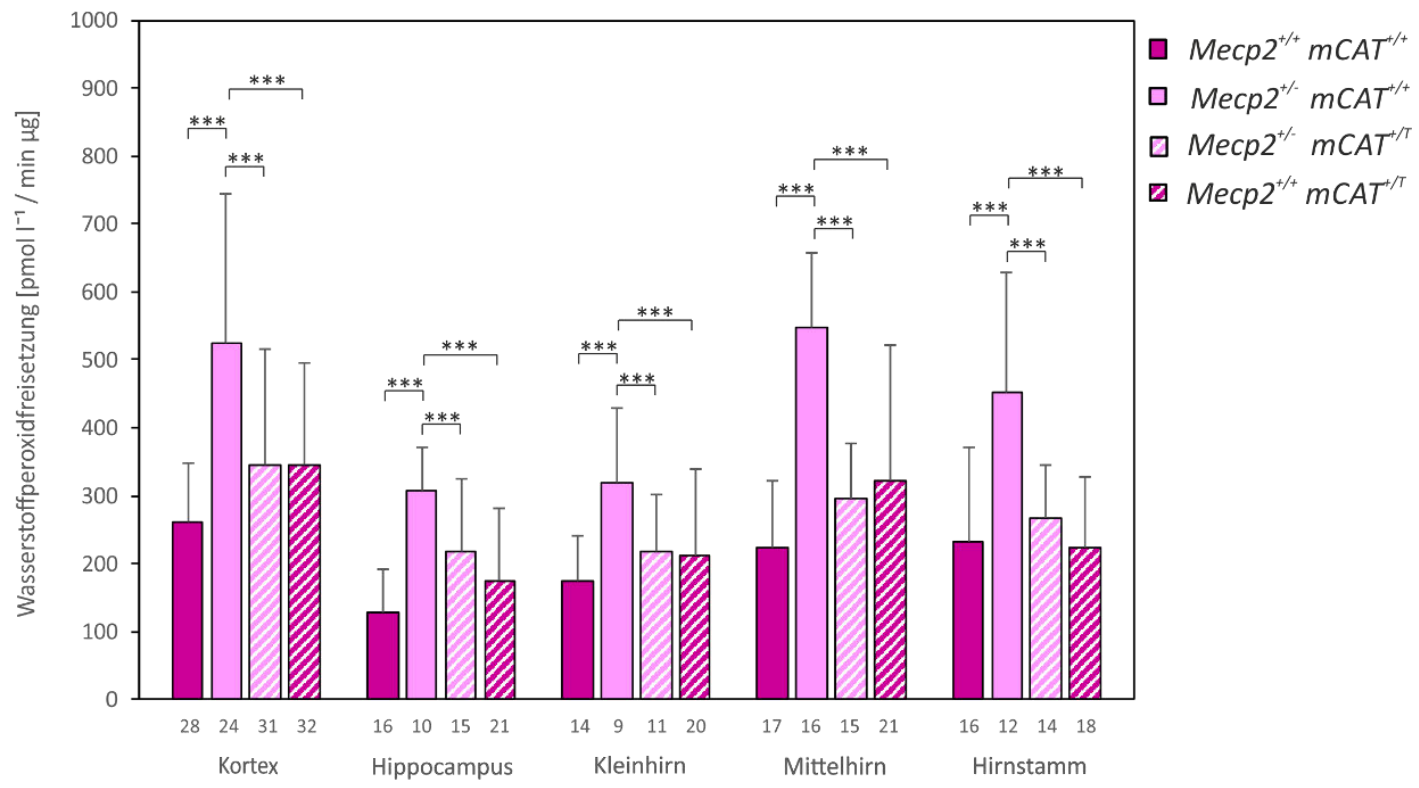

B

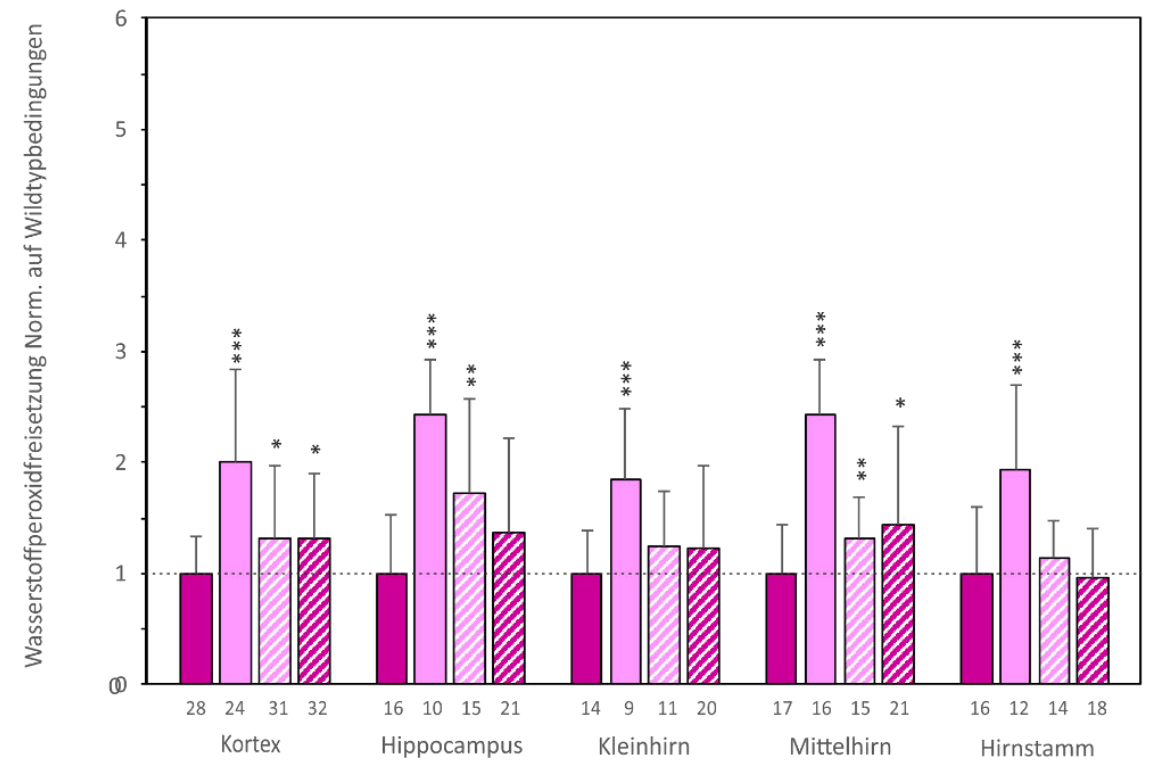

Abbildung 18: Reduktion der mitochondriale $\mathrm{H}_{2} \mathrm{O}_{2}$-Freisetzung in P200-Mecp2 $2^{+/-}$-Weibchen durch mitochondriale Katalase-Expression

A) In allen Hirnregionen ist eine signifikant erhöhte $\mathrm{H}_{2} \mathrm{O}_{2}$-Freisetzung im Rett-Syndrom im Vergleich zur WTKontrollgruppe zu beobachten. Die Anzahl der Küvetten (n) ist unter den Balken dargestellt. Die Signifikanzprüfung erfolgte mit Hilfe einer Einweg-Varianzanalyse. Für normalverteilte Daten wurde als posthoc test der Holm-Sidak Test und für nicht normalverteilte Daten der Dunn's Test genutzt. B) Durch die mitochondriale Katalase-Expression konnte die $\mathrm{H}_{2} \mathrm{O}_{2}$-Freisetzung im Rett-Syndrom in allen Hirnregionen gesenkt werden, dennoch konnte noch teilweise eine signifikante Erhöhung zwischen der Gruppe Mecp2 ${ }^{+/}$ $m C A T^{+/ T}$ und der WT-Kontrolle beobachtet werden. Die Signifikanzprüfung erfolgte mittels zweiseitigem Einstichproben t-Test. 
Im Gegensatz zu den protektiven Effekten der P50- und P200-Gruppen konnte im Alter von 400 Tagen bei den am Rett-Syndrom erkrankten Weibchen durch die Expression der mitochondrialen Katalase keine Reduktion der mitochondrialen $\mathrm{H}_{2} \mathrm{O}_{2}$-Freisetzung mehr beobachtet werden (Abbildung 19).

P400-Weibchen

A
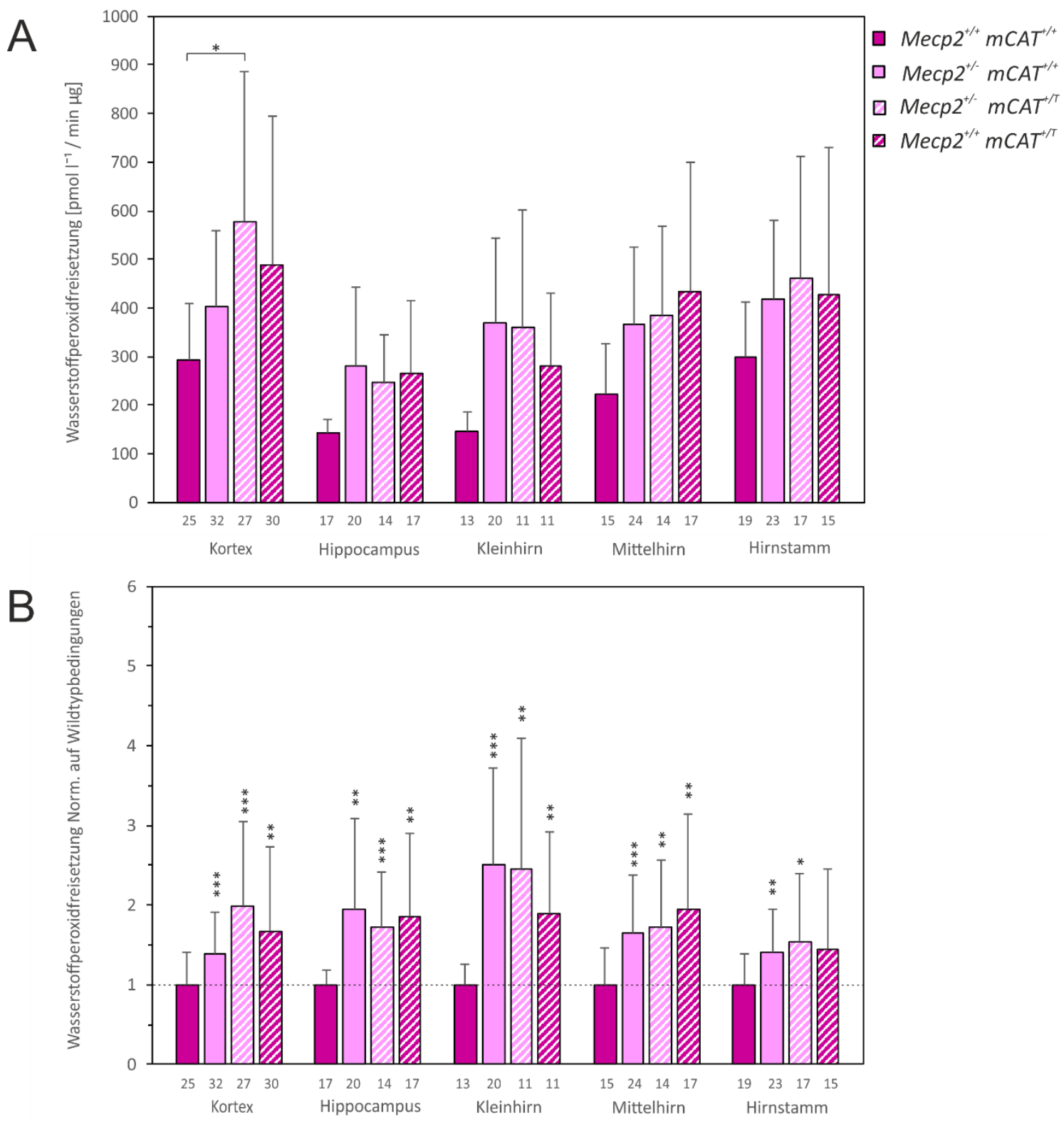

Abbildung 19: Verlust des therapeutisch wirksamen Effektes der mitochondrialen KatalaseExpression bei den P400-Mecp2 $2^{+/-W e i b c h e n ~}$

A) Auch bei den Weibchen der Altersgruppe $\mathrm{P} 400$ konnte in allen Hirnregionen eine signifikant erhöhte $\mathrm{H}_{2} \mathrm{O}_{2-}$ Freisetzung im Rett-Syndrom im Vergleich zur WT-Kontrollgruppe beobachtet werden. In der Gruppe $M e c p 2^{+/-} m C A T^{+/ T}$ konnten im Kortex sogar signifikant höhere Werte als in der $\mathrm{Mecp}^{+/-} m C A T^{4 /+}$ Gruppe beobachtet werden. B) Nach Normierung der unterschiedlichen Genotyp-Gruppen auf die Wildtyp-Gruppe zeigt sich, dass durch die mitochondriale Katalase-Expression die $\mathrm{H}_{2} \mathrm{O}_{2}$-Freisetzung nicht mehr gesenkt wurde und somit kein therapeutisch wirksamer Effekt mehr zu beobachten ist. Die Signifikanzprüfung erfolgte mittels zweiseitigem Einstichproben t-Test. 
In den am Rett-Syndrom erkrankten P400-Weibchen mit mitochondrialer KatalaseExpression $\left(\mathrm{Mecp}^{+/-} m \mathrm{CAT}^{+/ T}\right)$ ist die $\mathrm{H}_{2} \mathrm{O}_{2}$-Freisetzung in der Hirnregion Kortex sogar signifikant $(\mathrm{p}<0,05)$ höher als bei den heretozygoten Rett-Weibchen ohne mitochondriale Katalase-Expression. Der therapeutisch positive Effekt des Enzyms ist somit zeitlich eindeutig begrenzt und in älteren Altersstadien nicht mehr wirksam. Die Wildtyp-Tiere mit mitochondrialer Katalase-Expression $\left(\mathrm{Mecp}^{+/+} m C A T^{+/ T}\right)$ wiesen ebenso signifikant höhere mitochondriale $\mathrm{H}_{2} \mathrm{O}_{2}$-Freisetzungsraten im Kortex $(p<0,01)$, Hippocampus $(p<0,01)$, Kleinhirn $(\mathrm{p}<0,01)$ und Mittelhirn $(\mathrm{p}<0,01)$ auf im Vergleich zur Wildtyp-Kontrollgruppe $\left(\mathrm{Mecp} 2^{+/+} m C A T^{+/+}\right)$. 


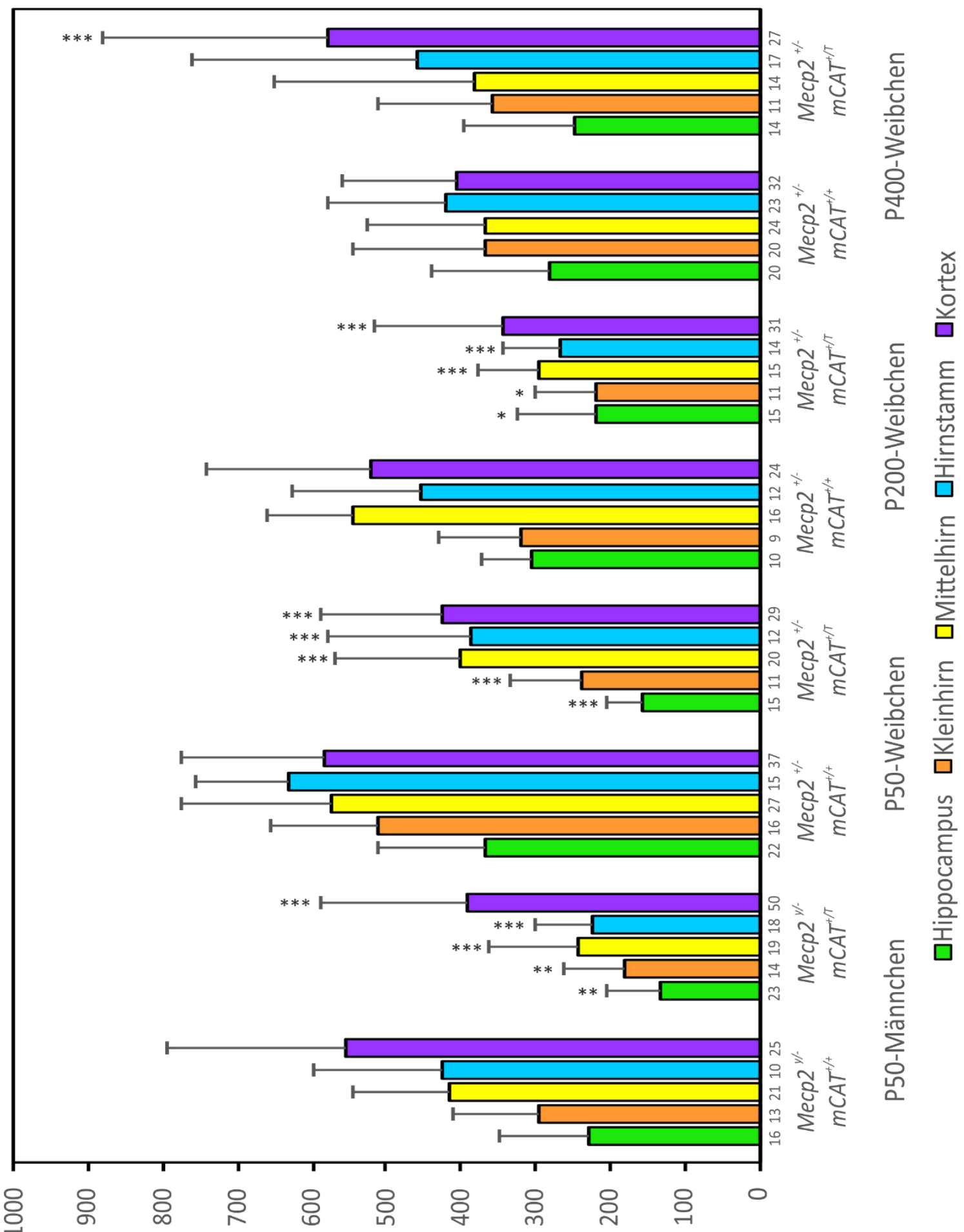

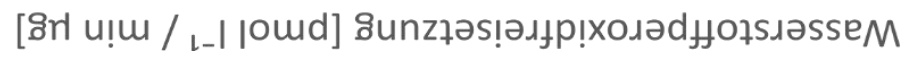

Abbildung 20: Einfluss der Expression der mitochondrialen Katalase auf die $\mathrm{H}_{2} \mathrm{O}_{2}$-Freisetzung im Rett-Syndrom

Die absolute $\mathrm{H}_{2} \mathrm{O}_{2}$-Freisetzung aller Hirnregionen und beider Geschlechter im Rett-Syndrom im Vergleich zu den Rett-erkrankten Tieren, die eine mitochondriale Katalase exprimieren $\left(\mathrm{Mecp}^{+/-} m \mathrm{CAT}^{+/ T}\right)$ zeigt, dass in den Altersgruppen P50 und P200 in beiden Geschlechtern und allen Hirnregionen die $\mathrm{H}_{2} \mathrm{O}_{2}$-Freisetzung durch die mitochondriale Katalase signifikant gesenkt wurde. In der Altersgruppe P400 konnte dieser therapeutisch positive Effekt jedoch nicht mehr nachgewiesen werden. Die Signifikanzprüfung erfolgte mittels ungepaartem Zweistichproben t-Test. 


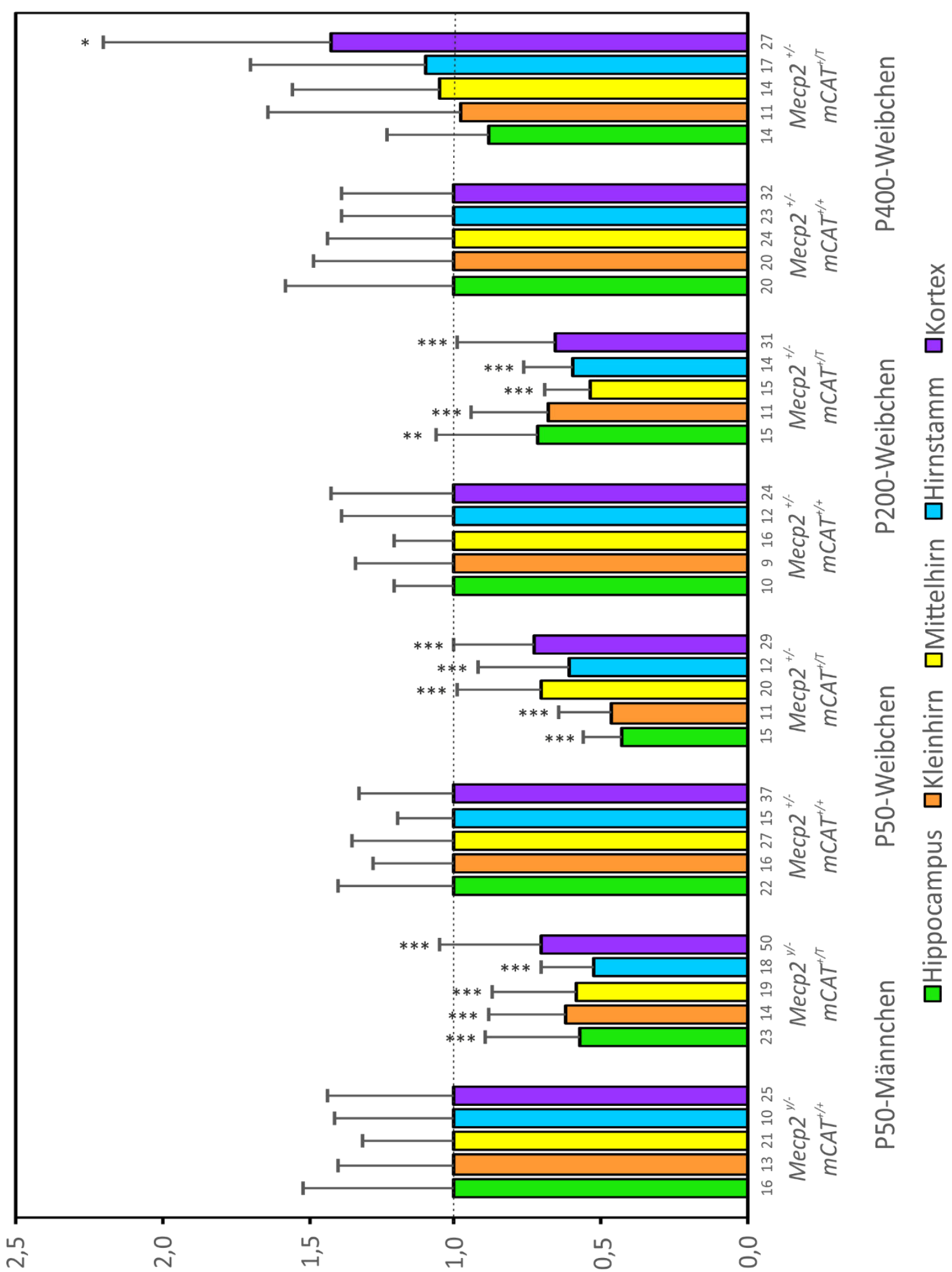

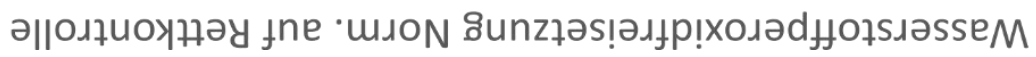

Abbildung 21: Deutliche Reduktion der $\mathrm{H}_{2} \mathrm{O}_{2}$-Freisetzung im Rett-Syndrom durch Expression einer mitochondrialen Katalase

Nach Normierung der $\mathrm{H}_{2} \mathrm{O}_{2}$-Freisetzung der $M e c p 2^{+/-} m C A T^{+/ T}$-Tiere auf Rett-Bedingungen zeigt sich, dass durch die mitochondriale Katalase-Expression die $\mathrm{H}_{2} \mathrm{O}_{2}$-Freisetzung in den Altersgruppen P50 und P200 um bis zu $57 \%$ gesenkt werden konnte. Bei den P400 alten Tieren war dieser Effekt nicht mehr zu beobachten. Die Signifikanzprüfung erfolgte mittels zweiseitigem Einstichproben t-Test. 


\subsection{Auswertung der allgemeinen phänotypischen Parameter}

Zur Bewertung möglicher Veränderungen der allgemeinen Parameter durch die Mecp2Defizienz oder die Expression der mitochondrialen Katalase wurden vier bis neun Tiere jeder Genotyp- und Altersgruppe in Bezug auf Körpergewicht, Größe, Hämatokrit und Blutglukosespiegel untersucht.

\subsubsection{Körpergewicht}

Im Rahmen der durchgeführten Gewichtsanalyse zeigte sich, dass sich lediglich in den jüngeren Altersgruppen (P50) und vor allem den hemizygoten Männchen signifikante Unterschiede zwischen den Genotypen beobachten ließen. Das Gewicht der männlichen $M e c p 2^{-/ y} m C A T^{+/+}$-P50-Tiere war signifikant niedriger $(\mathrm{P}<0,001)$ als das der Wildtypen $\left(M e c p 2^{+/ y} m C A T^{+/+}\right)$. Gleiches galt für die Mecp2 $2^{-1 y} m C A T^{+/ T}-\mathrm{P} 50-$ Männchen $(\mathrm{p}<0,001)$. Das Gewicht in dieser Gruppe war im Durchschnitt ebenfalls signifikant reduziert im Vergleich zu den Wildtypen, wobei sich zwischen den knockout-Männchen ohne und denen mit Expression der mitochondrialen Katalase keine signifikanten Unterschiede im Gewicht zeigten (Abbildung 22). Im Mittel wogen die Wildtyp-Männchen 22,6 \pm 1,5 g, die Mecp2 $2^{-1 y}$ $m C A T^{+/+}$-Männchen $12,2 \pm 2,2 \mathrm{~g}$ und die die transgenen $M e c p 2^{-1 y} m C A T^{+/ T}$-Männchen $13,0 \pm 3,5 \mathrm{~g}$.

\section{Körpergewicht}

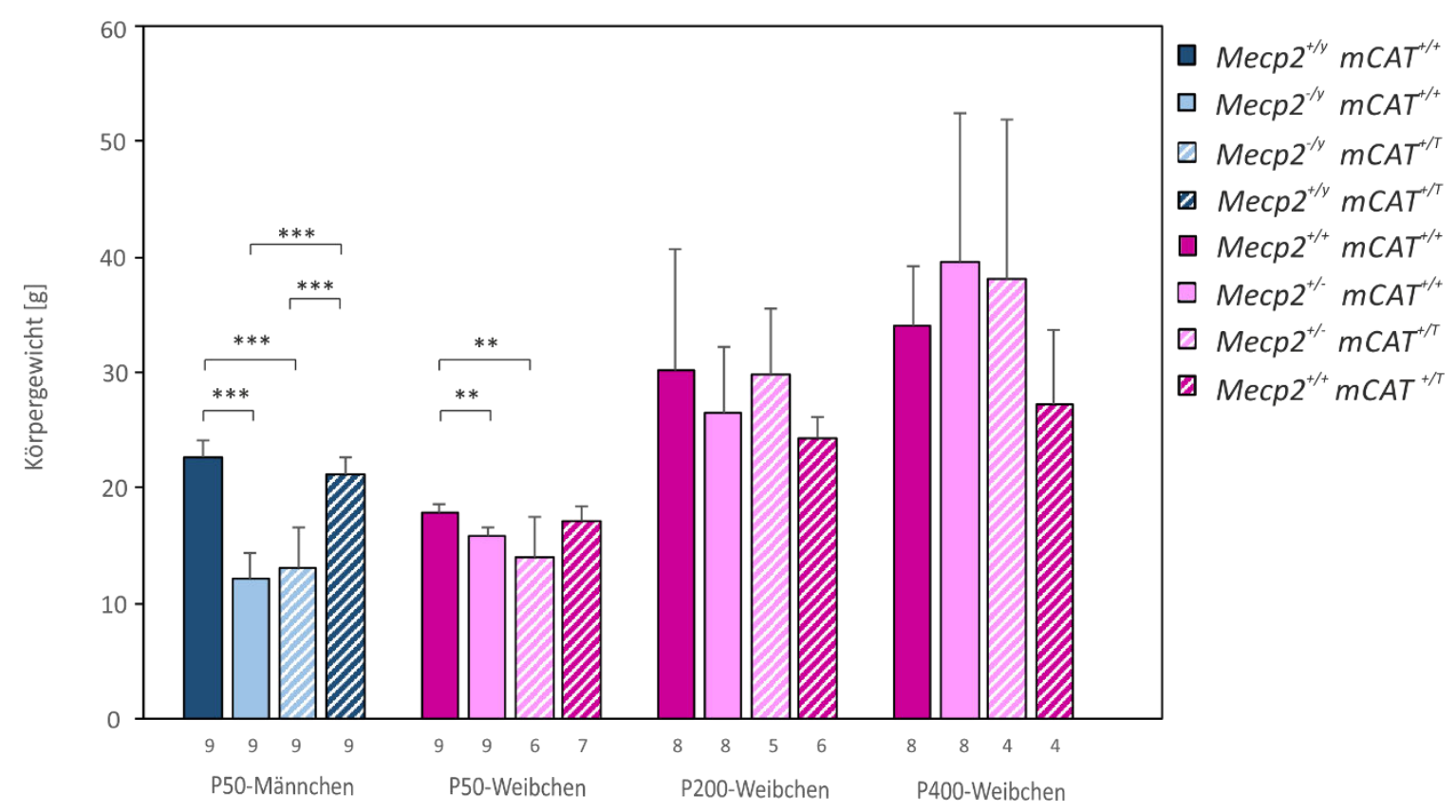

Abbildung 22: Reduziertes Körpergewicht im Rett-Syndrom in P50-Tieren beider Geschlechter

In den Altersgruppen P50 ist das Gewicht im Rett-Syndrom mit und ohne mitochondrialer KatalaseExpression im Vergleich zur WT-Kontrollgruppe signifikant reduziert. Die Anzahl der im Versuch genutzten Tiere (n) ist unter den Balken dargestellt. Die Signifikanzprüfung erfolgte mit Hilfe einer EinwegVarianzanalyse $(A N O V A)$. Für normalverteilte Daten wurde als posthoc test der Holm-Sidak Test und für nicht normalverteilte Daten der Dunn's Test genutzt. 
Ähnlich verhielt es sich bei den P50-Weibchen. Das Gewicht der heterozygoten RettWeibchen $\left(M_{e c p 2^{+/-}} m C A T^{+/+}\right)$war signifikant niedriger als das der Wildtyp-Weibchen $(\mathrm{p}<0,01)$, ebenfalls ließen sich keine signifikanten Unterschiede zwischen den heterozygoten Tieren ohne Expression der mitochondrialen Katalase und denen mit Expression des Enzyms $\left(M e c p 2^{+/-} m C A T^{+/ T}\right)$ beobachten. Außerdem konnte festgestellt werden, dass die $\operatorname{Mecp}^{+/+} m C A T^{+/ T}$ Tiere in beiden Geschlechtern keine signifikanten Gewichtsunterschiede im Vergleich zu den Wildtyp-Tieren ohne mitochondriale Katalase zeigten. In den Gruppen der 200- und 400 Tage alten Tiere konnten keine signifikanten Unterschiede zwischen den Genotyp-Gruppen in Bezug auf das Körpergewicht beobachtet werden. Im zeitlichen Verlauf ließ sich feststellen, dass die weiblichen Tiere in allen GenotypGruppen mit zunehmendem Alter signifikant an Gewicht zunahmen. So erhöhte sich das Körpergewicht der $M e c p 2^{+/+} m C A T^{+/+}$-Weibchen von 17,8 \pm 0,8 g im Alter von 50 Tagen auf 34,1 $\pm 5,1 \mathrm{~g}$ im Alter von 400 Tagen und stellte somit nahezu eine Verdopplung des Gewichtes im Lebensverlauf dar.

Im geschlechterspezifischen Vergleich zeigte sich, dass die $M e c p 2^{+/ y} m C A T^{+/+}$-Männchen 50 Tage postnatal im Mittel ein signifikant höheres Körpergewicht $(\mathrm{p}<0,01)$ aufwiesen, als die Wildtyp-Weibchen der gleichen Altersgruppe.

Im Gegenzug ließ sich bei den $M e c p 2^{-1 y} m C A T^{+/+}$-Männchen ein signifikant niedrigeres Körpergewicht $(\mathrm{p}<0,05)$ mit 12,2 $\pm 2,2 \mathrm{~g}$ als bei den heterozygoten Rett-Weibchen der Altersstufe P50 beobachten, die im Mittel ein Gewicht von 15,8 \pm 0,8 g aufwiesen. Dieser Sachverhalt zeigte sich unabhängig von der Expression der mitochondrialen Katalase.

\subsubsection{Körpergröße}

Im Hinblick auf die Analyse der Körpergröße der Tiere zeigten sich ähnliche Ergebnisse, wie bei der Gewichtsanalyse. Lediglich in den jüngeren Altersgruppen (P50) ließen sich signifikante Unterschiede verzeichnen (Abbildung 23). Die Körpergröße der männlichen P50-Mecp $2^{-/ y} m C A T^{+/+}$-Tiere $(6,9 \pm 0,3 \mathrm{~cm})$ war signifikant niedriger $(\mathrm{p}<0,001)$ als das der

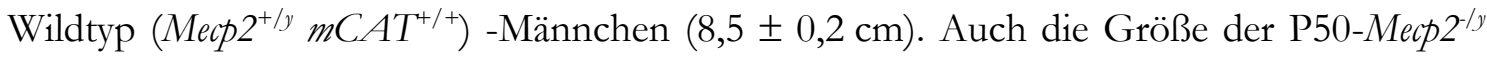
$m C A T^{+/ T}$-Männchen war signifikant reduziert $(7,1 \pm 0,8 \mathrm{~cm})$, wobei sich zwischen den knockout-Männchen mit - und ohne Expression der mitochondrialen Katalase keine signifikanten Unterschiede verzeichnen ließen. Der gleiche Sachverhalt konnte bei den P50Weibchen beobachtet werden, wobei das Signifikanzniveau bei $\mathrm{p}<0,01$ lag. Die Mecp $2^{+/ y}$ $m C A T^{+/ T}$-Tiere zeigten bei beiden Geschlechtern keine signifikanten Größenunterschiede im Vergleich zu den Wildtyp-Tieren ohne mitochondriale Katalase $\left(M e c p 2^{+/ y} m C A T^{+/+}\right)$. Es konnten keine signifikanten Unterschiede der Körpergröße zwischen den Genotypen in den Gruppen der 200- und 400 Tage alten Tiere nachgewiesen werden. 
Körpergröße

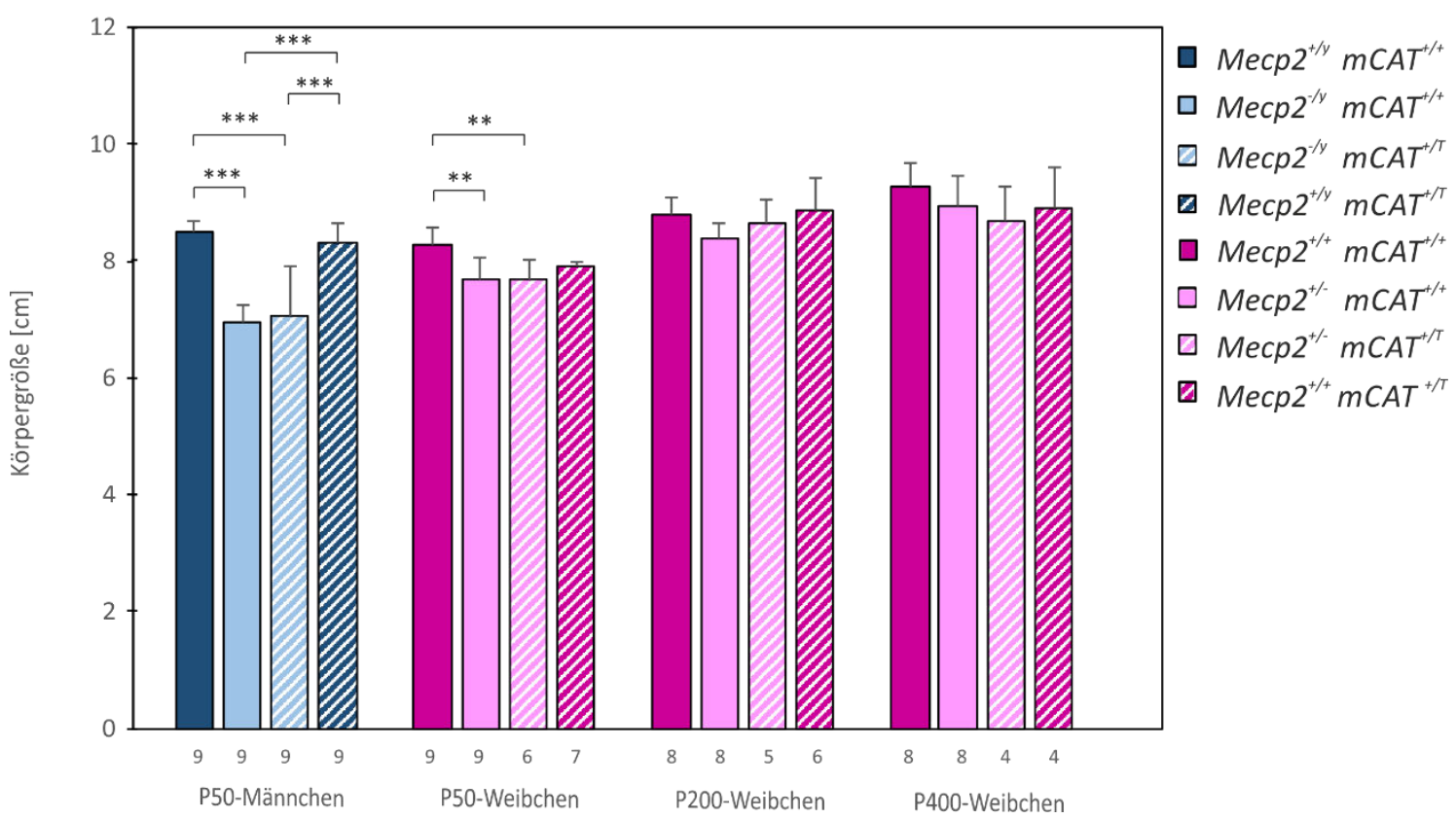

Abbildung 23: Initiale Reduktion der Körpergröße in P50-Tieren des Rett-Syndroms

In den Altersgruppen P50 ist auch die Körpergröße im Rett-Syndrom unabhängig von der mitochondrialen Katalase Expression im Vergleich zur WT-Kontrollgruppe signifikant reduziert. Die Anzahl der im Versuch genutzten Tiere (n) ist unter den Balken dargestellt. Die Signifikanzprüfung erfolgte mit Hilfe einer EinwegVarianzanalyse (ANOVA). Für normalverteilte Daten wurde als posthoc test der Holm-Sidak Test und für nicht normalverteilte Daten der Dunn's Test genutzt. 


\subsubsection{Hämatokrit}

Im Zuge der Analyse des Hämatokrits konnten bei den Weibchen sowohl zwischen den Genotyp-Gruppen als auch zwischen den unterschiedlichen Altersgruppen keine signifikanten Unterschiede beobachtet werden. Der Hämatokrit lag bei den Tieren durchschnittlich bei 40-50\%. Bei den P50-Männchen zeigte sich eine signifikante $(\mathrm{p}<0,001)$ Erhöhung des Hämatokrits bei den $M e c p 2^{-/ y} m C A T^{+/+}$und den Mecp2-ly $m C A T^{+/ T_{-}}$ Tieren im Vergleich zu den Wildtyp-Gruppen.

\section{Hämatokrit}

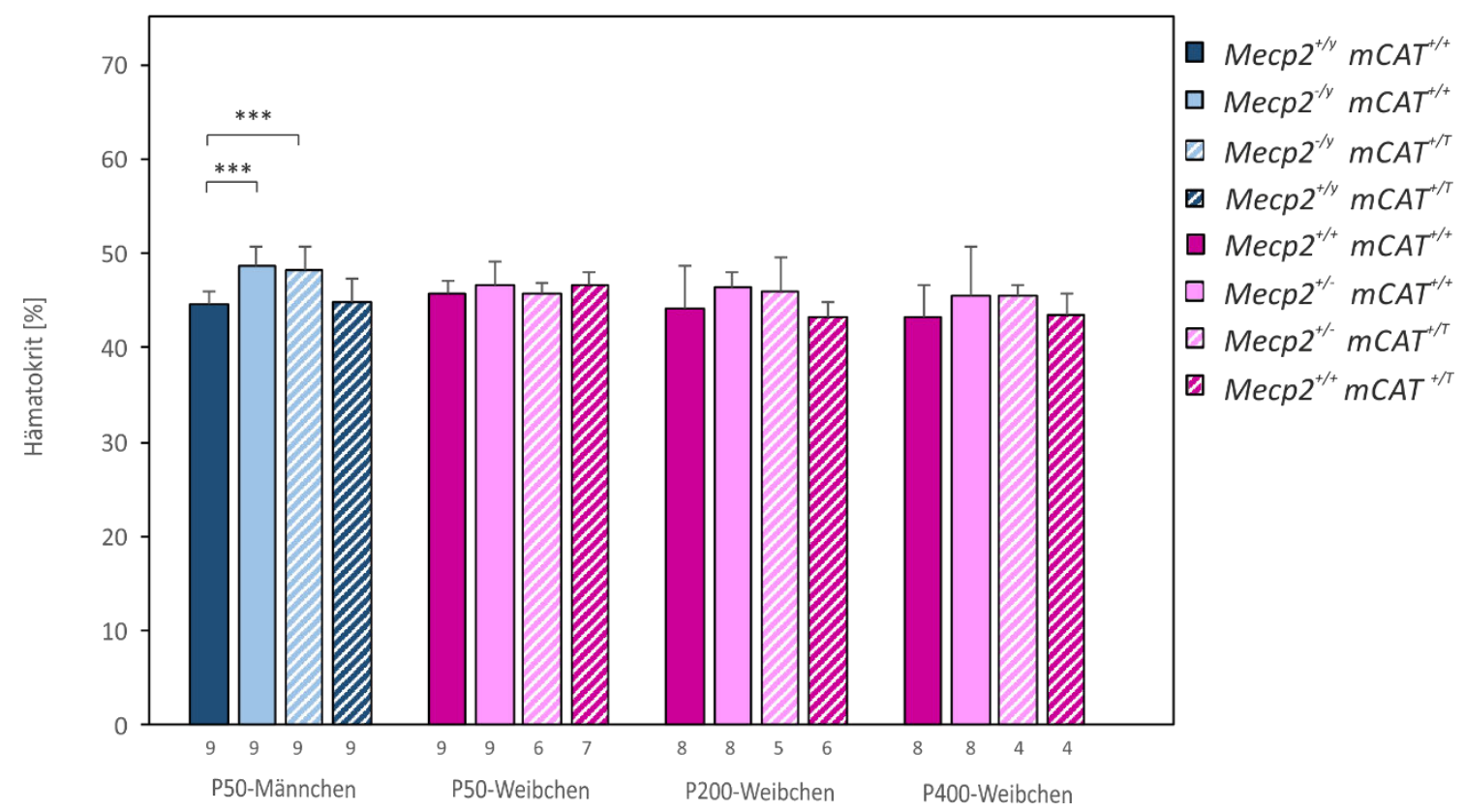

Abbildung 24: Signifikante Erhöhung des Hämatokrits bei den P50-Männchen im Rett-Syndrom

Bei den 50 Tage alten hemizygoten Rett-Männchen lag eine signifikante Erhöhung des Hämatokrits unabhängig von der mitochondrialen Katalase-Expression vor. Bei den Weibchen konnten keine signifikanten Unterschiede des Hämatokrits zwischen den Genotyp-Gruppen, Altersgruppen oder Geschlechtern beobachtet werden. Die Anzahl der im Versuch genutzten Tiere (n) ist unter den Balken dargestellt. Die Signifikanzprüfung erfolgte mit Hilfe einer Einweg-Varianzanalyse $(A N O V A)$. Für normalverteilte Daten wurde als posthoc test der Holm-Sidak Test und für nicht normalverteilte Daten der Dunn's Test genutzt. 


\subsubsection{Blutglukosespiegel}

Die Analysen des Blutglukosespiegels zeigten bei den P50-Männchen einen Trend

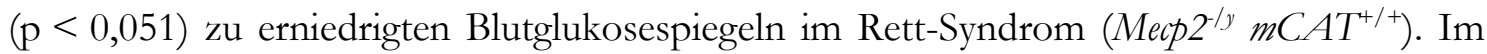
Vergleich zur Wildtyp-Gruppe mit mitochondrialer Katalase-Expression (Mecp2 $\left.2^{+/ y} m C A T^{+/ T}\right)$ ließ sich eine signifikante $(\mathrm{p}<0,05)$ Reduktion des Blutglukosespiegels in den hemizygoten Rett-Männchen $\left(M_{e c p} 2^{-1 y} m C A T^{+/+}\right)$feststellen. In den Gruppen der Weibchen konnte in den Altersgruppen P50 und P200 ein Trend ( $<$ 0,06) zu erhöhten Blutglukosespiegeln bei den heterozygoten Rett-Tieren $\left(M_{e c p} 2^{+/-} m C A T^{+/+}\right)$beobachtet werden, welcher sich im Alter von 400 Tagen jedoch nicht mehr deutlich abzeichnete.

\section{Blutglukosespiegel}

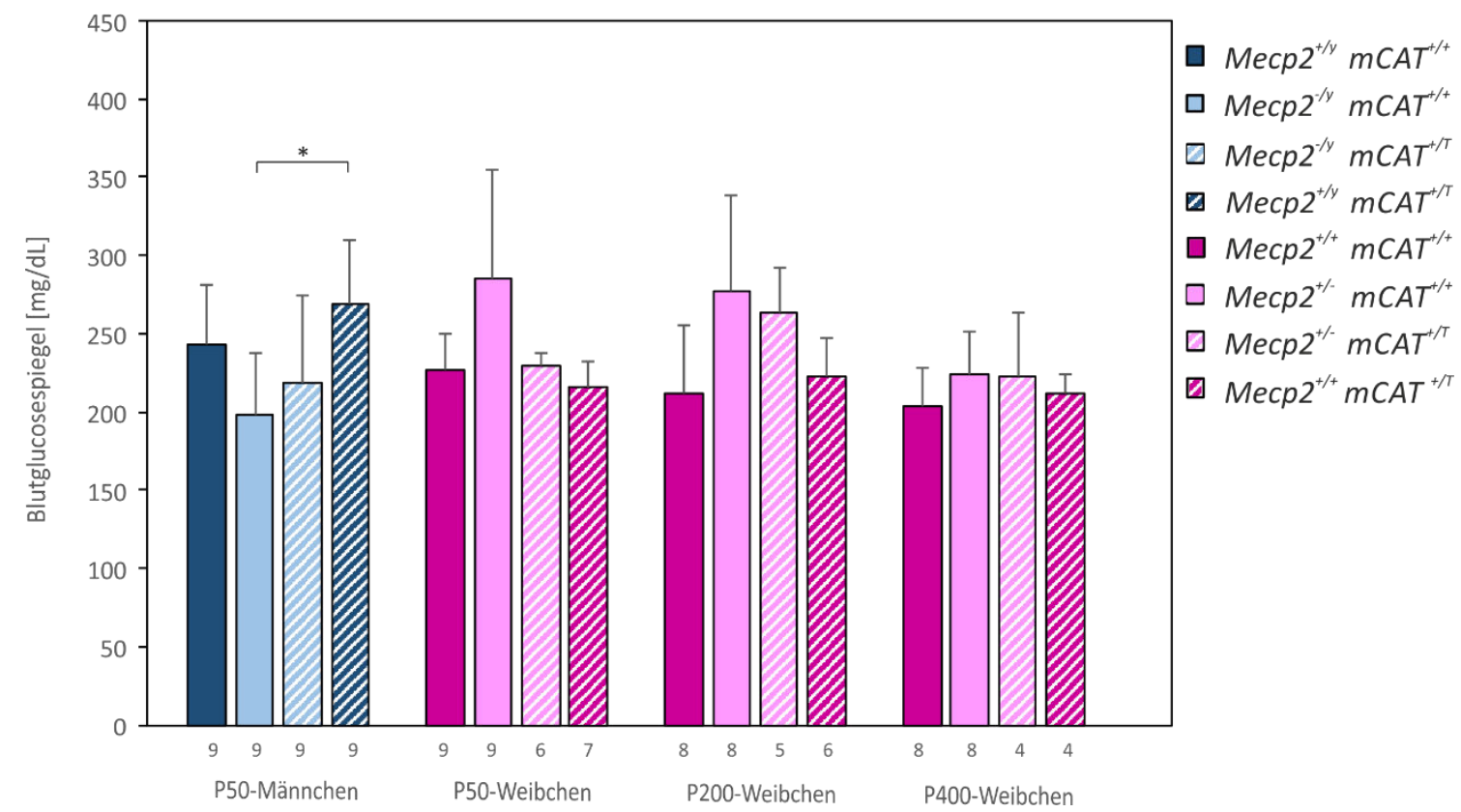

Abbildung 25: Blutglukose im Vergleich zwischen den Geschlechtern, Altersstufen und Genotypen

Dargestellt ist der Blutglukosespiegel unterschiedlicher Genotypen, beider Geschlechter und aller Altersgruppen in mg/dL. Bei den P50-Männchen zeigte sich ein Trend zu verringerten Blutglukosespiegeln im Rett-Syndrom. Bei den Weibchen zeigt sich in den Altersgruppen P50 und P200 ein Trend zu erhöhten Blutglukosespiegeln im Rett-Syndrom. Die Anzahl der im Versuch genutzten Tiere (n) ist unter den Balken dargestellt. Die Signifikanzprüfung erfolgte mit Hilfe einer Einweg-Varianzanalyse (ANOVA). Für normalverteilte Daten wurde als posthoc test der Holm-Sidak Test und für nicht normalverteilte Daten der Dunn's Test genutzt. 


\section{Diskussion}

Gegenstand dieser Arbeit war es, das Ausmaß der mitochondrialen Beteiligung an der RedoxImbalance im Rett-Syndrom zu definieren und anschließend einen therapeutischen Ansatz zur Wiedereinstellung der Redox-Homöostase zu evaluieren.

Mitochondrien gelten als größte Quelle zellulärer ROS Entstehung (Chance et al. 1979). Aufgrund der zahlreichen morphologischen und physiologischen mitochondrialen Veränderungen im Rett-Syndrom (Cornford et al. 1994) besteht die Vermutung, dass die mitochondriale Dysfunktion in direktem Zusammenhang mit der zellulären und systemischen Redox-Imbalance der Erkrankung steht (De Felice et al. 2009; Pecorelli et al. 2011; Großer et al. 2012). Ein Großteil der Superoxidderivate, die im Zuge der Atmungskette und der mitochondrialen Stoffwechselwege entstehen, wird von den Enzymen Superoxiddismutase 1 und 2 in $\mathrm{H}_{2} \mathrm{O}_{2}$ umgewandelt (McCord und Fridovich 1969). Die Tatsache, dass $\mathrm{H}_{2} \mathrm{O}_{2}$ in der Lage ist aus dem Intermembranraum und der mitochondrialen Matrix in das Zytosol zu diffundieren und somit gut zu detektieren ist, wurde im Rahmen dieser Arbeit genutzt, um die mitochondriale $\mathrm{H}_{2} \mathrm{O}_{2}$-Freisetzung frisch isolierter Mitochondrien zu untersuchen und damit das Ausmaß der mitochondrialen Beteiligung an der Redox-Imbalance im Rett-Syndrom beurteilen zu können.

\subsection{Validierung des Messverfahrens}

\subsubsection{Qualitätskontrolle der isolierten Mitochondrien}

Im Rahmen der Western-Blots zur Analyse der Qualität der isolierten Mitochondrien konnte festgestellt werden, dass sich geringfügige Anteile an Peroxisomen, endoplasmatischem Retikulum und zytosolischen Proteinen in der Mitochondriensuspension nachweisen ließen. Obwohl Anteile dieser Zellorganellen geringfügig vorhanden waren, konnte aufgezeigt werden, dass sich der größte Anteil dieser Organellen in den drei Zentrifugationsschritten von den Mitochondrien separierte. Es handelt sich daher in dem genutzten Küvetten-Assay nicht um hochreine Mitochondriensuspensionen, sondern eher um Mitochondrienangereicherte Suspensionen. Dennoch war die Dichte der Mitochondrien-Fraktion nach densitometrischer Analyse und Normierung auf den zytosolischen Marker GAPDH signifikant am höchsten, sodass davon ausgegangen werden kann, dass die Mehrheit der im Küvetten-Assay genutzten Proteine Mitochondrien darstellen.

Um hochreine Mitochondriensuspensionen im Rahmen der Proteomik zur Ermittlung und Quantifizierung von Proteinen $\mathrm{zu}$ erhalten, stellt die Ultrazentrifugation auf einem Dichtegradienten die Methode der Wahl dar (Afanasyeva et al. 2018). Zur Aufreinigung der mitochondrialen Fraktion wurde unter anderem die Zentrifugation auf einem SucroseGradienten beschrieben, allerdings konnten durch die hypertonen Bedingungen und den erhöhten zeitlichen Rahmen dieser Methodik die mitochondriale metabolische Aktivität 
nicht in vollem Umfang aufrechterhalten werden (Clark und Nicklas 1970). Andere Protokolle beschreiben die Isolation neuronaler Mitochondrien mittels Percoll-GradientenZentrifugation (Sims 1990). Im Rahmen dieses Protokolls ist es möglich, reine Mitochondrien-Fraktionen zu erhalten, die zwei bis drei Stunden nach Isolation in ihrer funktionellen Aktivität unbeeinträchtigt bleiben (Kristian 2010). Da im Rahmen des genutzten Küvetten-Assays vor allem die metabolische Aktivität der isolierten Mitochondrien von Bedeutung war, wurde sich für ein Isolationsverfahren entschieden, bei dem die physiologische Mitochondrienfunktion möglichst wenig beeinträchtigt wird und das Isolationsverfahren möglichst wenig Zeit in Anspruch nimmt. Zusätzlich sollte das Protokoll ermöglichen, auch nach Isolation drei bis vier Stunden Messungen mit metabolisch aktiven und unbeeinträchtigten Mitochondrien durchführen zu können, da durch das Betrachten aller Hirnregionen eines Tieres ein hoher Stichprobenumfang und somit auch eine erhöhte zeitliche Dauer der Messungen resultierte. Aus diesem Grund wurde sich im Rahmen der fluoreszenspektrometrischen Messungen für das Verfahren der DifferentialgeschwindigkeitZentrifugation zur Isolierung der Mitochondrien entschieden.

\subsubsection{Kontrollen zur Überprüfung der Validität und Reliabilität des Küvetten- Assays}

Im verwendeten Küvetten-Assay wird die Reaktion des Farbstoffes Amplex UltraRed mit $\mathrm{H}_{2} \mathrm{O}_{2}$ zu dem fluoreszierenden Farbstoff Amplex UltroxRed (Resorufin) unter Katalyse des Enzymes horseradish peroxidase genutzt, um die mitochondriale $\mathrm{H}_{2} \mathrm{O}_{2}$-Freisetzung zu detektieren (Zhou et al. 1997). Da der Farbstoff Amplex UltraRed weder in der Anwesenheit von anderen reaktiven Sauerstoffspezies noch in der Anwesenheit reaktiver Stickstoffspezies zu Resorufin reagiert, stellt er einen spezifischen Sensor zur $\mathrm{H}_{2} \mathrm{O}_{2}$-Detektion dar (Song et al. 2001). Dieser spezifische Sensor wurde daher ausgewählt, um diejenigen Mengen an $\mathrm{H}_{2} \mathrm{O}_{2}$ quantifizieren zu können, die unter zellulären Bedingungen aus den Mitochondrien in das Zytosol diffundieren und somit die Zellfunktion im Rett-Syndrom beeinflussen könnten.

Um die Reliabilität und Sensitivität des Amplex UltraRed Küvetten-Assays zu validieren wurden zahlreiche Kontrollen sowie Kalibrierungen durchgeführt. Im Rahmen der $\mathrm{H}_{2} \mathrm{O}_{2}$ Kalibrierung konnte gezeigt werden, dass Konzentrationen von $20 \mathrm{nM}$ bis $500 \mathrm{nM}$ reproduzierbar und valide detektiert werden konnten.

Trotz der Anwesenheit der respiratorisch aktiven Mitochondrien konnte in der Abwesenheit von HRP kein Anstieg der Fluoreszenzintensität registriert werden, sodass eine unkontrollierte Oxidation des Sensors Amplex UltraRed durch andere Komponenten des Küvetten-Assays ausgeschlossen werden kann. Resorufin entsteht jedoch auch artifiziell durch Belichtung des Farbstoffes Amplex UltraRed (Zhao et al. 2012). Aus diesem Grund wurde der Farbstoff im Rahmen der Experimente stets vor hohen Belichtungszeiten- und Intensitäten geschützt und zudem noch einer Leerwert (Blank) Korrektur unterzogen. 
$\mathrm{Da}$ in 3.1.1 gezeigt werden konnte, dass es sich bei den isolierten Mitochondrien eher um Mitochondrien-angereicherte Suspensionen handelte, wurden Kontrollmessungen durchgeführt, die validieren, dass die registrierte $\mathrm{H}_{2} \mathrm{O}_{2}$-Freisetzung tatsächlich mitochondrialen Ursprungs ist. In der Abwesenheit der mitochondrialen Substrate Pyruvat, Malat und Succinat war die $\mathrm{H}_{2} \mathrm{O}_{2}$-Freisetzung um $85 \%$ im Vergleich zur Kontrollgruppe gesenkt, was bestätigt, dass in der Tat der mitochondriale Metabolismus für die $\mathrm{H}_{2} \mathrm{O}_{2}$ Produktion verantwortlich ist. Diese Beobachtung konnte zusätzlich durch den Effekt des Entkopplers CCCP bestätigt werden, denn durch die Entkopplung des mitochondrialen Protonengradienten konnte die $\mathrm{H}_{2} \mathrm{O}_{2}$-Freisetzung um $59 \%$ gesenkt werden. Dies ist darauf zurückzuführen, dass die mitochondriale Superoxidanionen-Produktion abhängig vom elektrochemischen Gradienten ist, sodass die ROS-Produktion durch Entkopplung dieses Gradienten absinkt (Boveris und Chance 1973; Korshunov et al. 1997). Diese Versuche bestätigen, dass die in den Western-Blots gefundenen Anteile anderer Zellorganellen für den Amplex UltraRed Assay funktionell nicht von Bedeutung sind.

\subsection{Mitochondriale $\mathrm{H}_{2} \mathrm{O}_{2}$-Freisetzung}

\subsubsection{Mitochondriale $\mathrm{H}_{2} \mathrm{O}_{2}$-Freisetzung männlicher und weiblicher Wildtyp-Tiere}

Im Zuge dieser Arbeit konnte festgestellt werden, dass die $\mathrm{H}_{2} \mathrm{O}_{2}$-Freisetzung zwischen den verschiedenen Hirnregionen erheblich differierte, und dass außerdem entwicklungs- und altersspezifische Unterschiede zu beobachten waren. Die höchste $\mathrm{H}_{2} \mathrm{O}_{2}$-Freisetzung konnte im Kortex nachgewiesen werden, gefolgt von Mittelhirn und Hirnstamm. Die geringsten Freisetzungsraten wurden im Hippocampus nachgewiesen, gefolgt vom Kleinhirn.

Die Neurone des zentralen Nervensystems unterscheiden sich zwischen den Hirnregionen nicht nur in ihrer Größe und Anzahl sowie dem Ausmaß ihrer dendritischen und synaptischen Verzweigungen, sondern auch in ihrem spezifischen metabolischen Bedarf. So können die Unterschiede der $\mathrm{H}_{2} \mathrm{O}_{2}$-Freisetzung zwischen den Hirnregionen auf die unterschiedliche mitochondriale Aktivität der Regionen, sowie auf genetische und proteomische Variabilitäten zurückgeführt werden (Wang et al. 2009; Wang und Michaelis 2010). In genomischen Analysen konnte festgestellt werden, dass Neurone, die empfindlich gegen oxidativen Stress reagieren, wie die des Hippocampus oder Kleinhirns, eine niedrigere Expression der Gene aufweisen, die in der Energiegewinnung von Bedeutung sind (Wang et al. 2009). Somit lässt sich vermuten, dass die relativ niedrigere mitochondriale $\mathrm{H}_{2} \mathrm{O}_{2}$ Freisetzung dieser beiden Regionen durch veränderte metabolische Aktivität zustande kommt.

Transkriptom-Analysen des Mäusegehirns zeigen, dass die geringsten Unterschiede in der Gen-Expression zwischen den Hirnregionen zum Zeitpunkt der Geburt zu beobachten sind. Diesem Zustand folgt anschließend eine regionale Spezialisierung der Hirngewebe während der postnatalen Entwicklung (Liscovitch und Chechik 2013). In Bezug auf die 
unterschiedlichen Entwicklungs- und Altersstadien der Mäuse konnte die höchste $\mathrm{H}_{2} \mathrm{O}_{2}$ Freisetzung in der postnatalen Phase P50 detektiert werden. Ein starker Anstieg der Mitoseaktivität und der Hirnentwicklung kann in frühen Entwicklungsphasen nach der Geburt beobachtet werden, sodass sich vermuten lässt, dass ein erhöhter metabolischer Bedarf in dieser Phase mit den erhöhten mitochondrialen $\mathrm{H}_{2} \mathrm{O}_{2}$-Freisetzungen korreliert (Guo et al. 2019). Zudem ist die neuronale Differenzierung von einem metabolischen Wechsel der weniger effizienten Glykolyse zur Oxidativen Phosphorylierung begleitet (Son und Han 2018). Mit diesem Wechsel und der steigenden Expression mitochondrialer Komplexe, insbesondere des Komplex V, der ATP-Synthase, nimmt das mitochondriale Membranpotential ab und somit auch die mitochondriale ROS-Produktion (Liemburg-Apers et al. 2015). Die Abnahme der $\mathrm{H}_{2} \mathrm{O}_{2}$-Freisetzung in der Altersstufe P200 lässt sich wahrscheinlich ebenfalls auf diesen Zusammenhang zurückführen. Mit zunehmendem Alter akkumuliert dann der oxidative Schaden mitochondrialer Proteine und führt zu einem weniger effizienten mitochondrialen Metabolismus, einer Abnahme der mitochondrialen antioxidativen Kapazität und einem Anstieg der mitochondrialen ROS-Produktion (Sastre et al. 2000; Navarro und Boveris 2004). In denen im Rahmen dieser Arbeit erhobenen Daten wird dies durch die leicht erhöhte $\mathrm{H}_{2} \mathrm{O}_{2}$-Freisetzung in der Altersstufe $\mathrm{P} 400$ bestätigt.

In Bezug auf geschlechtsspezifische Unterschiede konnte ein Hirnregionen-übergreifender Trend zu höheren $\mathrm{H}_{2} \mathrm{O}_{2}$-Freisetzungen bei den Männchen im Vergleich zu den Weibchen beobachtet werden. Weibliche Tiere scheinen somit unter physiologischen Bedingungen resistenter gegenüber oxidativem Stress zu sein. Dies lässt sich zum einen auf die geschlechtsspezifischen Unterschiede der NADPH-Oxidase-Aktivität zurückführen, zum anderen auf die antioxidativen Eigenschaften des Östrogens (Kander et al. 2017).

Im Einklang mit den Ergebnissen dieser Arbeit wurde auch für isolierte Mitochondrien weiblicher Ratten, die 4-6 Monate alt waren, von einer niedrigeren $\mathrm{H}_{2} \mathrm{O}_{2}$-Freisetzung im Vergleich zu den männlichen Ratten berichtet (Borras et al. 2003). Ein Unterschied im mitochondrialen Sauerstoffverbrauch lag jedoch nicht vor. In dieser Studie kam es durch Ovarektomie zu einer Steigerung der $\mathrm{H}_{2} \mathrm{O}_{2}$-Freisetzung von über $60 \%$ in Mitochondrien aus der Leber und dem Gehirn, sodass letztlich kein signifikanter Unterschied zwischen männlichen und weiblichen Tieren bestand. Substitution von Östrogen konnte die Peroxidfreisetzung schließlich wieder auf den Ausgangszustand senken. Außerdem zeigen andere Studien, dass die Gluthathionperoxidase-Aktivität bei weiblichen Ratten 80 \% höher als bei den Männchen der gleichen Altersgruppe ist (Pinto und Bartley 1969). 


\subsubsection{Erhöhte mitochondriale $\mathrm{H}_{2} \mathrm{O}_{2}$-Freisetzung im Rett-Syndrom}

Sowohl die Redox-Imbalance als auch der daraus resultierende oxidative Stress scheinen einen großen Einfluss auf die Pathogenese und Progression des Rett-Syndroms zu nehmen (De Felice et al. 2009; Großer et al. 2012).

Bereits 1987 konnte eine Reduktion des Vitamin C- und GSH-Gehaltes in Post-mortemGewebe humaner Rett-Patientinnen festgestellt werden (Sofic et al. 1987). Außerdem wurde eine Abnahme des GSH-Spiegels in Fibroblasten der Haut von Rett-Patientinnen nachgewiesen (Signorini et al. 2014). Da das GSH/GSSG-Verhältnis ein Indikator des zellulären Redox-Satus ist, deutet die Abnahme auf eine veränderte Redox-Homoöstase im Rett-Syndrom hin.

In Mausmodellen des Rett-Syndroms konnte bereits in hemizygoten Mecp $2^{-1 y}$-Männchen ein Anstieg oxidativer Stressmarker sowohl im Blutplasma, als auch im Hirngewebe festgestellt werden, sodass die Vermutung besteht, dass es durch die veränderte Redox-Balance zu oxidativen Gewebeschädigungen kommt (De Felice et al. 2014). Funktionelle RedoxBildgebungsstudien unserer Arbeitsgruppe bestätigen zudem subzelluläre RedoxVerhältnisse zugunsten des oxidierten Zustandes sowie eine überschießende zelluläre Antwort in Bezug auf oxierende Redox-Veränderungen (Großer et al. 2012; Bebensee et al. 2017; Can et al. 2019) .

Die molekularen Mechanismen der zellulären Redox-Imbalance im Rett-Syndrom sind noch nicht vollständig geklärt. Zur Zeit besteht der Konsens, dass sowohl die mitochondriale als auch die extramitochondriale Produktion reaktiver Sauerstoffspezies eine Rolle spielt (Großer et al. 2012; Cervellati et al. 2015; Can et al. 2019). Darüber hinaus scheint die zelluläre Kapazität der ROS-Pufferung im Rett-Syndrom geschwächt zu sein (Formichi et al. 1998; Sierra et al. 2001; Gold et al. 2014). Die Aktivitäten der Schlüsselenzyme Gluthathionperoxidase, SOD und Thioredoxinreduktase sind im Rett-Syndrom signifikant erniedriegt (Cervellati et al. 2015), sodass eine Akkumulation reaktiver Sauerstoffspezies begünstigt wird. Es ist bekannt, dass ROS in hohen Konzentrationen Zellschäden verursachen, insbesondere an Nukleinsäuren, Lipiden und Proteinen (Halliwell und Gutteridge 1984b; Valko et al. 2007). Um solche oxidierten Zellstrukturen wie beschädigte Proteine zellulär zu eliminieren, wird eine physiologische Proteasomenaktivität benötigt. Es wurde jedoch festgestellt, dass diese sowohl bei den heterozygoten Mecp $2^{+/}$-Weibchen, als auch bei den hemizygoten $M e c p 2^{-1 y}$-Männchen siginifikant reduziert ist (Cervellati et al. 2015). Eine dadurch bedingte Akkumulation oxidativ-modifizierter Proteine könnte somit potentiell Einfluss auf die Progression des Rett-Syndroms haben.

In früheren Redox-Studien wurden lediglich spezifische Hirnregionen einzeln oder aber das gesamte Gehirn betrachtet. Im Rahmen dieser Arbeit konnte der mitochondriale Einfluss auf die Redox-Imbalance im Rett-Syndrom Hirnregionen-übergreifend untersucht werden, sowie der Einfluss des Alters und des Geschlechtes eindeutig nachgewiesen werden. Teile dieser Daten wurden bereits publiziert (Adebayo et al. 2020). Die Analysen zeigen 
eindrucksvoll, dass in allen Hirnregionen des Mausgehirns die mitochondriale $\mathrm{H}_{2} \mathrm{O}_{2}$ Freisetzung deutlich erhöht ist. Dieser Zustand ist bereits bei den P50-Tieren hochsignifikant in allen Hirnregionen und persistiert für die gesamte Lebensdauer bis P400.

Die genauen molekularen Ursachen für die erhöhte mitochondriale $\mathrm{H}_{2} \mathrm{O}_{2}$-Freisetzung müssen im Detail noch weiter untersucht werden. Bekannt ist jedoch, dass die Orte der größten mitochondrialen ROS-Freisetzung an den Komplexen I und III zu lokalisieren sind, wobei Komplex I Superoxidanionen in die Mitochondrienmatrix und Komplex III Superoxidanionen sowohl in die Mitochondrienmatrix, als auch in den Intermembranraum entlässt (Chen et al. 2003; Kudin et al. 2004; Brand 2010). Unter physiologischen Bedingungen ist die Menge des mitochondrial produzierten Superoxides abhängig von der Substratverfügbarkeit. Pyruvat und Malat sind Substrate des vorwärtsgerichteten Elektronentransportes innerhalb der Atmungskette. Die Verstoffwechselung dieser beiden Substrate führt zu niedriegen Superoxidproduktionsraten (Votyakova und Reynolds 2001). An Komplex II können höhere Superoxidmengen produziert werden, und zwar sowohl durch vorwärtsgerichteten Elektronentransport über das Substrat Succinat, als auch über rückläufigen Elektronentransport über den reduzierten Ubichinonpool (McLennan und Degli Esposti 2000; Quinlan et al. 2012).

In früheren Studien wurden bereits erhöhte mitochondriale Atmungsraten unter Einfluss des Komplex-II-Substrates Succinat beobachtet (Can et al. 2019). Zu beachten ist jedoch, dass die Mitochondrien sowohl in dieser früheren Studie, als auch die in dieser Arbeit verwendeten Mitochondrien aus einer heterogenen, neuronalen Zellpopulation stammen. Zur gezielten Untersuchung Zelltypen-spezifischer Unterschiede müssten optische Verfahren wie genetisch-codierte Redoxindikatoren genutzt werden.

Weiterführend konnte für Mitochondrien des gesamten Gehirns, die aus einem Jahr alten Mecp2-308-Rett-Weibchen isoliert wurden ebenfalls eine erhöhte $\mathrm{H}_{2} \mathrm{O}_{2}$-Freisetzung beobachtet werden (De Filippis et al. 2015). Diese Daten gehen einher mit der Feststellung dieser Dissertation, dass im Rett-Syndrom in allen Hirnregionen, allen Alterststufen und beiden Geschlechtern eine erhöhte $\mathrm{H}_{2} \mathrm{O}_{2}$-Freisetzung nachzuweisen ist.

Im geschlechtsspezifischen Vergleich zeigte sich, dass die mitochondriale $\mathrm{H}_{2} \mathrm{O}_{2}$-Freisetzung der heterozygoten Weibchen signifikant erhöht ist im Vergleich zu den hemizygoten Männchen. Atmungsmessungen konnten nachweisen, dass die Mitochondrien der RettWeibchen stärker Komplex II-abhängig sind als die Rett-Männchen (Khalifa et al. 2017). Die Tatsache, dass von einer Komplex II-Dysfunktion im Rett-Syndrom ausgegangen wird (De Filippis et al. 2015; Can et al. 2019) könnte die erhöhte $\mathrm{H}_{2} \mathrm{O}_{2}$-Freisetzung bei den RettWeibchen somit erklären.

In Bezug auf die $\mathrm{H}_{2} \mathrm{O}_{2}$-Freisetzung der unterschiedlichen Altersgruppen ließ sich feststellen, dass sowohl bei den Wildtyp-Tieren, als auch bei den Rett-Tieren zunächst ein leichter Abfall der $\mathrm{H}_{2} \mathrm{O}_{2}$-Freisetzung von P50 auf P200 zu beobachten war, es jedoch mit zunehmendem Alter bei den P400-Tieren zu einem erneuten Anstieg kam. Diese Daten werden bestätigt 
von der Theorie, dass es im Alter zu einer Steigerung der ROS-Freisetzung kommt (Harman 1956; Harman 1973; Harman 2003). In weiterführenden, noch nicht publizierten Studien der Arbeitsgruppe wurde festgestellt, dass fast alle Wildtyp-Weibchen die Altersstufe P400 erreichen, wohingegen lediglich ein Drittel der Mecp $2^{+/}$-Weibchen dieses Alter erreichen. Somit muss berücksichtigt werden, dass die Tiere mit stark ausgeprägten phänotypischen Befunden bereits vor den geplanten Messungen versterben und somit die Ergebnisse in der $\mathrm{H}_{2} \mathrm{O}_{2}$-Freisetzung dieser Altersgruppe durch die unvermeidbare Verzerrung möglicherweise beeinflusst werden.

\subsubsection{Positiver Einfluss einer mitochondrialen Katalase auf die Redox-Imbalance im Rett-Syndrom}

Im Zuge dieses Forschungsprojektes wurde eine erhöhte mitochondriale $\mathrm{H}_{2} \mathrm{O}_{2}$-Freisetzung im Rett-Syndrom in allen Hirnregionen und Altersstufen, sowohl bei den heterozygoten Weibchen, als auch bei den hemizygoten Männchen bewiesen. Die Bedeutung von $\mathrm{H}_{2} \mathrm{O}_{2}$ im Rahmen der zellulären Signalübertragung konnte bereits in zahlreichen Studien festgestellt werden (Doan et al. 1994; D'Autreaux und Toledano 2007). Die Tatsache, dass erste Studien nachweisen konnten, dass eine veränderte $\mathrm{H}_{2} \mathrm{O}_{2}$-Homöostase auf die synaptische Plastizität in Form von Inhibition und Stimulation der Langzeitpotenzierung und der Langzeitdepression Einfluss nimmt (Kamsler und Segal 2003), suggeriert die Notwendigkeit und Relevanz eines therapeutischen Ansatzes zur Wiedereinstellung der zellulären neuronalen Redox-Imbalance im Rett-Syndrom. Daher wurde das Ziel verfolgt, einen therapeutischen Ansatz zur Wiederherstellung der Redox-Homöostase zu evaluieren, indem transgene Tiere, die eine mitochondriale Katalase exprimieren in das Mausmodell des RettSyndroms eingekreuzt wurden.

Tatsächlich gelang es, durch die mitochondriale Katalase die $\mathrm{H}_{2} \mathrm{O}_{2}$-Freisetzung in allen Hirnregionen bis zu dem Alter P200 erfolgreich zu senken.

Im Rahmen des zellulären Metabolismus kommt es vor allem mitochondrial zu erhöhten $\mathrm{H}_{2} \mathrm{O}_{2}$-Freisetzungen, da Mitochondrien eine der Hauptquellen zellulärer ROS-Entstehung darstellen (Boveris et al. 1972). Das Glutathion-Glutathionperoxidase-System, welches im Mitochondrium gemeinsam mit der Superoxiddismutase für die Redox-Balance zuständig ist, ist jedoch durch die Level an GSH und NADPH limitiert, sodass es bei erhöhten $\mathrm{H}_{2} \mathrm{O}_{2}$ Freisetzungen und bereits veränderten Redoxbedingungen ineffizient wird (Bai und Cederbaum 2001). Durch die Akkumulation von $\mathrm{H}_{2} \mathrm{O}_{2}$ oder die Ausbildung von Hydroxylanionen kann es anschließend zu mitochondrialen Schäden kommen.

Das Enzym Katalase ist als regulatives Enzym der Redox-Homöostase vorallem in Peroxisomen lokalisiert und katalysiert den Abbau von $\mathrm{H}_{2} \mathrm{O}_{2}$ zu molekularem Sauerstoff und Wassser (De Duve und Baudhuin 1966). Anders als das Glutathion-System, ist die Katalase auch in der Abwesenheit von Elektronendonatoren und somit auch im veränderten RedoxMilieu, wie im Rett-Syndrom beobachtet, in der Lage, $\mathrm{H}_{2} \mathrm{O}_{2}$ abzubauen (Dai et al. 2017). 
Bereits 1978 wurde der protektive Effekt einer mitochondrialen Katalase auf oxidative Schäden analysiert. Es wurde festgestellt, dass sich in kardialen Mitochondrien von Ratten eine Katalase in der Mitochondrienmatrix befindet (Nohl und Hegner 1978). Diese Katalase ist für die Eliminierung von ca. $57 \%$ des in der Mitochondrienmatrix produzierten $\mathrm{H}_{2} \mathrm{O}_{2}$ verantwortlich (Bai und Cederbaum 2001) und für eine Reduktion der mitochondrialen Lipidperoxidation (Radi et al. 1993). Auch in Zellkulturen ist durch Expression einer mitochondrialen Katalase ein Schutz gegen Oxidantien-induzierte Zytotoxizität belegt, weil die mitochondriale Katalase die Zellen vor Oxidantien-induziertem Verlust des physiologischen Membranpotentials schützt (Bai und Cederbaum 2001). Analysen des zellulären Redox-Status in Muskelzellen transgener $m C A T$-Mäuse zeigten zudem ein Redoxgleichgewicht, das zu mehr reduzierten Bedingungen verschoben ist. Aufgrund eines erhöhten GSH/GSSG-Verhältnisses ist von einer erhöhten Redox-Toleranz in den Tieren, die eine mitochondriale Katalase exprimieren, auszugehen (Ryan et al. 2016).

Bei den männlichen P50-Tieren, die am Rett-Syndrom erkrankt waren, wurde die $\mathrm{H}_{2} \mathrm{O}_{2}$ Freisetzung durch die mitochondriale Katalase-Expression signifikant auf das WildtypNiveau gesenkt, wohingehend bei den heterozygoten Rett-Weibchen der Altersgruppe P50 die $\mathrm{H}_{2} \mathrm{O}_{2}$-Freisetzung durch die mitochondriale Katalase-Expression zwar signifikant gesenkt werden konnte, jedoch nicht auf Wildtyp-Niveau reduziert wurde. Dies wird durch die Tatsache erklärt, dass im Rahmen dieser Arbeit bereits gezeigt wurde, dass die absolute $\mathrm{H}_{2} \mathrm{O}_{2}$-Freisetzung im Rett-Syndrom bei den weiblichen Tieren signifikant höher ist, als bei den hemizygoten Männchen und somit die Vermutung besteht, dass der zelluläre Redoxstatus bei den Weibchen stärker zugunsten oxidativer Bedingungen verändert ist, als bei den Männchen.

Im altersspezifischen Vergleich zeigte sich, dass ein signifikanter therapeutischer Effekt der mitochondrialen Katalase-Expression bis zur Altersgruppe P200 nachzuweisen war. In der Altersgruppe P400 wurde keine Reduktion der mitochondrialen $\mathrm{H}_{2} \mathrm{O}_{2}$-Freisetzung durch die mitochondriale Katalase erzielt, im Kortex ließ sich sogar eine signifikante Erhöhung der $\mathrm{H}_{2} \mathrm{O}_{2}$-Freisetzung im Vergleich zu den erkrankten Tieren ohne mitochondriale Katalase beobachten.

Im Zuge der mitochondrialen Theorie des Alterns wurde bereits festgestellt, dass es im Rahmen des mitochondrialen Metabolismus zur Entstehung radikaler Sauerstoffspezies kommt und deren Akkumulation im zeitlichen Verlauf zu oxidativ bedingten somatischen Mutationen der mitochondrialen DNA führt. Veränderungen des mitochondrialen Genoms resultieren dann möglicherweise in Dysfunktionen der Atmungskette, welche wiederum eine erhöhte ROS-Freisetzung zur Folge haben (Harman 1983; Linnane et al. 1989; Wei 1992; Richter 1995). Somit kann sich die ROS-Freisetzung im zeitlichen Verlauf selbst verstärken. Im Rett-Syndrom konnte im Rahmen dieser Arbeit bereits eine erhöhte $\mathrm{H}_{2} \mathrm{O}_{2}$-Freisetzung im Vergleich zu den Wildtyp-Kontrollen nachgewiesen werden. Außerdem konnte wie bereits erwähnt festgestellt werden, dass diese durch die Expression der mitochondrialen 
Katalase bei den Weibchen nicht auf Wildtyp-Niveau gesenkt werden kann. Somit ist zwar ein therapeutischer Effekt durch verringerte $\mathrm{H}_{2} \mathrm{O}_{2}$-Freisetzungen in den Altersstufen P50 und P200 zu beobachten, dennoch bleiben die Redox-Bedingungen im leicht oxidierten Zustand bestehen. Allerdings kommt es im zeitlichen Verlauf durch das Fortbestehen dieser oxidativ-wirkenden Zustände widererwartend nicht zu einer weiteren Erhöhung der $\mathrm{H}_{2} \mathrm{O}_{2}$ Freisetzung, sodass die Vermutung, dass die mitochondriale Katalaseaktivität ihr Kapazitätsmaximum erreicht, nicht bestätigt werden kann. Eine mögliche Erklärung für den nachlassenden therapeutischen Effekt könnte allerdings eine Abnahme der Expression des Enzyms im Alter sein. Eindeutig zu klären wäre dies durch entsprechende Expressionsanalysen der Katalase in den älteren Tieren.

Die DNA der mitochondrialen Katalase (cDNA) in dem genutzten $m$ CAT-Mausmodell wurde über einen Expressionsvektor in das Genom integriert, der über einen CAGPromotor die Expression der Katalase reguliert (Schriner et al. 2005). Dieser enthält das Cytomegalovirus (CMV) early enhancer element (C), einen chicken $\beta$-actin promotor inklusive des ersten Introns des Gens (A) sowie die Spleißstelle des $3^{‘}$ Endes des rabbit-beta-globin Gens (G) (Niwa et al. 1991). Die genutzte Vektorsequenz konnte nach erfolgreicher Integration in das Wirtsgenom über mehrere Monate aufrechterhalten werden, sodass eine Expression des Gens (in diesem Fall der mitochondrialen Katalase) über einen Zeitraum von drei Monaten aufrechterhalten werden konnte (Niwa et al. 1991). Da dieser Zeitraum das Alter der im Rahmen dieser Arbeit genutzten Tiere ( 14 Monate) übersteigt, muss die Möglichkeit in Betracht gezogen werden, dass die Expression des Gens der mitochondrialen Katalase in höheren Altersstufen abnimmt und den Verlust der therapeutischen Wirkung erklärt.

\subsection{Veränderungen phänotypischer Parameter im Rett-Syndrom und deren Beeinflussung durch Expression einer mitochondrialen Katalase}

Im Zuge dieser Arbeit konnte festgestellt werden, dass sowohl die Körpergröße als auch das Körpergewicht in den jungen Altersstufen (P50) im Rett-Syndrom signifikant gesenkt ist. Die mitochondriale Katalase zeigte keinen therapeutischen Nutzen im Hinblick auf diese Parameterveränderungen. Analog zu den hier dargestellten Ergebnissen wurden in Studien am Mausmodell des Rett-Syndroms in Mecp2-defizienten P50-Männchen bereits reduzierte Körpergewichte und Körpergrößen beobachtet (Janc et al. 2016).

Auch in Studien des humanen Rett-Syndroms wurden bereits 1993 Verzögerungen der Gewichtszunahme und der Körpergrößenzunahme bei menschlichen Patientinnen beobachtet, welche bereits drei Monate nach Geburt zu detektieren waren und die gesamte Kindheit persistierten (Schultz et al. 1993). Auch in der späteren Entwicklung zwischen dem 3. und 16. Lebensjahr ist bei Patientinnen, die am klassischen Rett-Syndrom erkrankt sind, eine deutliche Reduktion des Body-Mass-Index festzustellen (Leonard et al. 1999). 
Diese ernährungsbedingten Probleme, die im Rett-Syndrom auftreten, können zum einen auf pathophysiologische Veränderungen des Magen- und Darmtraktes zurückgeführt werden, zum anderen besteht die Vermutung, dass durch Veränderungen im zellulären Metabolismus die beeinträchtigte Energiebalance durch reduzierte Nahrungsaufnahme sogar verschlechtert wird (Reilly und Cass 2001). So zeigen videofluoroskopische Aufnahmen der Nahrungsaufnahme bei Rett-Patientinnen eine reduzierte Bewegungsfähigkeit der mittleren und hinteren Zungenanteile mit verfrühter Übertragung des Nahrungs- und Flüssigkeitsbreies vom Mund in den Pharynx. Außerdem zeigten die Patientinnen eine verspätete pharyngeale Schluckreaktion (Morton et al. 1997). Es wurde außerdem von Schwierigkeiten beim Kauen und Schlucken berichtet, sowie der Gefahr der Aspiration von Nahrungsbestandteilen und das Erbrechen von Nahrung durch die Nase (Budden 1986). Generell ist jedoch auch eine reduzierte Nahrungsaufnahme als Ursache der Gewichts- und Größenreduktion im Rett-Syndrom zu nennen. So zeigten Studien, dass die mittlere Energiezufuhr der untersuchten Rett-Patientinnen lediglich 66,9\% der Empfehlung der Vereinigten Staaten Amerikas für das entsprechende Alter betrug (Thommessen et al. 1992). Außerdem konnte eine zweifache, aktivitätsbedingte Erhöhung des Energieverbrauches im Rett-Syndrom beobachtet werden, die durch phänotypische, unfreiwillig motorische Bewegungen der Patientinnen zustande kommt. Zusammen mit der reduzierten Nahrungsaufnahme führt diese Kombination insgesamt $\mathrm{zu}$ einer weniger positiven Energiebilanz, als in gesunden Referenzgruppen. Wenn eine solche geringfügige Differenz in der Energiebilanz über Monate und Jahre aufrechterhalten wird, kann diese durchaus als Ursache für die Reduktion des Körpergewichtes und der Körpergröße in Betracht gezogen werden (Motil et al. 1994). Insgesamt zeigten die Individuen mit der stärksten neurologischen Veränderung auch die deutlichste Reduktion der Körpergröße und des Körpergewichtes (Morton et al. 1997).

Anders als bei den klinischen Patienten-Studien, in denen sich die reduzierte Körpergröße und das reduzierte Körpergewicht auch bis in hohe Altersstufen manifestieren (Motil et al. 2012), wurde im Rahmen dieser Arbeit keine signifikante Reduktion in den Altersstufen P200 und P400 der erkrankten Tiere beobachtet. Da im Zuge der Untersuchung aller phänotypischer Parameter lediglich vier bis neun Tiere je Phänotyp und Altersgruppe für die Messungen genutzt wurden, kann eine fehlende Signifikanz aufgrund eines zu kleinen Stichprobenumfangs nicht ausgeschlossen werden.

Betreffend der Messung des phänotypischen Parameters Blutglukosespiegel zeigte sich bei den Mecp2-defizienten P50-Männchen ein Trend zu reduzierten Blutglukosespiegeln, eine signifikante Reduktion, wie in anderen Studien beschrieben (Janc et al. 2016), konnte hier jedoch, vermutlich aufgrund des geringen Stichprobenumfanges, nicht detektiert werden. Dieser Trend kann jedoch durch die Tatsache erklärt werden, dass, wie in Ratten gezeigt, mitochondriale ROS obligatorische Signalmoleküle für die Induktion der Glucoseinduzierten Insulinsekretion darstellen (Leloup et al. 2009). Aufgrund der erhöhten $\mathrm{H}_{2} \mathrm{O}_{2-}$ 
Freisetzung im Rett-Syndrom besteht somit die Vermutung einer erhöhten Insulinausschüttung und damit einhergehenden initial reduzierten Blutglukosespiegeln im Rett-Syndrom.

Interessanterweise wurde im Rahmen der Messungen des Blutglukosespiegels bei den Mecp $2^{+/}$-Weibchen der Altersstufe P50 und P200 ein Trend zu erhöhten Blutglukosespiegeln im Vergleich zu der Wildtyp-Kontrollgruppe beobachtet. Studien anderer Arbeitsgruppen berichten von Insulinresistenzen, die bei Mecp2-null-Mäusen beobachtet werden konnten und als mögliche Erklärung für die erhöhten Blutglukosespiegel in den höheren Altersstufen in Betracht gezogen werden sollten (Kyle et al. 2016). Möglicherweise besteht sogar ein Zusammenhang zwischen der initial erhöhten, ROS-bedingten Insulinausschüttung und der nachfolgenden Insulinresistenz.

Im Zuge der Messungen des Hämatokrits der Tiere zeigte sich analog zu anderen Studien eine signifikante Erhöhung der Hämatokritwerte bei den Mecp2-defizienten P50-Männchen (Janc et al. 2016). Diese Erhöhung lässt sich möglicherweise als adaptive Antwort der Tiere auf Atmungsirregularitäten und systemische Hypoxie im Rett-Syndrom erklären (Stettner et al. 2008; Fischer et al. 2009). Bei den Weibchen ließen sich in allen Altersstufen keine signifikanten Unterschiede des Hämatokrits beobachten, wobei auch hier ein zu geringer Stichprobenumfang als Ursache nicht ausgeschlossen werden kann.

Die Expression der mitochondrialen Katalase hatte keinen positiven Einfluss auf die Veränderungen der phänotypischen Parameter im verwendeten Mausmodell des RettSyndroms. Auch andere Studien berichten zwar von signifikanter Reduktion in der ROSEntstehung bei Mäusen mit mitochondrialer Katalase-Expression, jedoch konnte auch dort die signifikante Reduktion des Körpergewichtes kardial-erkrankter Tiere durch die mitochondriale Katalase nicht kompensiert werden (Johnson et al. 2018). Dies lässt sich dadurch erklären, dass das Enzym auf die zelluläre Redox-Balance wirkt und somit hauptsächlich einen symptomatisch-kurativen Ansatz darstellt. Die Hauptursache für das phänotypisch-klinische Erscheinungsbild im Rett-Syndrom sind jedoch Mutationen des Gens Mecp2, das für das Protein MeCP2 codiert. Dieses ist als Transkriptionsregulator vor allem für eine physiologische Hirnfunktion zwingend erforderlich (McGraw et al. 2011). Da die mitochondriale Katalase jedoch keinen positiven Einfluss auf die Mecp2-Mutationen hat, lässt sich erklären, dass lediglich einige Symptome der Erkrankung, insbesondere die veränderte Redox-Balance, therapeutisch positiv beeinflusst werden können.

Im Rahmen dieser Dissertation wurde nur ein Teilaspekt der umfassenden präklinischen Erprobung des enzymatischen Therapieansatzes dargestellt. Für eine abschließende Betrachtung sollten alle erhobenen Parameter wie Verhaltenstests, elektrophysiologische und biochemische Parameter gemeinsam bewertet werden. 


\subsection{Möglichkeiten der therapeutischen Anwendung der mitochondrialen Katalase-Expression am Menschen}

In dem im Rahmen dieser Arbeit verwendeten $m C A T$-Mausmodell wurde die DNA der mitochondrialen Katalase (cDNA) über einen Expressionsvektor (bovine papillomavirus vector) in das Genom integriert, der über einen CAG-Promotor die Expression der Katalase reguliert. Anschließend wurde die DNA im Rahmen des konventionellen Mikroinjektionsverfahrens in die Embryos der Wildtyplinie B6 injiziert (Schriner et al. 2005).

Das Nutzen Virus-basierter Vektoren zum Gentransfer stellt prinzipiell auch am Menschen eine realistische Therapieoption dar. Da im Rahmen dieser Arbeit festgestellt werden konnte, dass die mitochondriale $\mathrm{H}_{2} \mathrm{O}_{2}$-Freisetzung in allen Hirnregionen und allen Entwicklungsstadien im Rett-Syndrom erhöht ist, müsste eine derartige Gentherapie bereits früh nach Feststellung der Erkrankung erfolgen, und der genutzte Vektor für den Gentransfer möglichst das gesamte Hirngewebe erreichen können. Als mögliche Transfermethode wäre die cDNA ebenfalls über einen Expressionsvektor im Rahmen des Mikroinjektionsverfahrens direkt in die jeweilige Hirnregionen zu injizieren (Robbins und Ghivizzani 1998; Maguire et al. 2014).

Für das Hirngewebe haben sich besonders adeno-assoziierte Virusvektoren (AAV) etabliert, deren Injektion in effizienter Transduktion und langfristiger, beständiger Expression des zu integrierenden Genes über mehrere Monate resultiert (Kaplitt et al. 1994). Die Dauer und Effizienz der Genexpression kann gegebenenfalls über die Kombination adeno-assoziierter Viren mit anderen Virussystemen wie dem humanen Papillomvirus erhöht werden (Robbins und Ghivizzani 1998).

Ein Nachteil adeno-assoziierter Virusvektoren ist die Tatsache, dass mit ihnen keine großflächige Transduktion erzielt werden kann, sondern lediglich Zellen lokal um die Einstichstelle erreicht werden (Lo et al. 1999). Transportbarrieren nach der Injektion in das Hirngewebe stellen beispielsweise die Diffusion durch die extrazelluläre Matrix dar (Kuriyama et al. 2000). Um eine ausgedehnte Vektorverbreitung zu erzielen besteht beispielsweise die Möglichkeit als Injektionsziel Hirnregionen zu wählen, die zahlreiche afferente und efferente Projektionsneurone aufweisen (Cearley und Wolfe 2007). Eine andere Möglichkeit besteht in der Nutzung konvektionsverstärkter Abgabetechniken (Convection enhanced delivery), bei denen die Aufrechterhaltung eines Druckgradienten während der interstitiellen Infusion die Ausbreitung adeno-assoziierter Virusvektoren im Hirngewebe erhöht (Hadaczek et al. 2006). Andere Arbeitsgruppen berichten von ersten vielversprechenden Studien, in denen AAV intravenös appliziert werden und erfolgreich Zellen des zentralen Nervensystems im Mausmodell erreichen (Foust et al. 2009) sowie von intrathekalen Injektionen, die die Limitation der Blut-Hirn-Schranke umgehen ( $\mathrm{Li}$ et al. 2019). Prinzipiell bieten sich die AAV-Serotypen 5 und 9 an, da diese über größere Strecken im Hirngewebe in vivo diffundieren (Shevtsova et al. 2005). 
Der Gentransfer mittels AAV wird bereits am Menschen seit einigen Jahren angewendet. Allerdings sind bislang lediglich zwei zugelassene Produkte auf dem Markt, die jedoch beide nicht das Hirngewebe betreffen (Buning 2013; Wang et al. 2019). Das Medikament Glybera ${ }^{\circledR}$ ist ein adeno-assoziierter viraler Vektor der für die Lipoprotein-Lipase codiert. Menschen mit Lipoprotein-Lipase-Defizienz wird dieser adeno-assoziierte Virusvektor intramuskulär injiziert (Buning 2013). Das Medikament Luxturna ${ }^{\circledR}$ bietet eine AAV-Therapie bei Patienten mit retinaler Dystrophie (RPE65-Mutationen) und wird lokal in das Auge injiziert (Russell et al. 2017). AAV, die das Hirngewebe anzielen und die Bluthirnschranke passieren oder umgehen, sind noch nicht am Menschen zugelassen und befinden sich noch in der klinischen Erprobung (Wang et al. 2019).

Des Weiteren stellt sich die Frage, warum im Rahmen einer Gentherapie mit AAV nicht direkt das Gen MECP2 therapeutisch angezielt werden kann. Dies erklärt sich durch die Tatsache, dass im Rett-Syndrom ein zelluläres Mosaik durch die X-ChromosomInaktivierung entsteht (Young und Zoghbi 2004). Welche und wie viele Zellen MECP2 exprimieren, kann demnach zwischen den Individuen stark variieren. Da auch eine Verdopplung der MeCP2 Konzentration im Mausmodell des Rett-Syndroms in ähnlichen klinischen Phänotypen resultierte (Collins et al. 2004), ist eine gezielte Gentherapie des Gens MECP2 therapeutisch nicht sinnvoll.

Somit ist festzustellen, dass die Anwendung der mitochondrialen Katalase-Expression im Rett-Syndrom als möglicher Therapieansatz der Redox-Imbalance am Menschen durchaus in Frage kommen kann, jedoch bedarf es ausgiebiger präklinischer und klinischer Studien für die weitere Erprobung. Hinzuzufügen ist, dass es sich bei einem solchen Therapieansatz zudem um einen irreversiblen Eingriff in die Hirnfunktion handelt. Des Weiteren wären für die Injektion des Vektors ein oder sogar mehrere neurochirurgische Eingriffe notwendig, die immer auch ein Infektionsrisiko für die Patientinnen darstellen. Aus ethischer Sicht wäre es daher nötig, zu untersuchen, ob oral applizierte Pharmaka mit antioxidativem Wirkungsspektren nicht ähnliche therapeutisch-positive Effekte bei geringerer Invasivität und geringerem Risiko für die Patientinnen erzielen, zumal derartige Behandlungen auch problemlos hinsichtlich der Dosis oder Behandlungsdauer an die jeweiligen Bedingungen des individuellen Patienten oder als Ergänzungstherapie im Sinne einer personalisierten Medizin angepasst werden könnten. 


\section{$5 \quad$ Zusammenfassung}

Im Rett-Syndrom manifestieren sich sowohl mitochondriale Veränderungen als auch der durch oxidativen Stress entstandene Hirnschaden bereits einige Wochen vor dem Auftreten klinischer Symptome, sodass die Vermutung besteht, dass die mitochondriale Beeinträchtigung für die Progression der Krankheit von größerer Bedeutung ist (De Felice et al. 2014). Therapeutische Ansätze, die das Redox-Gleichgewicht in den Mausmodellen des Rett-Syndroms stabilisieren oder die mitochondriale Funktion verbessern, können daher möglicherweise das Auftreten von Symptomen verzögern oder den Schweregrad des Krankheitsverlaufes mildern (Shulyakova et al. 2017). In der aktuellen Literatur wurde hauptsächlich der Effekt nicht enzymatischer Antioxidantien auf die Redox-Imbalance im Rett-Syndrom untersucht. In wie weit sich jedoch eine erhöhte Expression antioxidativ wirkender Enzyme auswirkt stand bis dato noch aus. Ziel dieser Arbeit war es demnach, die Redox-Imbalance im Rett-Syndrom hirnregionen-, entwicklungsstadien- und geschlechtsspezifisch zu untersuchen, sowie den therapeutischen Nutzen einer mitochondrialen Katalase-Expression auf die erhöhte $\mathrm{H}_{2} \mathrm{O}_{2}$-Freisetzung im Mausmodell des Rett-Syndroms zu evaluieren. Ergänzend sollten auch mögliche Verbesserungen des allgemeinen phänotypischen Erscheinungsbildes der Tiere bewertet werden, indem Größe, Gewicht, Blutglukosespiegel und Hämatokrit untersucht wurden.

Im Zuge der Datenerhebung wurden Mitochondrien der Hirnregionen Kortex, Hippocampus, Kleinhirn, Mittelhirn und Hirnstamm isoliert und in fluoreszenzspektrometrischen Messungen deren $\mathrm{H}_{2} \mathrm{O}_{2}$-Freisetzung quantifiziert. Die Reinheit der genutzten, angereicherten Mitochondriensuspension wurde mit Hilfe von Western-Blots beurteilt, zur Validierung der fluoreszenzspektrometrischen Messmethode wurden außerdem zahlreiche Kontrollmessungen durchgeführt sowie eine $\mathrm{H}_{2} \mathrm{O}_{2}-$ Kalibrierungskurve erstellt.

Es wurde bewiesen, dass die mitochondriale $\mathrm{H}_{2} \mathrm{O}_{2}$-Freisetzung im Rett-Syndrom in allen Hirnregionen und allen Altersstufen unabhängig vom Geschlecht signifikant erhöht ist. Außerdem wurde gezeigt, dass durch die Expression der mitochondrialen Katalase die $\mathrm{H}_{2} \mathrm{O}_{2}$ Freisetzung im Rett-Syndrom sowohl bei den P50-Männchen als auch bei den P50- und P200-Weibchen signifikant gesenkt werden kann. Bei den P400-Weibchen ist dieser Effekt hingegen nicht mehr zu beobachten. Körpergröße und Körpergewicht sind im Rett-Syndrom bei den P50-Weibchen und Männchen signifikant reduziert, wobei die Expression der mitochondrialen Katalase jedoch keinen positiven Einfluss auf die phänotypischen allgemeinen Parameter wie Größe, Gewicht, Blutglukose und Hämatokrit der Tiere vermittelte.

Zusammenfassend kann die mitochondriale Katalase-Expression im Rett-Syndrom als möglicher Therapieansatz in Betracht gezogen werden, um einen positiven Einfluss auf die zelluläre Redox-Imbalance der Erkrankung zu nehmen. Die Konsequenzen für den mitochondrialen Metabolismus sind jedoch noch zu klären. 


\section{$6 \quad$ Literaturverzeichnis}

Adebayo OL, Dewenter I, Rinne L, Golubiani G, Solomonia R, Müller M (2020): Intensified mitochondrial hydrogen peroxide release occurs in all brain regions, affects male as well as female Rett mice, and constitutes a life-long burden. Arch Biochem Biophys 696, 108666

Adler DA, Quaderi NA, Brown SD, Chapman VM, Moore J, Tate P, Disteche CM (1995): The X-linked methylated DNA binding protein, Mecp2, is subject to X inactivation in the mouse. Mamm Genome $\underline{6}, 491-492$

Afanasyeva MA, Ustiugova AS, Golyshev SA, Kopylov AT, Bogolyubova AV, Demin DE, Belousov PV, Schwartz AM (2018): Isolation of large amounts of highly pure mitochondria for "omics" studies. Biochemistry (Mosc) $\underline{83}, 76-85$

Amir RE, van den Veyver IB, Wan M, Tran CQ, Francke U, Zoghbi HY (1999): Rett syndrome is caused by mutations in X-linked MECP2, encoding methyl-CpG-binding protein 2. Nat Genet $\underline{23}, 185-188$

Armstrong DD (2005): Neuropathology of Rett syndrome. J Child Neurol 20, 747-753

Bai J, Cederbaum AI (2001): Mitochondrial catalase and oxidative injury. Biol Signals Recept 10, 189-199

Bebensee DF, Can K, Müller M (2017): Increased mitochondrial mass and cytosolic redox imbalance in hippocampal astrocytes of a mouse model of Rett Syndrome: Subcellular changes revealed by ratiometric imaging of JC-1 and roGFP1 fluorescence. Oxid Med Cell Longev 2017, 3064016

Borras C, Sastre J, Garcia-Sala D, Lloret A, Pallardo FV, Vina J (2003): Mitochondria from females exhibit higher antioxidant gene expression and lower oxidative damage than males. Free Radic Biol Med 34, 546-552

Boveris A, Chance B (1973): The mitochondrial generation of hydrogen peroxide. General properties and effect of hyperbaric oxygen. Biochem J 134, 707-716

Boveris A, Oshino N, Chance B (1972): The cellular production of hydrogen peroxide. Biochem J 128, 617-630

Boveris A, Cadenas E, Stoppani AO (1976): Role of ubiquinone in the mitochondrial generation of hydrogen peroxide. Biochem J 156, 435-444 
Brand MD (2010): The sites and topology of mitochondrial superoxide production. Exp Gerontol 45, 466-472

Brown DI, Griendling KK (2009): Nox proteins in signal transduction. Free Radic Biol Med 47, 1239-1253

Budden SS (1986): Rett syndrome: studies of 13 affected girls. Am J Med Genet Suppl 1, 99109

Buning H (2013): Gene therapy enters the pharma market: the short story of a long journey. EMBO Mol Med $\underline{5}, 1-3$

Buonocore G, Perrone S, Tataranno ML (2010): Oxygen toxicity: chemistry and biology of reactive oxygen species. Semin Fetal Neonatal Med $\underline{15}$, 186-190

Can K, Menzfeld C, Rinne L, Rehling P, Kügler S, Golubiani G, Dudek J, Müller M (2019): Neuronal redox-imbalance in Rett syndrome affects mitochondria as well as cytosol, and is accompanied by intensified mitochondrial $\mathrm{O}_{2}$ consumption and ROS release. Front Physiol $\underline{10}, 479$

Cape JL, Bowman MK, Kramer DM (2007): A semiquinone intermediate generated at the Qo site of the cytochrome bc1 complex: importance for the Q-cycle and superoxide production. Proc Natl Acad Sci U S A $\underline{104}$, 7887-7892

Cearley CN, Wolfe JH (2007): A single injection of an adeno-associated virus vector into nuclei with divergent connections results in widespread vector distribution in the brain and global correction of a neurogenetic disease. J Neurosci 27, 9928-9940

Cervellati C, Sticozzi C, Romani A, Belmonte G, De Rasmo D, Signorile A, Cervellati F, Milanese C, Mastroberardino PG, Pecorelli A et al. (2015): Impaired enzymatic defensive activity, mitochondrial dysfunction and proteasome activation are involved in RTT cell oxidative damage. Biochim Biophys Acta 1852, 2066-2074

Chahrour M, Zoghbi HY (2007): The story of Rett syndrome: from clinic to neurobiology. Neuron $\underline{56}, 422-437$

Chahrour M, Jung SY, Shaw C, Zhou X, Wong ST, Qin J, Zoghbi HY (2008): MeCP2, a key contributor to neurological disease, activates and represses transcription. Science $\underline{320}, 1224-$ 1229

Chance B, Sies H, Boveris A (1979): Hydroperoxide metabolism in mammalian organs. Physiol Rev $\underline{59}$, 527-605 
Chen Q, Vazquez EJ, Moghaddas S, Hoppel CL, Lesnefsky EJ (2003): Production of reactive oxygen species by mitochondria: central role of complex III. J Biol Chem 278, 36027-36031

Christodoulou J, Grimm A, Maher T, Bennetts B (2003): RettBASE: The IRSA MECP2 variation database-a new mutation database in evolution. Hum Mutat 21, 466-472

Clark JB, Nicklas WJ (1970): The metabolism of rat brain mitochondria. Preparation and characterization. J Biol Chem $\underline{245}, 4724-4731$

Collins AL, Levenson JM, Vilaythong AP, Richman R, Armstrong DL, Noebels JL, David Sweatt J, Zoghbi HY (2004): Mild overexpression of MeCP2 causes a progressive neurological disorder in mice. Hum Mol Genet 13, 2679-2689

Cornford ME, Philippart M, Jacobs B, Scheibel AB, Vinters HV (1994): Neuropathology of Rett syndrome: case report with neuronal and mitochondrial abnormalities in the brain. J Child Neurol $\underline{9}, 424-431$

D'Autreaux B, Toledano MB (2007): ROS as signalling molecules: mechanisms that generate specificity in ROS homeostasis. Nat Rev Mol Cell Biol $\underline{8}$, 813-824

Dai DF, Chiao YA, Martin GM, Marcinek DJ, Basisty N, Quarles EK, Rabinovitch PS (2017): Mitochondrial-targeted catalase: extended longevity and the roles in various disease models. Prog Mol Biol Transl Sci 146, 203-241

Dayer AG, Bottani A, Bouchardy I, Fluss J, Antonarakis SE, Haenggeli CA, Morris MA (2007): MECP2 mutant allele in a boy with Rett syndrome and his unaffected heterozygous mother. Brain Dev 29, 47-50

De Duve C, Baudhuin P (1966): Peroxisomes (microbodies and related particles). Physiol Rev $\underline{46}, 323-357$

De Felice C, Ciccoli L, Leoncini S, Signorini C, Rossi M, Vannuccini L, Guazzi G, Latini G, Comporti M, Valacchi G et al. (2009): Systemic oxidative stress in classic Rett syndrome. Free Radic Biol Med 47, 440-448

De Felice C, Signorini C, Durand T, Ciccoli L, Leoncini S, D'Esposito M, Filosa S, Oger C, Guy A, Bultel-Ponce V et al. (2012): Partial rescue of Rett syndrome by $\omega-3$ polyunsaturated fatty acids (PUFAs) oil. Genes Nutr $\underline{7}, 447-458$ 
De Felice C, Della Ragione F, Signorini C, Leoncini S, Pecorelli A, Ciccoli L, Scalabri F, Marracino F, Madonna M, Belmonte G et al. (2014): Oxidative brain damage in Mecp2mutant murine models of Rett syndrome. Neurobiol Dis $\underline{68}, 66-77$

De Filippis B, Valenti D, de Bari L, De Rasmo D, Musto M, Fabbri A, Ricceri L, Fiorentini C, Laviola G, Vacca RA (2015): Mitochondrial free radical overproduction due to respiratory chain impairment in the brain of a mouse model of Rett syndrome: protective effect of CNF1. Free Radic Biol Med $\underline{83}$, 167-177

Deisseroth A, Dounce AL (1970): Catalase: Physical and chemical properties, mechanism of catalysis, and physiological role. Physiol Rev $\underline{50}$, 319-375

Doan TN, Gentry DL, Taylor AA, Elliott SJ (1994): Hydrogen peroxide activates agonistsensitive $\mathrm{Ca}^{2+}$-flux pathways in canine venous endothelial cells. Biochem J 297, 209-215

Dotti MT, Manneschi L, Malandrini A, De Stefano N, Caznerale F, Federico A (1993): Mitochondrial dysfunction in Rett syndrome. An ultrastructural and biochemical study. Brain Dev $\underline{15}, 103-106$

Dröge W (2002): Free radicals in the physiological control of cell function. Physiol Rev $\underline{82}$, 47-95

Eeg-Olofsson O, Al-Zuhair AG, Teebi AS, Daoud AS, Zaki M, Besisso MS, Al-Essa MM (1990): Rett syndrome: a mitochondrial disease? J Child Neurol $\underline{5}, 210-214$

Fischer M, Reuter J, Gerich FJ, Hildebrandt B, Hägele S, Katschinski D, Müller M (2009): Enhanced hypoxia susceptibility in hippocampal slices from a mouse model of rett syndrome. J Neurophysiol 101, 1016-1032

Formichi P, Battisti C, Dotti MT, Hayek G, Zappella M, Federico A (1998): Vitamin E serum levels in Rett syndrome. J Neurol Sci 156, 227-230

Foust KD, Nurre E, Montgomery CL, Hernandez A, Chan CM, Kaspar BK (2009): Intravascular AAV9 preferentially targets neonatal neurons and adult astrocytes. Nat Biotechnol 27, 59-65

Fridovich I (1995): Superoxide radical and superoxide dismutases. Annu Rev Biochem 64, $97-112$

Fukuda T, Itoh M, Ichikawa T, Washiyama K, Goto Y (2005): Delayed maturation of neuronal architecture and synaptogenesis in cerebral cortex of Mecp2-deficient mice. J Neuropathol Exp Neurol 64, 537-544 
Galla H-J, Müller H-J: Spektroskopische Methoden in der Biochemie; Thieme Stuttgart, 1988

Gilbert HF (1995): Thiol/disulfide exchange equilibria and disulfide bond stability. Methods Enzymol 251, 8-28

Gold WA, Williamson SL, Kaur S, Hargreaves IP, Land JM, Pelka GJ, Tam PP, Christodoulou J (2014): Mitochondrial dysfunction in the skeletal muscle of a mouse model of Rett syndrome (RT'T): implications for the disease phenotype. Mitochondrion 15, 10-17

Großer E, Hirt U, Janc OA, Menzfeld C, Fischer M, Kempkes B, Vogelgesang S, Manzke TU, Opitz L, Salinas-Riester G et al. (2012): Oxidative burden and mitochondrial dysfunction in a mouse model of Rett syndrome. Neurobiol Dis $\underline{48}, 102-114$

Guo H, Chen G, Gao M, Wang R, Liu Y, Yu F (2019): Imaging of endogenous hydrogen peroxide during the process of cell mitosis and mouse brain development with a nearinfrared ratiometric fluorescent probe. Anal Chem $\underline{11}$, 1203-1210

Guy J, Hendrich B, Holmes M, Martin JE, Bird A (2001): A mouse Mecp2-null mutation causes neurological symptoms that mimic Rett syndrome. Nat Genet 27, 322-326

Haas RH, Rice MA, Trauner DA, Merritt TA (1986): Therapeutic effects of a ketogenic diet in Rett syndrome. Am J Med Genet Suppl 1, 225-246

Haas RH, Light M, Rice M, Barshop BA (1995): Oxidative metabolism in Rett syndrome: 1. Clinical studies. Neuropediatrics $\underline{26}, 90-94$

Hadaczek P, Kohutnicka M, Krauze MT, Bringas J, Pivirotto P, Cunningham J, Bankiewicz K (2006): Convection-enhanced delivery of adeno-associated virus type 2 (AAV2) into the striatum and transport of AAV2 within monkey brain. Hum Gene Ther 17, 291-302

Hagberg B, Witt-Engerström I (1986): Rett syndrome: a suggested staging system for describing impairment profile with increasing age towards adolescence. Am J Med Genet Suppl 1 , 47-59

Hagberg B, Aicardi J, Dias K, Ramos O (1983): A progressive syndrome of autism, dementia, ataxia, and loss of purposeful hand use in girls: Rett's syndrome: report of 35 cases. Ann Neurol $\underline{14}$, 471-479

Halliwell B (2006): Reactive species and antioxidants. Redox biology is a fundamental theme of aerobic life. Plant Physiol 141, 312-322 
Halliwell B, Gutteridge JM (1984a): Oxygen toxicity, oxygen radicals, transition metals and disease. Biochem J 219, 1-14

Halliwell B, Gutteridge JM (1984b): Lipid peroxidation, oxygen radicals, cell damage, and antioxidant therapy. Lancet $1,1396-1397$

Halliwell B, Gutteridge J (1999): Free radicals in medicine and biology. Clarendon: Oxford

Han D, Williams E, Cadenas E (2001): Mitochondrial respiratory chain-dependent generation of superoxide anion and its release into the intermembrane space. Biochem J $\underline{353}$, 411-416

Harman D (1956): Aging: a theory based on free radical and radiation chemistry. J Gerontol 11, 298-300

Harman D (1973): Free radical theory of aging. Triangle 12, 153-158

Harman D (1983): Free radical theory of aging: consequences of mitochondrial aging. Age $\underline{6}, 86-94$

Harman D (2003): The free radical theory of aging. Antioxid Redox Signal $\underline{5}$, 557-561

Jan MM, Dooley JM, Gordon KE (1999): Male Rett syndrome variant: application of diagnostic criteria. Pediatr Neurol 20, 238-240

Janc OA, Müller M (2014): The free radical scavenger Trolox dampens neuronal hyperexcitability, reinstates synaptic plasticity, and improves hypoxia tolerance in a mouse model of Rett syndrome. Front Cell Neurosci $\underline{8}, 56$

Janc OA, Hüser MA, Dietrich K, Kempkes B, Menzfeld C, Hülsmann S, Müller M (2016): Systemic radical scavenger treatment of a mouse model of Rett syndrome: merits and limitations of the vitamin E derivative Trolox. Front Cell Neurosci 10, 266

Jian L, Nagarajan L, De Klerk N, Ravine D, Bower C, Anderson A, Williamson S, Christodoulou J, Leonard H (2006): Predictors of seizure onset in Rett syndrome. J Pediatr $\underline{149}, 542-547$

Johnson JM, Ferrara PJ, Verkerke ARP, Coleman CB, Wentzler EJ, Neufer PD, Kew KA, de Castro Bras LE, Funai K (2018): Targeted overexpression of catalase to mitochondria does not prevent cardioskeletal myopathy in Barth syndrome. J Mol Cell Cardiol 121, 94-102 
Julu PO, Kerr AM, Apartopoulos F, Al-Rawas S, Engerstrom IW, Engerstrom L, Jamal GA, Hansen S (2001): Characterisation of breathing and associated central autonomic dysfunction in the Rett disorder. Arch Dis Child $\underline{85}, 29-37$

Jung BP, Jugloff DG, Zhang G, Logan R, Brown S, Eubanks JH (2003): The expression of methyl $\mathrm{CpG}$ binding factor MeCP2 correlates with cellular differentiation in the developing rat brain and in cultured cells. J Neurobiol $\underline{55}$, 86-96

Kamata H, Hirata H (1999): Redox regulation of cellular signalling. Cell Signal 11, 1-14

Kamsler A, Segal M (2003): Paradoxical actions of hydrogen peroxide on long-term potentiation in transgenic superoxide dismutase-1 mice. J Neurosci $\underline{23}$, 10359-10367

Kander MC, Cui Y, Liu Z (2017): Gender difference in oxidative stress: a new look the mechanisms for cardiovascular diseases. J Cell Mol Med 21, 1024-1032

Kaplitt MG, Leone P, Samulski RJ, Xiao X, Pfaff DW, O'Malley KL, During MJ (1994): Long-term gene expression and phenotypic correction using adeno-associated virus vectors in the mammalian brain. Nat Genet $\underline{8}, 148-154$

Khalifa AR, Abdel-Rahman EA, Mahmoud AM, Ali MH, Noureldin M, Saber SH, Mohsen M, Ali SS (2017): Sex-specific differences in mitochondria biogenesis, morphology, respiratory function, and ROS homeostasis in young mouse heart and brain. Physiol Rep $\underline{5}$,

Khan AU, Wilson T (1995): Reactive oxygen species as cellular messengers. Chem Biol 2 , 437-445

Korshunov SS, Skulachev VP, Starkov AA (1997): High protonic potential actuates a mechanism of production of reactive oxygen species in mitochondria. FEBS Lett $\underline{416}, 15-18$

Kriaucionis S, Bird A (2004): The major form of MeCP2 has a novel N-terminus generated by alternative splicing. Nucleic Acids Res $\underline{32}, 1818-1823$

Kriaucionis S, Paterson A, Curtis J, Guy J, Macleod N, Bird A (2006): Gene expression analysis exposes mitochondrial abnormalities in a mouse model of Rett syndrome. Mol Cell Biol 26, 5033-5042

Kristian T (2010): Isolation of mitochondria from the CNS. Curr Protoc Neurosci $\underline{7}$, Unit 7 22

Kudin AP, Bimpong-Buta NY, Vielhaber S, Elger CE, Kunz WS (2004): Characterization of superoxide-producing sites in isolated brain mitochondria. J Biol Chem $\underline{279}$, 4127-4135 
Kuriyama N, Kuriyama H, Julin CM, Lamborn K, Israel MA (2000): Pretreatment with protease is a useful experimental strategy for enhancing adenovirus-mediated cancer gene therapy. Hum Gene Ther 11, 2219-2230

Kussmaul L, Hirst J (2006): The mechanism of superoxide production by NADH:ubiquinone oxidoreductase (complex I) from bovine heart mitochondria. Proc Natl Acad Sci U S A $\underline{103}, 7607-7612$

Kyle SM, Saha PK, Brown HM, Chan LC, Justice MJ (2016): MeCP2 co-ordinates liver lipid metabolism with the NCoR1/HDAC3 corepressor complex. Hum Mol Genet 25, 3029-3041

Leloup C, Tourrel-Cuzin C, Magnan C, Karaca M, Castel J, Carneiro L, Colombani AL, Ktorza A, Casteilla L, Penicaud L (2009): Mitochondrial reactive oxygen species are obligatory signals for glucose-induced insulin secretion. Diabetes $\underline{58}, 673-681$

Leonard H, Thomson MR, Glasson EJ, Fyfe S, Leonard S, Bower C, Christodoulou J, Ellaway C (1999): A population-based approach to the investigation of osteopenia in Rett syndrome. Dev Med Child Neurol 41, 323-328

Leto TL, Geiszt M (2006): Role of Nox family NADPH oxidases in host defense. Antioxid Redox Signal $\underline{8}, 1549-1561$

Lewis JD, Meehan RR, Henzel WJ, Maurer-Fogy I, Jeppesen P, Klein F, Bird A (1992): Purification, sequence, and cellular localization of a novel chromosomal protein that binds to methylated DNA. Cell $\underline{69}$, 905-914

Li D, Li Y, Tian Y, Xu Z, Guo Y (2019): Direct intrathecal injection of recombinant adenoassociated viruses in adult mice. J Vis Exp

Liemburg-Apers DC, Willems PH, Koopman WJ, Grefte S (2015): Interactions between mitochondrial reactive oxygen species and cellular glucose metabolism. Arch Toxicol $\underline{89}$, 1209-1226

Linnane AW, Marzuki S, Ozawa T, Tanaka M (1989): Mitochondrial DNA mutations as an important contributor to ageing and degenerative diseases. Lancet $\underline{1}, 642-645$

Liscovitch N, Chechik G (2013): Specialization of gene expression during mouse brain development. PLoS Comput Biol $\underline{9}$, e1003185 
Lo WD, Qu G, Sferra TJ, Clark R, Chen R, Johnson PR (1999): Adeno-associated virusmediated gene transfer to the brain: duration and modulation of expression. Hum Gene Ther $\underline{10}, 201-213$

Maguire CA, Ramirez SH, Merkel SF, Sena-Esteves M, Breakefield XO (2014): Gene therapy for the nervous system: challenges and new strategies. Neurotherapeutics $\underline{11}$, 817-839

Matsuishi T, Urabe F, Percy AK, Komori H, Yamashita Y, Schultz RS, Ohtani Y, Kuriya N, Kato H (1994): Abnormal carbohydrate metabolism in cerebrospinal fluid in Rett syndrome. J Child Neurol $\underline{9}, 26-30$

McCord JM, Fridovich I (1969): Superoxide dismutase. An enzymic function for erythrocuprein (hemocuprein). J Biol Chem 244, 6049-6055

McGraw CM, Samaco RC, Zoghbi HY (2011): Adult neural function requires MeCP2. Science $\underline{333}, 186$

McLennan HR, Degli Esposti M (2000): The contribution of mitochondrial respiratory complexes to the production of reactive oxygen species. J Bioenerg Biomembr $\underline{32}$, 153-162

Miki H, Funato Y (2012): Regulation of intracellular signalling through cysteine oxidation by reactive oxygen species. J Biochem 151, 255-261

Miller DM, Buettner GR, Aust SD (1990): Transition metals as catalysts of "autoxidation" reactions. Free Radic Biol Med $\underline{8}$, 95-108

Mills GC (1957): Hemoglobin catabolism. I. Glutathione peroxidase, an erythrocyte enzyme which protects hemoglobin from oxidative breakdown. J Biol Chem 229, 189-197

Milton VJ, Sweeney ST (2011): Oxidative stress in synapse development and function. Dev Neurobiol $\underline{72}, 100-110$

Miwa S, St-Pierre J, Partridge L, Brand MD (2003): Superoxide and hydrogen peroxide production by Drosophila mitochondria. Free Radic Biol Med $\underline{35}$, 938-948

Morton RE, Bonas R, Minford J, Kerr A, Ellis RE (1997): Feeding ability in Rett syndrome. Dev Med Child Neurol 39, 331-335

Motil KJ, Schultz R, Brown B, Glaze DG, Percy AK (1994): Altered energy balance may account for growth failure in Rett syndrome. J Child Neurol 9, 315-319 
Motil KJ, Caeg E, Barrish JO, Geerts S, Lane JB, Percy AK, Annese F, McNair L, Skinner SA, Lee HS et al. (2012): Gastrointestinal and nutritional problems occur frequently throughout life in girls and women with Rett syndrome. J Pediatr Gastroenterol Nutr $\underline{55}$, 292-298

Muller FL, Liu Y, Van Remmen H (2004): Complex III releases superoxide to both sides of the inner mitochondrial membrane. J Biol Chem $\underline{279}$, 49064-49073

Müller M (2019): Disturbed redox homeostasis and oxidative stress: potential players in the developmental regression in Rett syndrome. Neurosci Biobehav Rev $\underline{98}, 154-163$

Müller M, Can K (2014): Aberrant redox homoeostasis and mitochondrial dysfunction in Rett syndrome. Biochem Soc Trans $\underline{42}$, 959-964

Murthy MR, Reid TJ, 3rd, Sicignano A, Tanaka N, Rossmann MG (1981): Structure of beef liver catalase. J Mol Biol 152, 465-499

Navarro A, Boveris A (2004): Rat brain and liver mitochondria develop oxidative stress and lose enzymatic activities on aging. Am J Physiol Regul Integr Comp Physiol 287, R1244-1249

Niwa H, Yamamura K, Miyazaki J (1991): Efficient selection for high-expression transfectants with a novel eukaryotic vector. Gene $\underline{108}, 193-199$

Nohl H, Hegner D (1978): Evidence for the existence of catalase in the matrix space of ratheart mitochondria. FEBS Lett $\underline{89}$, 126-130

Olsen RH, Johnson LA, Zuloaga DG, Limoli CL, Raber J (2013): Enhanced hippocampusdependent memory and reduced anxiety in mice over-expressing human catalase in mitochondria. J Neurochem $\underline{125}$, 303-313

Panchenko LF, Brusov OS, Gerasimov AM, Loktaeva TD (1975): Intramitochondrial localization and release of rat liver superoxide dismutase. FEBS Lett $\underline{55}, 84-87$

Panighini A, Duranti E, Santini F, Maffei M, Pizzorusso T, Funel N, Taddei S, Bernardini N, Ippolito C, Virdis A et al. (2013): Vascular dysfunction in a mouse model of Rett syndrome and effects of curcumin treatment. PLoS One $\underline{8}$, e64863

Pecorelli A, Ciccoli L, Signorini C, Leoncini S, Giardini A, D'Esposito M, Filosa S, Hayek J, De Felice C, Valacchi G (2011): Increased levels of 4HNE-protein plasma adducts in Rett syndrome. Clin Biochem $\underline{44}, 368-371$ 
Pecorelli A, Leoni G, Cervellati F, Canali R, Signorini C, Leoncini S, Cortelazzo A, De Felice C, Ciccoli L, Hayek J et al. (2013): Genes related to mitochondrial functions, protein degradation, and chromatin folding are differentially expressed in lymphomonocytes of Rett syndrome patients. Mediators Inflamm 2013, 137629

Peeters-Joris C, Vandevoorde AM, Baudhuin P (1975): Subcellular localization of superoxide dismutase in rat liver. Biochem J 150, 31-39

Pinto RE, Bartley W (1969): The effect of age and sex on glutathione reductase and glutathione peroxidase activities and on aerobic glutathione oxidation in rat liver homogenates. Biochem J 112, 109-115

Pozzo-Miller L, Pati S, Percy AK (2015): Rett Syndrome: reaching for clinical trials. Neurotherapeutics $\underline{12}$, 631-640

Quinlan CL, Orr AL, Perevoshchikova IV, Treberg JR, Ackrell BA, Brand MD (2012): Mitochondrial complex II can generate reactive oxygen species at high rates in both the forward and reverse reactions. J Biol Chem $\underline{287}$, 27255-27264

Radi R, Sims S, Cassina A, Turrens JF (1993): Roles of catalase and cytochrome c in hydroperoxide-dependent lipid peroxidation and chemiluminescence in rat heart and kidney mitochondria. Free Radic Biol Med 15, 653-659

Reichwald K, Thiesen J, Wiehe T, Weitzel J, Poustka WA, Rosenthal A, Platzer M, Stratling WH, Kioschis P (2000): Comparative sequence analysis of the MECP2-locus in human and mouse reveals new transcribed regions. Mamm Genome 11, 182-190

Reilly S, Cass H (2001): Growth and nutrition in Rett syndrome. Disabil Rehabil $\underline{23}$, 118-128

Renieri A, Meloni I, Longo I, Ariani F, Mari F, Pescucci C, Cambi F (2003): Rett syndrome: the complex nature of a monogenic disease. J Mol Med (Berl) $\underline{81}$, 346-354

Rett A (1966): Über ein eigenartiges hirnatrophisches Syndrom bei Hyperammonämie im Kindesalter. Wien Med Wochenschr 116, 723-726

Richter C (1995): Oxidative damage to mitochondrial DNA and its relationship to ageing. Int J Biochem Cell Biol 27, 647-653

Robbins PD, Ghivizzani SC (1998): Viral vectors for gene therapy. Pharmacol Ther $\underline{80}$, 3547 
Russell S, Bennett J, Wellman JA, Chung DC, Yu ZF, Tillman A, Wittes J, Pappas J, Elci O, McCague $S$ et al. (2017): Efficacy and safety of voretigene neparvovec (AAV2-hRPE65v2) in patients with RPE65-mediated inherited retinal dystrophy: a randomised, controlled, open-label, phase 3 trial. Lancet $\underline{390}, 849-860$

Ryan TE, Schmidt CA, Green TD, Spangenburg EE, Neufer PD, McClung JM (2016): Targeted expression of catalase to mitochondria protects against ischemic myopathy in highfat diet-fed mice. Diabetes $\underline{65}, 2553-2568$

Sastre J, Pallardo FV, Garcia de la Asuncion J, Vina J (2000): Mitochondria, oxidative stress and aging. Free Radic Res $\underline{32}$, 189-198

Schafer FQ, Buettner GR (2001): Redox environment of the cell as viewed through the redox state of the glutathione disulfide/glutathione couple. Free Radic Biol Med $\underline{30}, 1191-1212$

Schriner SE, Linford NJ, Martin GM, Treuting P, Ogburn CE, Emond M, Coskun PE, Ladiges W, Wolf N, Van Remmen H et al. (2005): Extension of murine life span by overexpression of catalase targeted to mitochondria. Science $\underline{308}, 1909-1911$

Schultz RJ, Glaze DG, Motil KJ, Armstrong DD, del Junco DJ, Hubbard CR, Percy AK (1993): The pattern of growth failure in Rett syndrome. Am J Dis Child 147, 633-637

Segal AW, Shatwell KP (1997): The NADPH oxidase of phagocytic leukocytes. Ann N Y Acad Sci $\underline{832}, 215-222$

Shahbazian MD, Sun Y, Zoghbi HY (2002): Balanced X chromosome inactivation patterns in the Rett syndrome brain. Am J Med Genet 111, 164-168

Shan XQ, Aw TY, Jones DP (1990): Glutathione-dependent protection against oxidative injury. Pharmacol Ther $\underline{47}, 61-71$

Shevtsova Z, Malik JM, Michel U, Bahr M, Kugler S (2005): Promoters and serotypes: targeting of adeno-associated virus vectors for gene transfer in the rat central nervous system in vitro and in vivo. Exp Physiol 90, 53-59

Shulyakova N, Andreazza AC, Mills LR, Eubanks JH (2017): Mitochondrial dysfunction in the pathogenesis of Rett syndrome: implications for mitochondria-targeted therapies. Front Cell Neurosci $\underline{11}, 58$

Sierra C, Vilaseca MA, Brandi N, Artuch R, Mira A, Nieto M, Pineda M (2001): Oxidative stress in Rett syndrome. Brain Dev 23 Suppl 1, 236-239 
Signorini C, Leoncini S, De Felice C, Pecorelli A, Meloni I, Ariani F, Mari F, Amabile S, Paccagnini E, Gentile M et al. (2014): Redox imbalance and morphological changes in skin fibroblasts in typical Rett syndrome. Oxid Med Cell Longev 2014, 195935

Sims NR (1990): Rapid isolation of metabolically active mitochondria from rat brain and subregions using Percoll density gradient centrifugation. J Neurochem $\underline{55}$, 698-707

Sofic E, Riederer P, Killian W, Rett A (1987): Reduced concentrations of ascorbic acid and glutathione in a single case of Rett syndrome: a postmortem brain study. Brain Dev $\underline{9}, 529$ 531

Son G, Han J (2018): Roles of mitochondria in neuronal development. BMB Rep $\underline{51}$, 549556

Song C, Al-Mehdi AB, Fisher AB (2001): An immediate endothelial cell signaling response to lung ischemia. Am J Physiol Lung Cell Mol Physiol 281, 993-1000

St-Pierre J, Buckingham JA, Roebuck SJ, Brand MD (2002): Topology of superoxide production from different sites in the mitochondrial electron transport chain. J Biol Chem $\underline{277}, 44784-44790$

Starkov AA, Fiskum G, Chinopoulos C, Lorenzo BJ, Browne SE, Patel MS, Beal MF (2004): Mitochondrial alpha-ketoglutarate dehydrogenase complex generates reactive oxygen species. J Neurosci 24, 7779-7788

Stettner GM, Huppke P, Gärtner J, Richter DW, Dutschmann M (2008): Disturbances of breathing in Rett syndrome: results from patients and animal models. Adv Exp Med Biol $\underline{605}, 503-507$

Thommessen M, Kase BF, Heiberg A (1992): Growth and nutrition in 10 girls with Rett

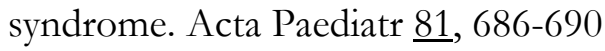

Trachootham D, Lu W, Ogasawara MA, Nilsa RD, Huang P (2008): Redox regulation of cell survival. Antioxid Redox Signal 10, 1343-1374

Tretter L, Sipos I, Adam-Vizi V (2004): Initiation of neuronal damage by complex I deficiency and oxidative stress in Parkinson's disease. Neurochem Res $\underline{29}$, 569-577

Valko M, Rhodes CJ, Moncol J, Izakovic M, Mazur M (2006): Free radicals, metals and antioxidants in oxidative stress-induced cancer. Chem Biol Interact 160, 1-40 
Valko M, Leibfritz D, Moncol J, Cronin MT, Mazur M, Telser J (2007): Free radicals and antioxidants in normal physiological functions and human disease. Int J Biochem Cell Biol $\underline{39}, 44-84$

Votyakova TV, Reynolds IJ (2001): $\Delta \Psi$ m-dependent and -independent production of reactive oxygen species by rat brain mitochondria. J Neurochem $\underline{79}$, 266-277

Wang D, Tai PWL, Gao G (2019): Adeno-associated virus vector as a platform for gene therapy delivery. Nat Rev Drug Discov $\underline{18}, 358-378$

Wang X, Michaelis EK (2010): Selective neuronal vulnerability to oxidative stress in the brain. Front Aging Neurosci 2, 12

Wang X, Zaidi A, Pal R, Garrett AS, Braceras R, Chen XW, Michaelis ML, Michaelis EK (2009): Genomic and biochemical approaches in the discovery of mechanisms for selective neuronal vulnerability to oxidative stress. BMC Neurosci $\underline{10}, 12$

Weese-Mayer DE, Lieske SP, Boothby CM, Kenny AS, Bennett HL, Silvestri JM, Ramirez JM (2006): Autonomic nervous system dysregulation: breathing and heart rate perturbation during wakefulness in young girls with Rett syndrome. Pediatr Res $\underline{60}$, 443-449

Wei YH (1992): Mitochondrial DNA alterations as ageing-associated molecular events. Mutat Res $\underline{275}, 145-155$

Young JI, Zoghbi HY (2004): X-chromosome inactivation patterns are unbalanced and affect the phenotypic outcome in a mouse model of Rett syndrome. Am J Hum Genet $\underline{74}$, 511-520

Zhao B, Summers FA, Mason RP (2012): Photooxidation of Amplex Red to resorufin: implications of exposing the Amplex Red assay to light. Free Radic Biol Med $\underline{53}$, 1080-1087

Zhou M, Diwu Z, Panchuk-Voloshina N, Haugland RP (1997): A stable nonfluorescent derivative of resorufin for the fluorometric determination of trace hydrogen peroxide: applications in detecting the activity of phagocyte NADPH oxidase and other oxidases. Anal Biochem 253, 162-168 


\section{Danksagung}

Für die außergewöhnliche fachliche Betreuung und Unterstützung sowie das wundervolle zwischenmenschliche Miteinander während dieses Dissertationsprojektes möchte Ich mich ganz herzlich bei der Arbeitsgruppe von Prof. Dr. rer. nat. Michael Müller im Institut für Neuro-und Sinnesphysiologie der Georg-August-Universität Göttingen bedanken. Ein besonderer Dank gilt meinem Doktorvater Prof. Dr. rer. nat. Müller, der diese Arbeit ausgezeichnet betreut hat und mir immer unterstützend zur Seite stand, sowohl bei der Datenerhebung- und Auswertung als auch bei der Verschriftlichung dieser Arbeit.

Des Weiteren möchte ich mich bei Dr. Olusegun Adebayo für die Unterstützung bei der Datenerhebung bedanken sowie bei Belinda Kempkes, die mich an viele Laborarbeitsschritte herangeführt hat und mir immer hilfsbereit zur Seite stand. Ein großes Dankeschön möchte ich zudem an Bettina Homberg richten, die mich bei der Durchführung der Western Blots angeleitet und unterstützt hat. Außerdem Danke ich Birte Schulze und Ann-Kathrin Schuster für das Korrekturlesen dieser Arbeit. 